\title{
Preliminary Evaluation of Wind Energy Potential-Cook Inlet Area, Alaska
}

T. R. Hiester

June 1980

Prepared for

the Alaska Power Administration

under a Related Services Agreement

with the U.S. Department of Energy

under Contract DE-AC06-76RLO 1830

Pacific Northwest Laboratory

Operated for the U.S. Department of Energy

by Battelle Memorial Institute 


\title{
NOTICE
}

This report was prepared as an account of work sponsored by the United States Government. Neither the United States nor the Department of Energy, nor any of their employees, nor any of their contractors, subcontractors, or their employees, makes any warranty, express or implied, or assumes any legal liability or responsibility for the accuracy, completeness or usefulness of any information, apparatus, product or process disclosed, or represents that its use would not infringe privately owned rights.

The views, opinions and conclusions contained in this report are those of the contractor and do not necessarily represent those of the United States Government or the United States Department of Energy.

PACIFIC NORTHWEST LABORATORY

operated by

BATTELLE

for the

UNITED STATES DEPARTMENT OF ENERCY

Under Contract DE-AC06-76RLO 1830

\author{
Printed in the United States of America \\ Available from \\ National Technical Information Service \\ Unired States Department of Commerce \\ 5285 Port Royal Road \\ Springfield, Virginia 22751
}

Price: Printed Copy $\$$

*; Microfiche $\$ 3.00$

NTIS

- Pages Selling Price

001-025 \$4.00

026-050 \$4.50

051-075 \$5.25

076-100 $\$ 6.00$

$101-125 \quad \$ 6.50$

126-150 \$7.25

$151-175 \quad \$ 8.00$

$176-200 \quad \$ 9.00$

201-225 \$9.25

226-250 \$9.50

251-275 \$10.75

$276-300 \quad \$ 11.00$ 


\author{
PRELIMINARY EVALUATION OF WIND \\ ENERGY POTENTIAL -- \\ COOK INLET AREA, ALASKA
}

T. R. Hiester

June 1980

Prepared for the Alaska Power Administration under a Related Services Agreement with the U.S. Department of Energy under Contract DE-ACO6-76RLO 1830

Pacific Northwest Laboratory Richland, Washington 99352 
- 


\section{CONTENTS}

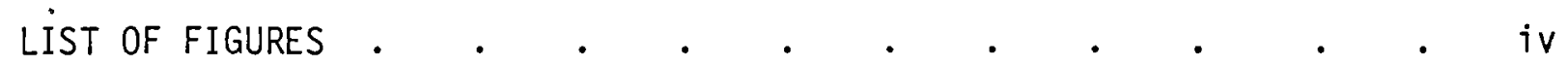

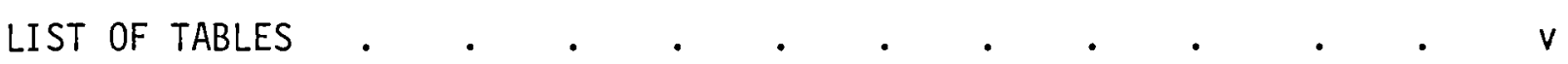

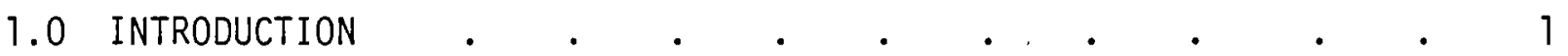

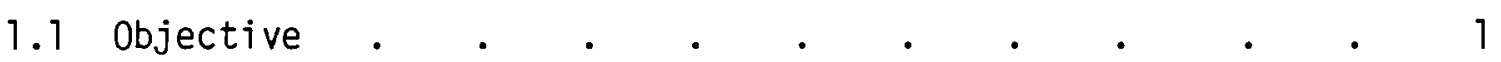

1.2 Method . . . . . . . . . . . . . 3

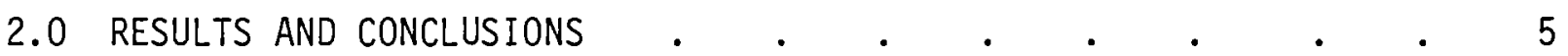

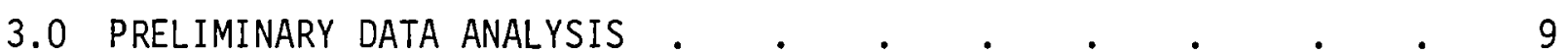

3.1 Minimum Requirements of the Wind Resource . . . . . 9

3.2 Wind Resource Characteristics at Existing Data Stations $\quad 15$

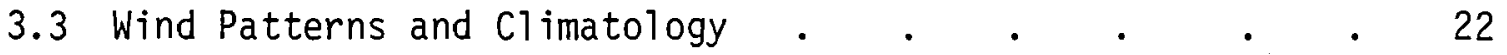

3.4 Selection of Candidate Sites $. \quad . \quad . \quad . \quad . \quad . \quad 34$

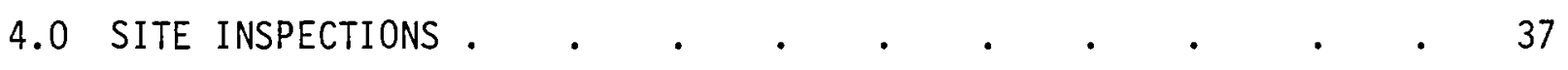

5.0 RECOMMENDATIONS FOR MEASUREMENT PROGRAMS . . . . . . . . . . 49

5.1 Instrumentation . . . . . . . . . . . . 49

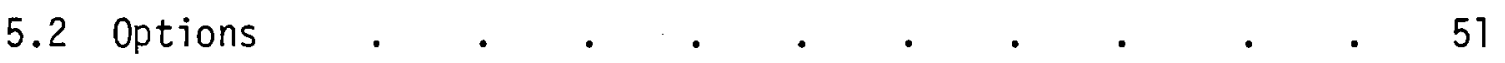

References

Appendix A: Topographic Maps of the Cook Inlet Area

Appendix B: Siting Technologies for Large Wind Turbine Clusters 


\section{FIGURES}

3.1 Power Output as a Function of Wind Speed at 30 Feet for Three . . 11 Wind Turbines Developed by DOE (Thomas and Robbins, 1979) . . . .

3.2 Approximate Annual Energy Output as a Function of Annual Mean . . 13 Wind Speed at 30 Feet (Thomas and Robbins, 1979)

3.3 Cost of Energy (1977) as a Function of Annual Mean Wind Speed . . 14 at 30 Feet (Thomas and Robbins, 1979)

3.4 Wind Speed Frequency Distributions for Cook Inlet Area . . . . . 17

3.5 Wind Speed Duration Curves for Cook Inlet Area. . . . . . . . 19

3.6 Wind Power Duration Curves for Cook Inlet Area . . . . . . . 20

3.7 Monthly Average Wind Power and Speed . . . . . . . . . . . 21

3.8 Durinal Variation of Wind Speed by Season . . . . . . . . . 23

3.9 Sea Level Atmospheric Pressure Distributions in Millibars for . . 27 Six Basic Types from a Group of 13 Subtypes Derived by Overland and Hiester for Characterizing the Synoptic Climatology of the Gulf of Alaska

3.10 Directiona1 Frequency and Average Speed Distributions . . . . . 32

4.1 Griggs Putnam Index for Conifers . . . . . . . . . . . . 38

4.2 Flagged Tree near Indian Creek, Turnagain Arm . . . . . . . . 45

4.3 Flagged Trees on Bird Point, Turnagain Arm . . . . . . . . . . 47 


\section{TABLES}

3.1 Wind Speed Frequency Distributions Obtained from AEIDC . . . . . 24

3.2 Percent Occurrence of Each Weather Type During Each Season . . 28

4.1 Wind Speed Frequency Distribution for Diamond M. Dragon . . . . 40

5.1 Rough Cost Estimates for Demonstration Program (DP) Option . . . 54

5.2 Rough Cost Estimates for Rapid Investigation of Large Wind Turbine Penetration (RLWP) Option .......... 56

5.3 Rough Cost Estimates for Gross Resource Assessment (GRA) Option ................... 59 

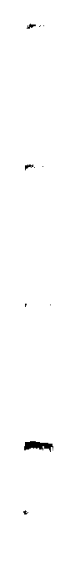

$\rightarrow$

$-$

$-$

- 


\title{
PRELIMINARY EVALUATION OF WIND ENERGY POTENTIAL-- \\ COOK INLET AREA, ALASKA
}

\author{
Prepared for the \\ Alaska Power Administration
}

by

Pacific Northwest Laboratory

May 1980

\subsection{INTRODUCTION}

In recent years a number of uncertainties have had a large impact on electricity generation planning. The chief uncertainties have been: 1) the ability to construct and license base load plants, and 2) the ability to estimate fuel cost escalations. The time delays due to (1) and the economic impacts of (2) have led to increasing interest in alternative sources of electrical energy, such as solar-electric. Over the past five years the U.S. Department of Energy (DOE) has funded programs for the development of large wind turbines. These programs are demonstrating the technical feasibility of utility scale generation of electricity through wind energy conversion systems (WECS). Recent studies (U.S. DOE Solar Working Group) have indicated that of the solar-electric options, wind turbine systems are the closest to economic viability.

\subsection{Objective}

This report summarizes work on a project performed under contract to the Alaska Power Administration (APA). The objective of this research was to make a preliminary assessment of the wind energy potential for interconnection with the cook Inlet area electric power transmission and distribution systems, to identify the most likely candidate regions (25 - 100 square miles each) for energy potential, and to recommend a monitoring program sufficient to quantify the potential. 
The primary area of consideration follows the existing transmission systems: the eastern shores of Cook Inlet from Kenai to Homer, east from Kena $i$ to Seward, north and west from Seward through Turnagain Arm past Anchorage and into the Matanuska - Sustina Valley regions around Palmer, and west to Beluga. ${ }^{a}$ However, to understand the behavior of the winds in this region, terrain up through Broad Pass, up the Matanuska Valley to Tahneta Pass, and down to the southern tip of the Kenai Peninsula also were studied. These peripheral areas were incorporated into the study because of the possible future interconnections between Anchorage and Fairbanks and between Anchorage and Glennallen, and because of the intertie between Homer and Seldovia.

What are the sites that appear to have sufficient potential to justify a monitoring program? That is the central question this study addressed. The answer to this question depends on many screening factors not related to the magnitude of the wind resource, such as:

- match between time of occurrence of wind power and load

- access to adequate transmission and distribution systems

- hazards at that site

- environmental considerations of site

- public acceptance of wind turbines at the site

- safety and security

These items were not treated rigorously in this project. Instead they were treated as assumptions that influenced the selection of sites. For example, we assumed that nearness of existing transmission lines to a candidate site is a desirable attribute. However, we also recognized that deeper study is required to judge the capability of existing lines to handle the output of a cluster of wind turbines. Therefore the prime concern is simply to identify locations that have some minimum average wind energy. This is the ante required before other factors even become germane.

\footnotetext{
${ }^{a}$ Appendix A contains maps covering the study area.
} 


\subsection{Method}

Execution of this project consisted of three phases:

- preliminary data analysis

- site inspection

- monitoring program recommendations

In the preliminary investigation phase all data from Cook Inlet region that are contained in the Pacific Northwest Laboratory ${ }^{a}$ (PNL) wind energy data base ${ }^{b}$ were examined. These data were screened for wind power potential at the data stations. Next, the climatology of the winds in the area were studied. This was done through searching the literature on the large scale $\left(10^{3} \mathrm{~km}\right)$ weather patterns, by examining the wind speed and wind direction frequency distributions at each data station, and by interpreting both the large scale weather patterns and the local wind characteristics in terms of the interaction between the terrain features and the air flow. Topographical maps $(1: 250,000 \mathrm{scale})$ were then examined to select regions where the terrain is expected to enhance ambient winds, thereby causing a relative maximum in wind energy potential. The screening factors listed previously were applied to 1 imit the number of potential sites. Section 3 discusses the preliminary analysis phase and its results.

The purpose of the site inspection phase is to examine firsthand the sites identified by the preliminary data analys is phase and to seek out new information or new sites overlooked in the preliminary analysis phase.

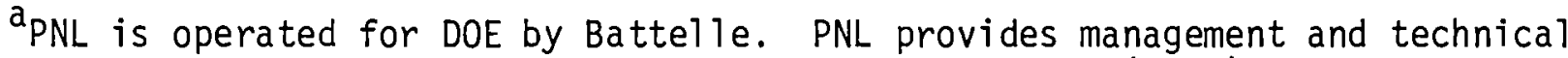
support for the Wind Characteristics Program Element (WCPE) of the Federal Wind Energy Program.

${ }^{b}$ As part of the work of the WCPE, wind energy atlases are being produced for the entire U.S. and its territories. The atlases are products of regional resource assessments being performed by subcontractors of PNL. The wind energy data base consists of weather station data, stored at the National Climatic Center (NCC), that have been processed by PNL into summarized form and stored on microfiche. PNL supplied the subcontractors with these data. They will combine these data with local data not archived at NCC to produce the regional resource assessments. The Alaskan resource assessment is scheduled for completion in FY 81. For further studies of this nature the wind energy atlases would be referred to as the source of preliminary information.
} 
Indicators of wind power potential that were developed by DOE through the leadership of PNL were used during site visits. These include topographical, ecological, geomorphological, and social and cultural indicators. The site inspection phase is discussed in Section 4.

Finally, Section 5 proposes options for programs designed to collect sufficient information to either prove that the wind resource is economically viable, or to demonstrate that wind energy is not a viable energy alternative in the Cook Inlet region. The options are presented so that the APA may choose a course that fits programmatic constraints. 


\subsection{RESULTS AND CONCLUSIONS}

At this time there is no conclusive evidence that large scale generation of electrical energy by megawatt scale wind turbines is a significant viable energy option in the Cook Inlet area. This conclusion is based on the criterion that a site must have a minimum annual average wind speed at 10 meters $(\mathrm{m})$ of $6.5 \mathrm{~m} / \mathrm{sec}$. At the present time there are no sites where it can be concluded that this criterion has been met. Consequently it is premature to consider embarking on large scale, high intensity wind prospecting programs at this time. However, there are indirect indications of potential wind resource areas. The quantity and quality of the wind resource at those sites should be determined through simple measurement programs before decisions are made on the future course of wind energy prospecting in the Cook Inlet area.

The above criterion is based on the energy production characteristics of the MOD-2 wind turbine. The MOD-2 is the most advanced wind turbine designed by DOE so far. Though it is considered as an intermediate design in a series that should culminate in a cost-effective wind turbine, it is expected to be cost-effective in some markets right now if it were in ful 1 production. At a site with an annual mean wind speed of $6.5 \mathrm{~m} / \mathrm{sec}$ at $10 \mathrm{~m}$ the MOD-2 would produce about $10 \mathrm{gwh}$ of electrical energy per turbine. This would result in a cost of energy near $3 \$ / \mathrm{kWh}(\$ 1977)$, based on the projected cost of the one hundredth turbine produced (signifying full production status as apposed to custom production) in a cluster of 25 turbines sited on a reasonably accessible and workable parcel of 1 and (25 turbines could require about 8 square miles of land), and a fixed charge rate of $18 \%$. Federal and municipal utilities may be able to lower energy costs through less expensive capital than at the $18 \%$ rate.

Existing wind data stations tend to be located in sheltered locations so it is not surprising that a viable wind resource does not exist at those sites. Regions of potentially enhanced winds located between existing data stations were identified by studying large scale weather patterns and 
interpreting their interaction with topographical features. Twenty-one candidates were established.

Of the twenty-one candidates, six regions were selected for recommendation as measurement locations in the first year of a wind measurement program. The six sites are judged to have sufficient wind energy potential to warrant measurements, or are judged to be useful locations for gathering data to enhance our understanding of regional patterns of the wind resource. The six regions are:

- the hills north of Homer

- Portage Creek Valley - Turnagain Arm

- Bird Point - Turnagain Arm

- Cantwe11 - Summit - Broad Pass area

- Anchor Point - northwest of Homer

- Tahneta Pass - crest of Glennallen Highway

The quantity and quality of the wind resource will have to be evaluated through measurements.

The most inviting wind resource region is on the bald hills north of Homer. These hills are exposed to the prevailing northerly winter winds and the summer southerly winds, as well as occasional winds from the southwest across lower Cook Inlet, and strong southeasterly winds crossing the Kenai Mountains. The gentle hills probably do not enhance the undisturbed winds upstream of them, but probably do reduce the ambient turbulent intensity of the flow. The principal advantage of these hills is their elevation above the surrounding plains into regions of higher wind speeds. These hills could support significant clusters of megawatt scale wind turbines. The hills nearest Homer have road, transmission, and substation access, but are also sites of radio and microwave transmission equipment. Wind turbines are known to interfere with electromagnetic radiation transmission and reception. Hills farther to the northeast currently have no access.

Several sites in Turnagain Arm probably have an adequate average quantity of wind energy. Land availability, turbulence due to the closeness of canyon walls, icing, and a proven earthquake potential are possible 
problems. Mid-sized wind turbines (100-600 kw) and vertical axis wind turbines may be most practical.

Large wind turbine clusters could be sited in the Broad Pass- Denali Highway area, if a good resource can be found. The wind resource at Summit almost qualifies. The wind patterns are complex in that area so location of the most consistently enhanced sites will be difficult. Some types of numerical models of air flow over terrain would work well there. Wind data from several locations within the area will be required to drive the models.

The bluffs north of Anchor Point near Homer are also potential resource areas. Exact locations of the most windy sites cannot yet be determined. A prospecting program consisting of spot measurements is probably the logical place to begin locating and evaluating that particular resource.

Three options, or suggestions, are proposed for measurement programs that the APA might choose to embark upon. The first option assumes that early operational experience with a medium scale and a large scale wind turbine is desired. This option suggests that time series measurements be made at two sites with two-minute sample intervals and at two heights. An existing tower could be used at the proposed large wind turbine site near Homer.

A second option assumes that rapid exploitation of practically available wind energy is the principal goal. More than one year of measurements would be required to carry this program to completion. The exact measurement strategy would change as some sites are eliminated and others are moved into serious consideration. Suggestions are made for measurements to be made at four sites for the first year of such a program. First year measurements could consist of (depending on the site) time series measurements recorded on magnetic tape cassettes or strip charts, or simple odometer measurements of average wind speed.

The third option assumes that a slower but broader wind prospecting program for resource evaluation is the goal. The first year of this program would rely primarily on odometer measurements of average wind speed at sites spanning the entire region. Follow-up measurements would become more sophisticated if the measured wind resource justifies this. 


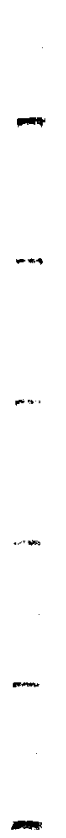

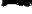

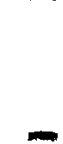




\subsection{PRELIMINARY DATA ANALYSIS}

The principal objectives of the preliminary data analysis are:

- determine if existing data stations indicate a viable wind resource

- determine flow mechanisms responsible for the wind climatology

- identify areas where the topography locally enhances the wind speed. We must first consider what magnitude of resource must be located in a wind prospecting program for a site to be considered economically viable.

\subsection{Minimum Requirements of the Wind Resource}

It is not simple to determine with certainty that a given wind resource is economically viable. Generic planning models have been developed to analyze the value of energy produced by a cluster of WECS (JBF Scientific Corp., 1979 and Marsh 1979). These models are straightforward modifications to existing utility planning procedures but modified to account for the stochastic nature of wind. Those studies clearly demonstrated that the temporal characteristics of the wind resource are critical to the computation of the value of wind energy. In this project load matching is a consideration (i.e., a good load match is a desirable attribute as described in section 1.1) but is not an overriding concern.

Whereas the value of energy is maximized by appropriate load matching, the cost of wind energy is minimized by selecting sites that maximize energy capture and minimize capital investment, and operations and maintenance (0\&M) costs. Energy capture increases (to a point) as site mean wind speed increases. Capital investment increases the more remote a site is, and OoM costs are likely to be higher at harsh sites where excessive turbulence, icing, or salt spray occur frequentiy. We therefore attempt to locate sites that are reasonably accessible and show the greatest promise of having the most

\footnotetext{
${ }^{a}$ In a project of this nature it is not difficult to compare load distribution with wind variations on a seasonal basis. However it is not safe to assume that the diurnal variations in wind speed measured at a standard height of 10 meters are in phase with the diurnal variations in electric power produced by a large wind turbine (Hiester and Pennel1, 1980).
} 
wind in the vicinity yet are likely to be free of hazards.

A look at the status of wind turbine development programs clarifies what magnitude resource we are looking for. Figure 3.1 shows the power output as a function of the wind speed at 30 feet $^{\mathrm{a}}$ for three wind turbines developed in the DOE Wind Energy Program. ${ }^{b}$ Four MOD-OA wind turbines have been built; at $\mathrm{Cl}$ ayton, NM, the MOD-OA has demonstrated that a large wind turbine can operate in an isolated diesel powered utility. At Culebra, Puerto Rico, the second MOD-OA is being tested in a remote environment. At Block Island, RI, the third MOD-OA is demonstrating the use of high penetrations of wind generated electricity. The fourth MOD-OA is to begin operation in 1980 on Oahu, HI, where the ability of wind turbines to produce in strong, steady resources will be demonstrated. The MOD-1 at Boone, NC is demonstrating the technical feasibility of very large wind turbines. The first three MOD-2 wind turbines to be erected will be installed at Goodnoe Hills, WA, where the use of wind turbines in a cluster will be studied in a system dominated by hydroelectric generation. Though intended as an intermediate design in a development cycle progressing toward cost effective wind turbines, the MOD-2 is expected to be cost effective in some current markets .

A rough estimate of the annual energy output of a wind turbine is obtained by computing the integral of the product of the wind speed frequency distribution and the power output curve, and multiplying the result by 8760 hours/year. For annual mean wind speeds exceeding $4 \mathrm{~m} / \mathrm{sec}$, it is sufficient,

\footnotetext{
a This uses a commonly assumed distribution of wind speed with height where the ratio of wind speeds at two heights is equal to the ratio of the two heights raised to the $1 / 7$ power. This is strictly for convenience and perspective since most wind data is gathered near the 30 foot level. However, use of the power law frequently leads to gross errors. For proper evaluation, the wind resource must be assessed at heights comparable to the height of the wind turbine. The $1 / 7$ power 1 aw will be used in this report since we are only addressing the possibilities of locating a viable wind resource.

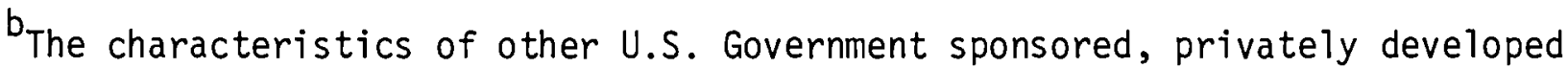
and foreign large wind turbines are described in "Large Wind Turbine Design Characteristics and R\&D Requirements," DOE Publication CONF-7904111.
} 


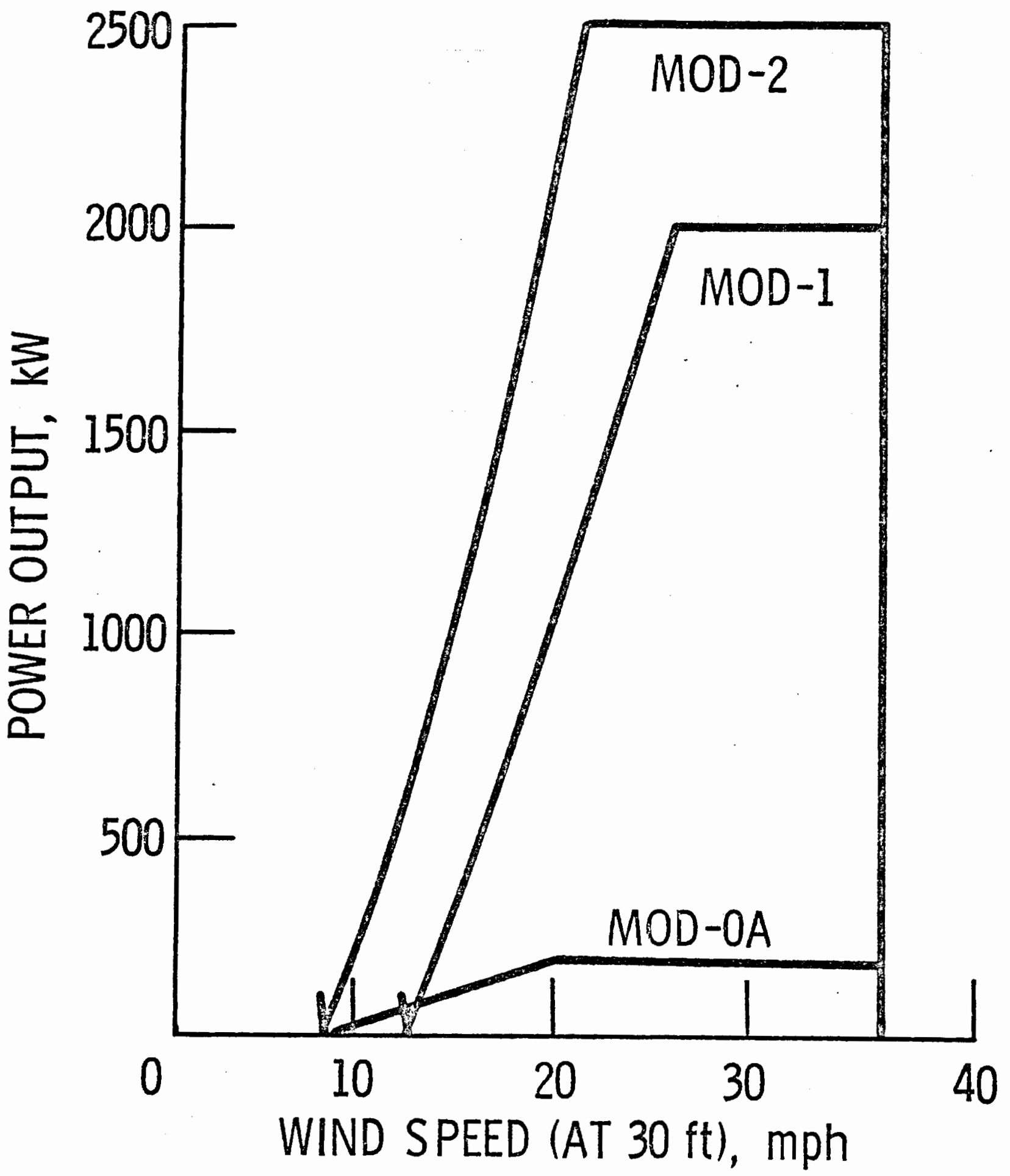

3.1 Power Output as a Function of Wind Speed at 30 Feet for Three Wind Turbines Developed by DOE (Thomas and Robbins, 1979) 
for this procedure, to estimate the wind speed frequency distribution with a Rayleigh distribution ( $\mathrm{Cliff}, 1977$ ). The Rayleigh distribution is simply an analytical probability distribution (such as the Gaussion distribution or bell curve) that has been empiricaliy found to describe the probability of observing a given wind speed. The Rayleigh distribution is:

$$
p(v)=\frac{\Pi v}{2 \bar{v}^{2}} \exp \left[\frac{-\Pi v^{2}}{4 \bar{V}^{2}}\right]
$$

where:

$$
\begin{aligned}
p(v) & =\text { frequency distribution of wind speed } \\
v & =\text { wind speed } \\
\bar{v} & =\text { long-term average wind speed }
\end{aligned}
$$

Other more complicated distributions may be used, but the principal advantage of the Rayleigh distribution is that it depends only upon one parameter, the mean wind speed, which is frequently the only information available from existing data stations. Figure 3.2 shows the annual energy output of the MOD-OA, MOD- 1 , and the MOD-2 as a function of annual average wind speed at 30 feet, assuming a Rayleigh distribution and $90 \%$ availability of the wind turbine.

DOE computes the cost of energy from these wind turbines as:

$$
\mathrm{COE}=\frac{\mathrm{IC} \cdot \mathrm{FCR}+\mathrm{LF} \cdot \mathrm{AOM}}{\mathrm{AEP}}
$$

where:

$$
\begin{aligned}
\text { COE }= & \text { cost of energy in } \$ / \mathrm{kWh} \\
F C R= & \text { fixed charge rate } \\
A O M= & \text { annual operations and maintenance costs } \\
L F= & \text { a levelizing factor to account for inflation of } 0 \& M \text { costs } \\
& \text { during the life of the system } \\
A E P= & \text { anticipated annual energy production of the system. }
\end{aligned}
$$

Figure 3.3 shows the cost of energy (\$1977) for the three wind turbines as a function of the site annual mean wind speed. The computation of COE assumes a fixed charge rate of $18 \%$ typical of investor owned utilities. 


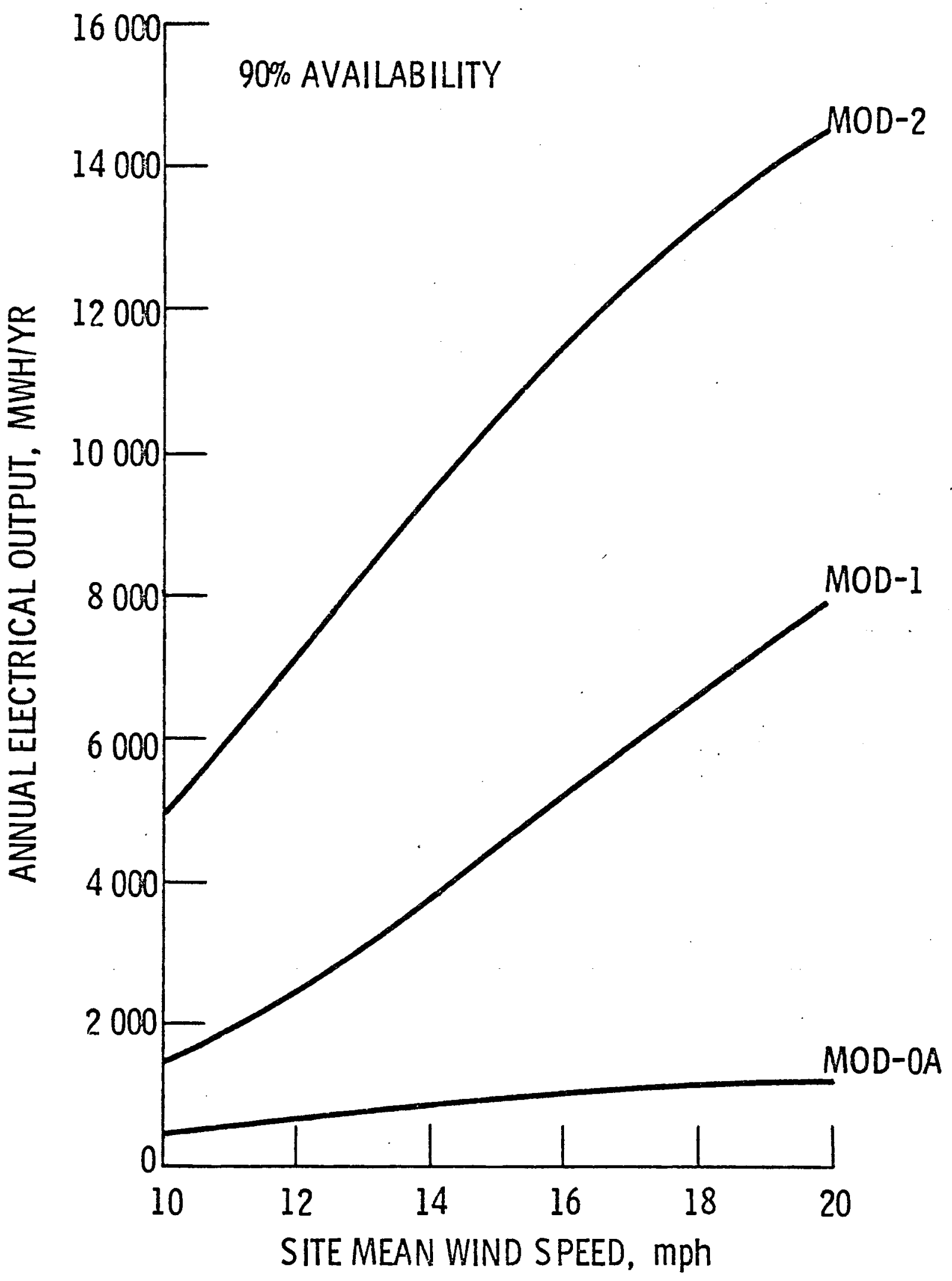

3.2 Approximate Annual Energy Output as a Function of Annual Mean Wind Soeed at 30 Feet (Thomas and Robbins. 1979) 


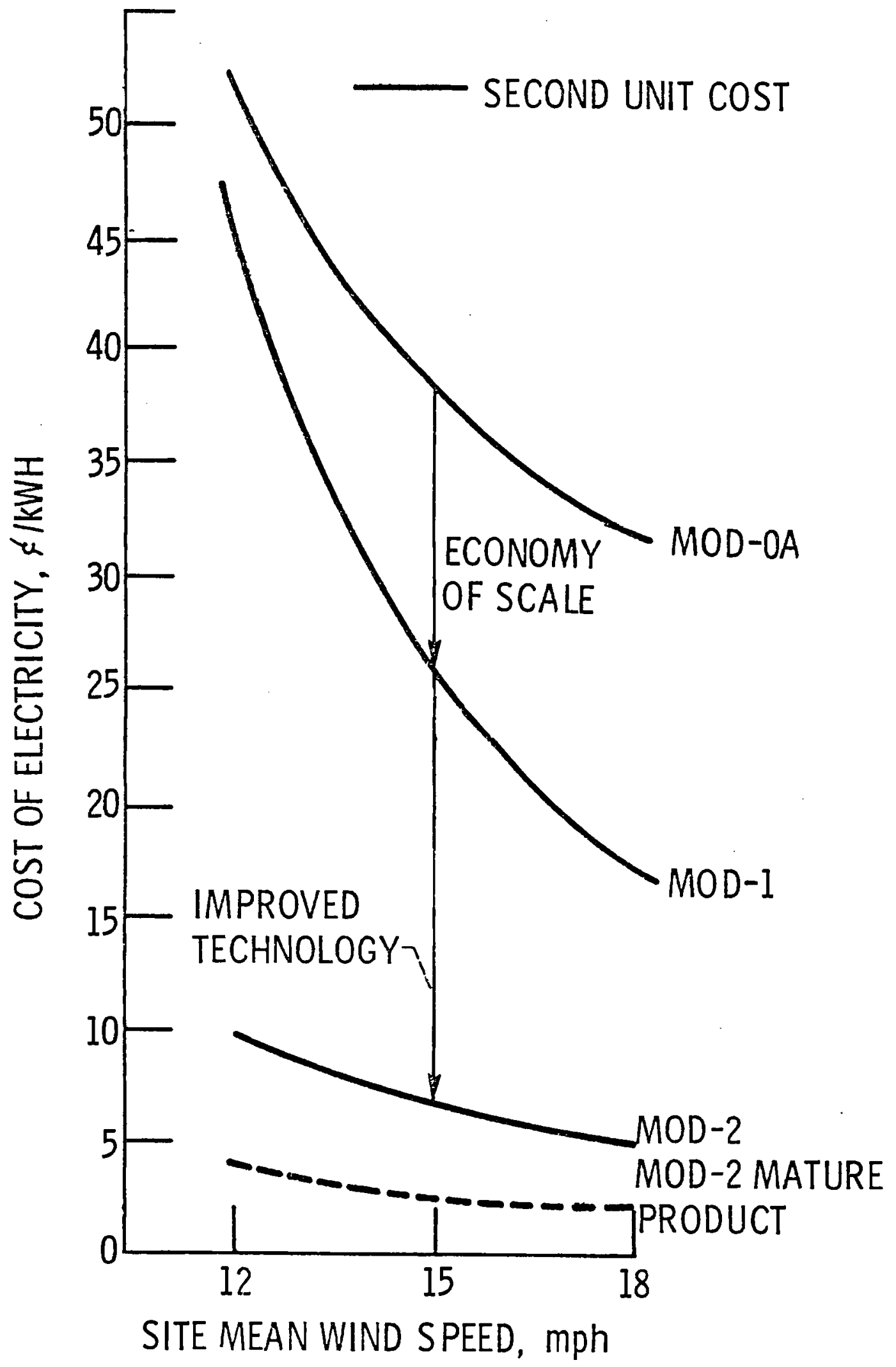

3.3 Cost of Energy (1977) as a Function of Annual Mean Wind Speed at 30 Feet (Thomas and Robbins. 1979) 
Although the fixed charge rate for Federal or municipal utilities is substantially lower than for investor owned utilities, it is assumed that if wind technology does not satisfy the broader market, mass production will not begin. The next advanced large wind turbine to be developed by DOE, the MOD-5, is expected to shave about $0.5 \$ / \mathrm{kWh}$ off of the MOD-2 mature product curve of Figure 3.3. Note that the flat appearance of the MOD-2 mature product curve is an illusion of scale. There is a variation of nearly a factor of two in the cost of energy between 12 and $18 \mathrm{mph}$ sites and the cost of energy rises sharply at wind speeds below $12 \mathrm{mph}$.

The current average power costs in the cook Inlet area systems are less than $2 \phi / \mathrm{kWh}$. Average power costs are expected to increase to about $5-7 \phi / k W h$ by 1990 (Upper Susitna River Project Power Market Analyses, APA, 1979. Appendix A, page 86). It is evident from Figure 3.3 that wind energy is not competitive at the present time except in very high wind regions and for reduced cost of capital. However, this situation may change as wind technology improves and as the current modes of generation by combustion turbines fired by low-cost oil and gas changes.

For our purposes we will consider an annual average wind speed of $5 \mathrm{~m} / \mathrm{sec}(\mathrm{N} 11 \mathrm{mph})$ or average power of 150 watts $/ \mathrm{m}^{2}$ at a height of $10 \mathrm{~m}$ ( 230 feet) above ground as a minimum threshold for consideration. A wind resource of $6.5 \mathrm{~m} / \mathrm{sec}(14.5 \mathrm{mph})$ or average power of 325 watts $/ \mathrm{m}^{2}$ will be regarded as a good resource.

\subsection{Wind Resource Characteristics at Existing Data Stations}

Wind data from the PNL wind energy data base and wind data obtained through the cooperation of the Artic Environmental Information and Data Center (AEIDC) were screened for wind energy potential. The stations from the PNL data base included:

- Anchorage/Elmendorf

- Anchorage/International

- Anchorage/Merrill Field

- Homer 
- Kenai

- Il iamna

- North Dutch Island (Prince William Sound)

- Skwenta

- Summit

- Talkeetna

Data provided by AEIDC included the following stations:

- Palmer

- Seward

- Portage

- Tyonek

Figure 3.4 shows wind speed frequency distributions and fitted Rayleigh distributions for the PNL supplied data. At the head of each plot is:

- the station name

- dates between which data were collected

- station identification number

- the height of the anemometer above ground (m)

- a letter designating anemometer placement ( $G$ for ground mounted, $R$ for roof top)

- average wind speed ( $\mathrm{m} / \mathrm{sec})$

- average wind power density (watts $/ \mathrm{m}^{2}$ )

Based on the criteria set in the preceeding section, no station represents a good wind energy resource (i.e., $>6.5 \mathrm{~m} / \mathrm{sec}$ average wind speed or $>325$ watts $/ \mathrm{m}^{2}$ at $\left.10 \mathrm{~m}\right)$. Summit and North Dutch Island are the only stations indicating a wind resource worth considering $(>5 \mathrm{~m} / \mathrm{sec}$ average wind speed or $>150$ watts $/ \mathrm{m}^{2}$ at $\left.10 \mathrm{~m}\right)$.

At Summit the mean wind speed is $5.1 \mathrm{~m} / \mathrm{sec}$ and the average power density is 169 watts $/ \mathrm{m}^{2}$. At North Dutch Island the mean wind speed is 1 ess $(4.5 \mathrm{~m} / \mathrm{sec})$, but the average power density is substantially greater ( 241 watts $\left./ \mathrm{m}^{2}\right)$. Since the power in the wind is porportional to the cube of the wind speed, average wind power density is very sensitive to relatively infrequent occurrences of high winds. High winds occur more frequently on North Dutch Island than 


\section{ANNUAL AVERAGE WIND SPEED FREQUENCY \\ - ACTUAL DISTRIBUTION ORDINATE - PERCENT \\ RAYLEIGH DISTRIBUTION ABSCISSA - M/SEC}
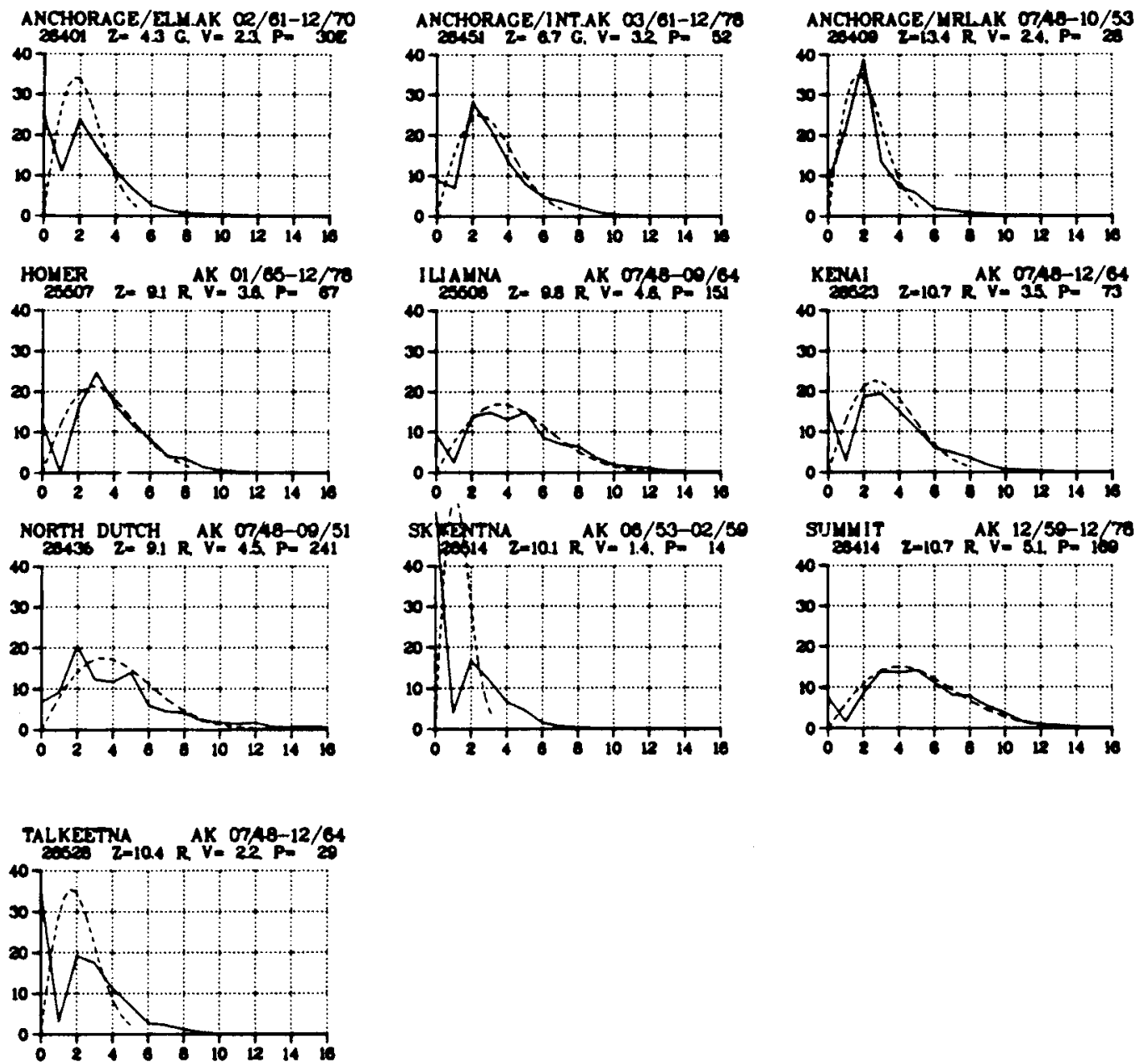

3.4 Wind Speed Frequency Distributions for Cook Inlet Area 
at Summit as Figure 3.4 shows, however, the wind speed duration curves shown in Figure 3.5 illustrate this more clearly. The effect on the wind power is demonstrated by the comparison between wind power duration curves at Summit and North Dutch Island shown in Figure 3.6.

The greater average wind power density at North Dutch Island does not necessarily indicate that North Dutch Island has a more usable wind resource. As the wind speed exceeds the rated wind speed of a wind turbine, excess wind power must be dumped (for example, by blade pitch control or aerodynamic sta11) in order to keep the electrical power at the rated output. Therefore, significant amounts of wind power frcm wind speeds beyond the rated wind speed are not used. Of course, all wind power is lost from a wind speed above the cut-out wind speed.

We have made some preliminary estimates for the energy production characteristics at Summit and North Dutch Island for a MOD-2 wind turbine. These estimates are obtained by integrating the product of the wind speed frequency distribtuions shown in Figure 3.4 with a power output curve for the MOD-2. at Summit we estimate an annual energy production of $5.5 \mathrm{GWh} /$ year at an average power output of $625 \mathrm{KW}$ for a plant factor of 0.25 . The windspeeds would be in the operating range of a MOD-2 about $55 \%$ of the time but only at the rated power $7 \%$ of the time. On the other hand, the winds on North Dutch Island would only be in the operating region of the MOD-2 about $38 \%$ of the time. Again, only $7 \%$ of the winds are in the range for producing the rated power output. In total only $3.5 \mathrm{GWh} /$ year of energy would be produced per MOD-2 at North Dutch Island at an average power output of less than $400 \mathrm{KW}$ for a plant factor of about 0.16 .

The Cook Inlet loads peak in the winter and in the daytime. Seasonal load matching characteristics of the wind resource can be judged from the distribution of monthly average wind power and speed plotted in Figure 3.7. Wind power peaks in the wintertime at Summit and North Dutch Island but is reasonably constant for most other stations. Diurnal variation in wind

a A $1 / 7$ power law variation of wind speed with height has been assumed; this is one of the largest uncertainties in these rough estimates. 


\section{WIND SPEED DURATION - ANNUAL AVERAGE ORDINATE - PERCENT \\ ABSCISSA - M/SEC}
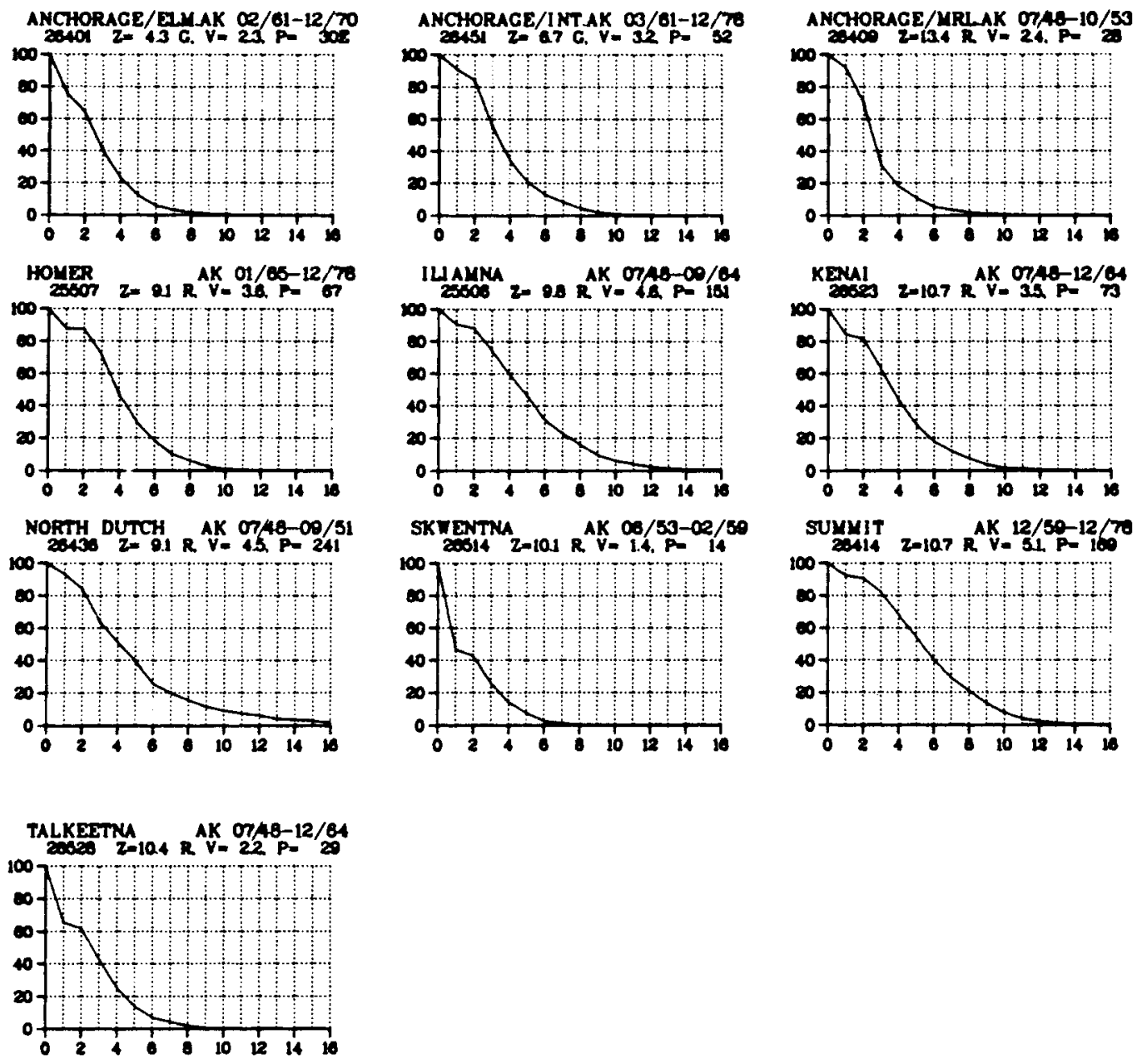

3.5 Wind Speed Duration Curves for Cook Intet Area 


\section{WIND POWER DURATION - ANNUAL AVERAGE ORDINATE - PERCENT ABSCISSA - WATTS/ $\mathbf{M}^{2}$}
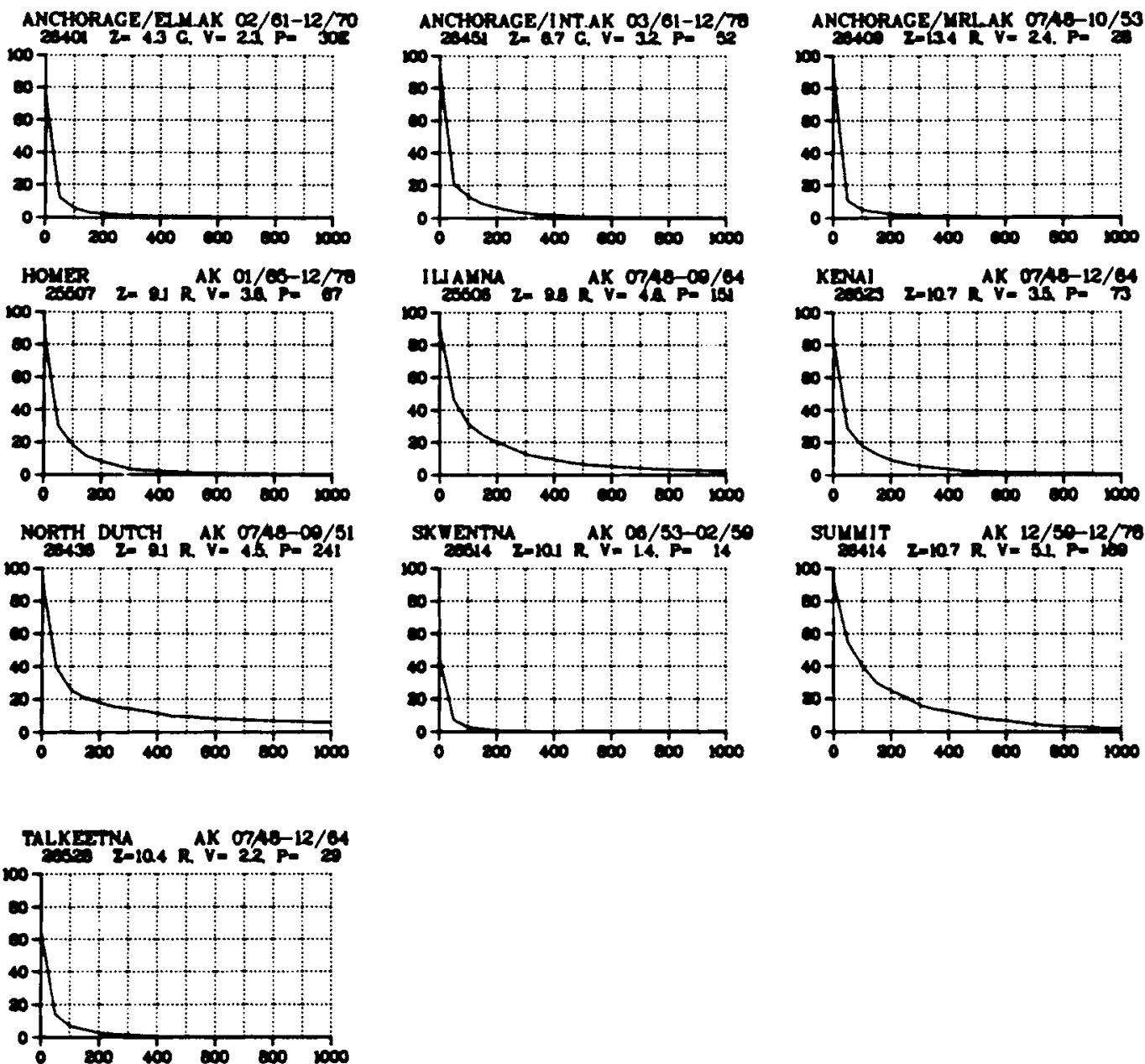

3.6 Wind Power Duration Curves for Cook Inlet Area 


\section{MONTHLY AVERAGE WIND POWER AND SPEED WIND POWER WIND SPEED LEFT ORDINATE - WATTS $/ M^{2}$ RIGHT ORDINATE - M/SEC ABSCISSA - MONTH \\ $\checkmark$ AND $P$ ADJUSTED FROM $Z$ TO $10 \mathrm{M}$ BY $1 / 7$ POWER LAW}

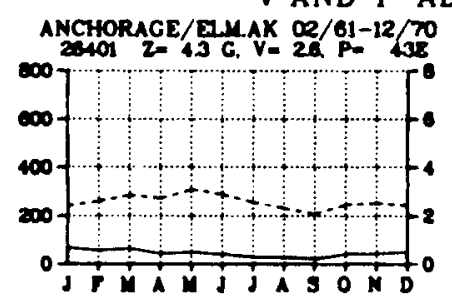

ANCHORAGE/INT-AK $03 / 61-12 / 70$

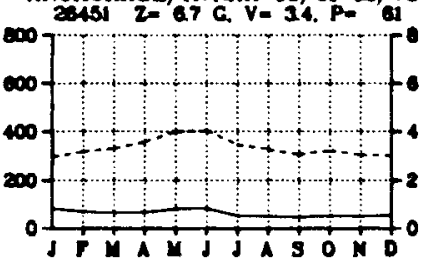
NCHORAGE/MRLAK O7/O-10/53
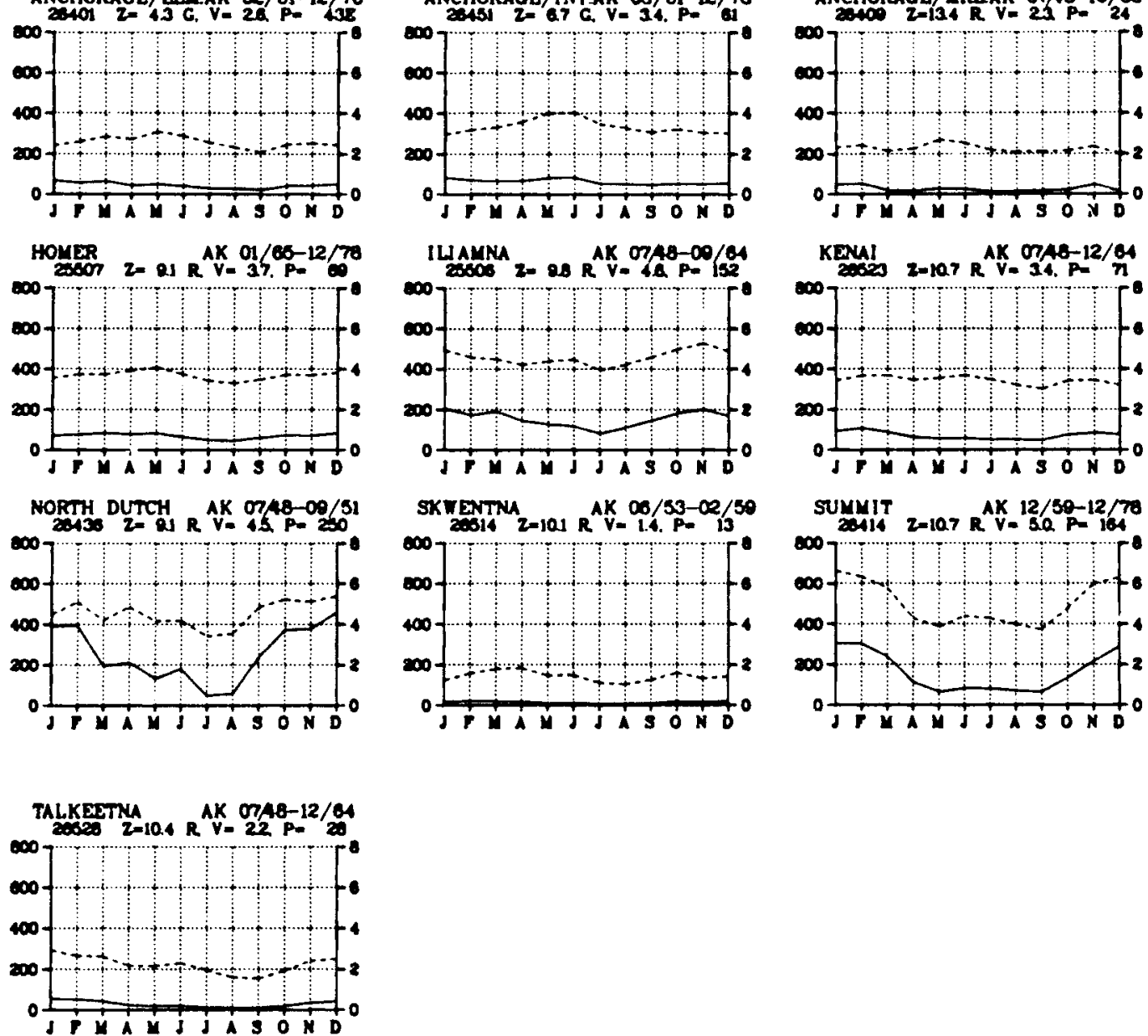

3.7 Monthly Average Wind Power and Speed 
power near the surface is small at most stations as Figure 3.8 shows. Of course, one does not expect much diurnal variation in summer or winter at high latitudes.

The wind speed frequency distributions for the data supplied by the AEIDC are tabulated in Table 3.1 using the original units of speed. Also shown are anemometer heights if they are known or estimates if the information was not supplied by AEIDC. The length of record is listed as is the nominal number of observations per day that were to have been collected. A comparison of the average number of observations per day with the scheduled number indicates that significant data gaps exist in the record. If these data gaps are not randomly distributed throughout the year, the data will be biased toward the wind characteristics of the season of greatest data collection. An estimate of the mean wind speed in $\mathrm{m} / \mathrm{sec}$ was made by weighting the median wind speed in each class by the percentage of wind speeds that occurred in that class. This is not a good assumption for very broad speed classes but Table 3.1 shows that for all stations the estimated mean wind speed is well below the threshold of consideration.

We conclude that, for utility scale exploitation of wind energy, there is no economically viable wind resource at the locations of the data stations used in this preliminary analysis. The wind data from Summit suggest that it may be possible to locate a viable utility scale resource in the vicinity of summit if regions of terrain enhanced winds exist. ${ }^{2}$ The low average wind speeds at most historical data stations is not surprising since people tended to seek sheltered places to live and, until the recent surge of interest in wind energy exploitation, most anemometers were not sited with the intention of evaluating the wind resources.

\subsection{Wind Patterns and Climatology}

The next step in the wind prospecting process is to determine if there are regions of enhanced winds located between or around the existing data stations. A number of techniques are available to do this interpolation

asmall scale local generation of electricity by residents in the SummitCantwell region is worthy of consideration as a supplement to diesel generated power. 


$$
\begin{aligned}
& \text { DIURNAL WIND SPEED BY SEASON } \\
& \Longrightarrow \text { WINTER } \cdots \text {-... SPRING ORDINATE - M/SEC } \\
& \text { - }- \text { SUMMER }- \text { AUTUMN ABSCISSA - HOUR }
\end{aligned}
$$
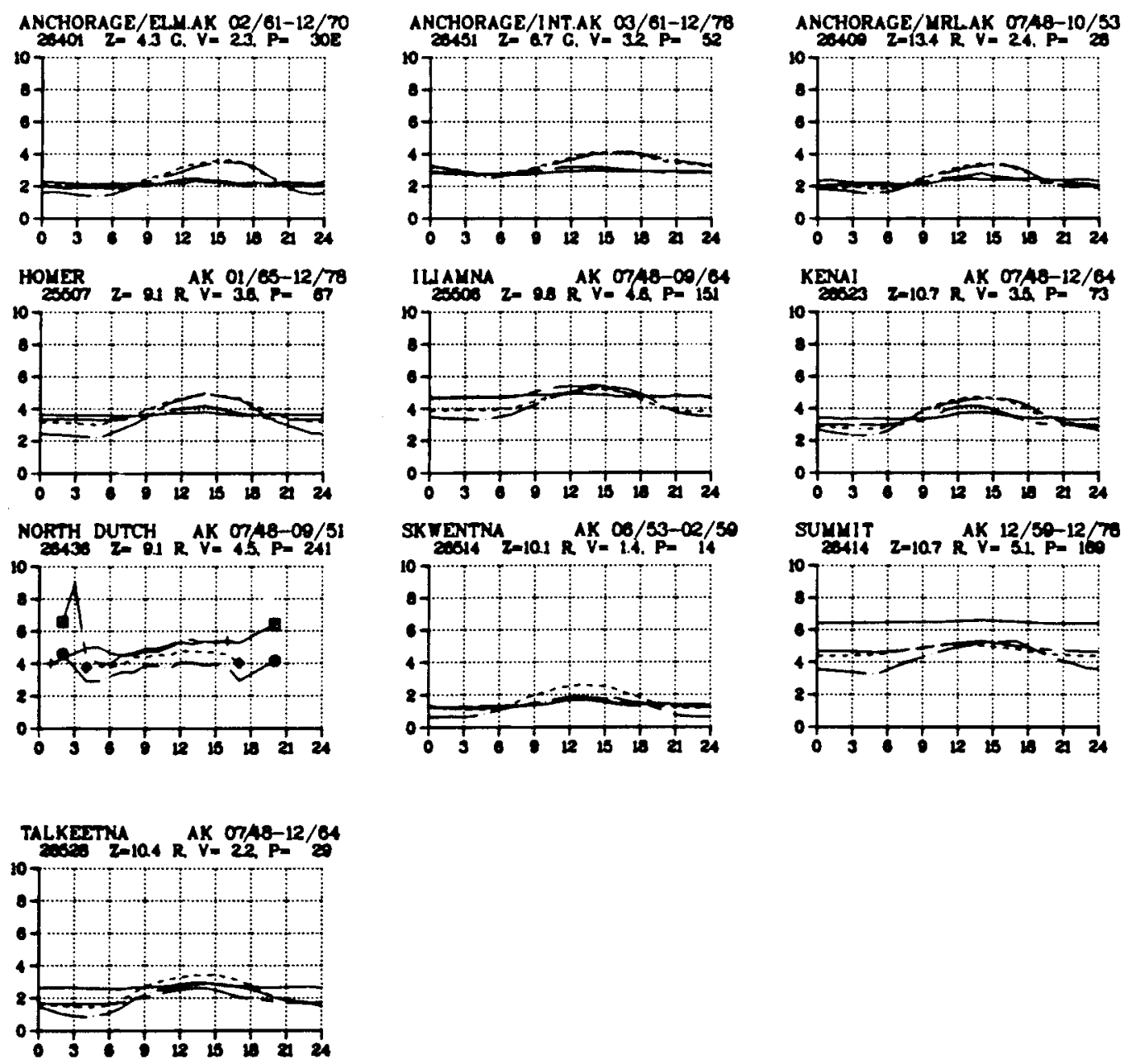

3.8 Durinal Variation of Wind Speed by Season 
TABLE 3.1. Wind Speed Frequency Distributions Obtained from AEIDC

PALMER $(7 / 77-6 / 79)$

\begin{tabular}{|c|c|c|c|c|c|c|c|}
\hline Anemometer hei & & $5.5 r$ & & & & & \\
\hline Scheduled & & 5 of & & & & & \\
\hline Estimated mean & find $s p$ & & $3.6 n$ & & & & \\
\hline Speed (knots) & CALM & $1-3$ & $4-6$ & $7-10$ & $11-16$ & $17-21$ & 22 \\
\hline Percent & 17 & 10 & 32 & 20 & 13 & 6 & 2 \\
\hline
\end{tabular}

Anemometer height 5-10m (Estimated)

Scheduled 2-13 obs/day Average 1.3 obs/day

Estimated mean wind speed $\quad 3.1 \mathrm{~m} / \mathrm{sec}$

$\begin{array}{llllll}\text { Speed (mph) CALM } & 4-15 & 16-21 & 32-47 & 47\end{array}$

Percent

$38 \quad 52$

9

1

PORTAGE $(10-35-4 / 41)$

Anemometer height $\quad 5-10 \mathrm{~m}$ (Estimated)

Scheduled 1-2 obs/day Average 0.87 obs/day

Estimated mean wind speed $\quad 2.5 \mathrm{~m} / \mathrm{sec}$

Speed (mph) CALM $4-15 \quad 16-31$

$\begin{array}{llll}\text { Percent } & 48 & 48 & 4\end{array}$

TYONEK $(6 / 40-4 / 41)$

Anemometer height $5-10 \mathrm{~m}$ (Estimated)

Scheduled 2 obs/day

Estimated mean wind speed $\quad 2.7 \mathrm{~m} / \mathrm{sec}$

$\begin{array}{lllll}\text { Speed (mph) CALM } & 4-15 & 16-31 & 32-47\end{array}$

Percent

3960

*Less than $1 / 2 \%$ 
or extrapolation (Hiester and Penne11, 1980). Numerical models provide an objective method for estimating the effects of terrain on airflow and for data interpolation. The accuracy achieved in numerical model solutions depends on the accuracy and density of the input data and on the amount of realism in the mathematical relationships that make up the model. Flow over terrain may also be simulated by placing a scaled representation of the terrain in a suitably designed wind tunnel. This approach can yield useful results only if the modeled region is no more than a few tens of kilometers in size, and the portion of the atmosphere to be studied is the lowest few hundred meters.

Historically, wind machines have been sited by applying topographical indicators which are empirical guidelines describing the general effects of terrain or surface obstacles on the wind. Currently, topographical indicators are being used extensively in the DOE regional resource assessments (Wende11, 1979). Topographical guidelines are based on a physical understanding of how topography affects flow and on experience gained through observation. An understanding of these guidelines is also invaluable in interpreting the results of numerical and physical modeling studies and measurements.

A number of topographical features are recognized as indicators of high wind energy potential. One group includes gaps, passes, and gorges in areas of frequent strong pressure gradients. These strong pressure gradients occur when large temperature gradients form across a mountain barrier. For example, coastal mountains separate a nearly uniform temperature marine air mass from continental air masses. The inland air can become hot in summer or daytime, or cold in winter or at night, thereby causing seasonal and diurnal fluctuations in the pressure gradient across passes. Pressure gradients also form across mountain ranges when strong winds, as from a storm, blow up against the mountain barrier. If the flow has insufficient kinetic energy to cross the potential energy barrier that the mountains represent, the gaps, passes, and gorges are the relief points for the winds driven by the storm.

Long valleys extending parallel to prevailing wind directions are often good wind energy regions also. The wind stream is channelled by the 
valley walls. At narrow points along a broad valley, mass conservation causes winds to accelerate through the constriction. In the opposite way the river of air spreads out and slows down where the valley widens.

Ridges and mountains are ususally enhanced wind resource areas. Over small scale hills and ridges (less than $300 \mathrm{~m} \mathrm{high),} \mathrm{the} \mathrm{air} \mathrm{accelerates}$ over the crest. This is also due to mass conservation; a stream of air is vertically compressed as it flows over the hill and so must move faster in the constricted region. This is not necessarily so for the flow over large scale mountains. The winds at summit elevation of a high mountain may actually slow down near the summit because of the drag that the mountain exerts on the flow. However, mountains and ridges are still usually good resource areas because they are like tall towers which intercept the flow at higher levels where winds are usually stronger.

Some features that indicate low wind energy potential are basins and valleys that are perpendicular to the prevailing wind. These features can be low wind areas because the flow spreads out over them, opposite to the effect of flow acceleration over ridges, or because they collect cold, heavy air which stagnates at potential energy minima.

We began the application of topographical indicators by examining large scale flow patterns and the synoptic climatology. A synoptic climatology regards patterns of weather (wind, clouds, precipitation, etc.) as an implicit function of the static surface pressure distribution (Barry and Perry, 1973). There are at least three studies of the synoptic climatology that cover the Alaskan region (Sorkina, 1963; Putnins, 1966; and Overland and Hiester, 1980).

Overland and Hiester synthesized elements of Sorkina's and Putnins' works to produce a set of characteristic surface pressure distribution patterns with emphasis on the detail in the Northeast Gulf of Alaska and Cook Inlet. Six pattern types were derived and further divided into 13 subtypes. The six basic types are shown in Figure 3.9 and their frequency of occurrence is shown in Table 3.2. The importance of these patterns to this study is that the lines of constant pressure approximately describe 

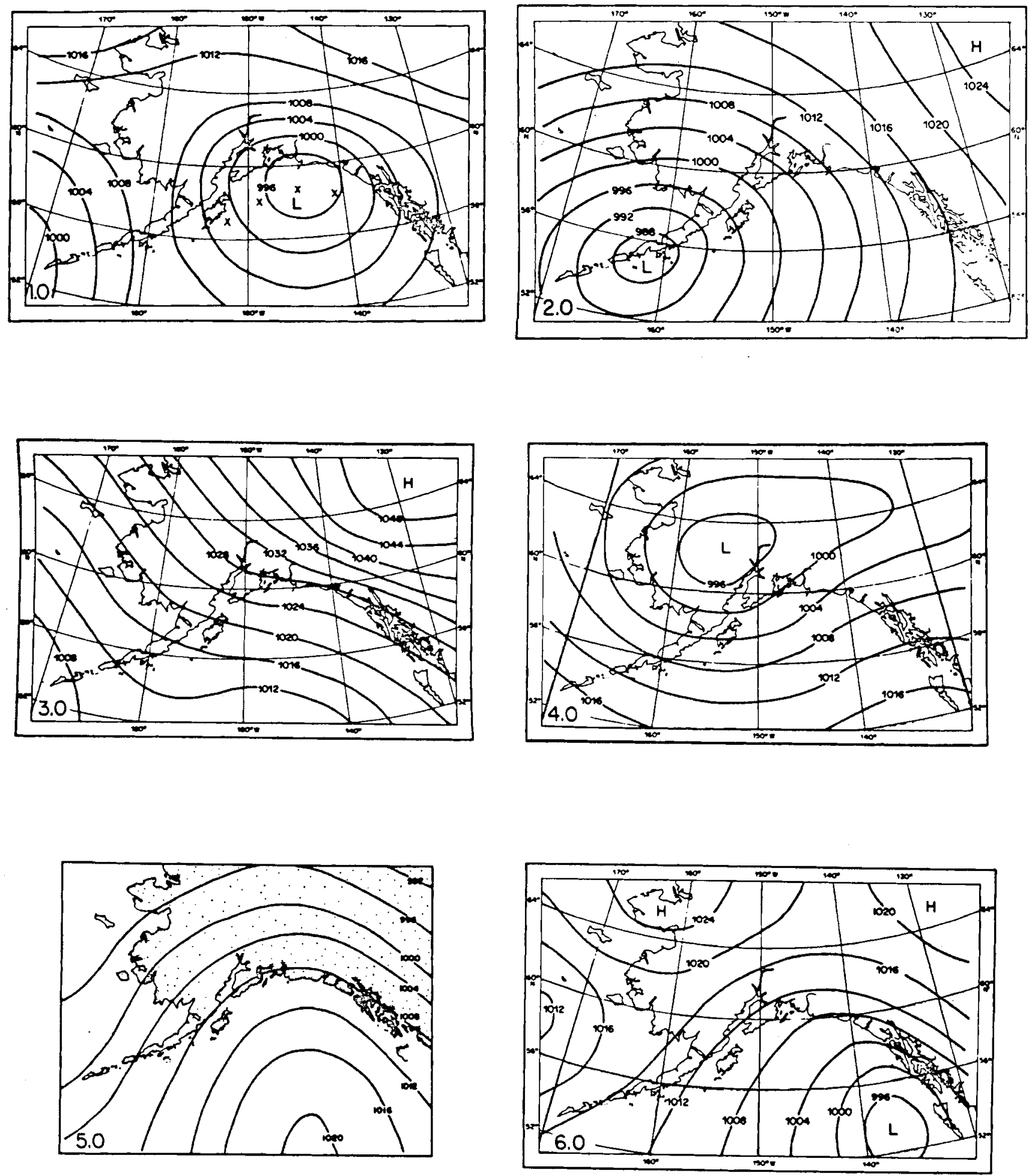

3.9 Sea Level Atmospheric Pressure Distributions in Millibars for Six Basis Tvpes of Group of 13 Subtypes Derived by Overland and Hiester for Characterizing the Synoptic Climatology of the fullf of Alaska 
TABLE 3.2. Percent Occurrence of Each Weather Type During Each Season

Type

\begin{tabular}{lrrrrrr}
\hline & 1 & 2 & 3 & 4 & 5 & 6 \\
\hline Year & 12 & 33 & 8 & 18 & 12 & 17 \\
Winter & 16 & 32 & 16 & 7 & 3 & 26 \\
Spring & 11 & 36 & 7 & 18 & 10 & 18 \\
Summer & 6 & 32 & 3 & 25 & 27 & 7 \\
Fal1 & 15 & 32 & 7 & 22 & 7 & 17 \\
\hline
\end{tabular}

streamlines of the large scale wind patterns. Winds blow roughly parallel to the lines of constant pressure with low pressure to the left as one looks downwind. Significant departures form this approximation occur due to the drag of the earth's surface, which causes a component of the wind to be directed toward low pressure, or due to rapidly changing pressure or movement of these patterns, which causes a component of the wind to be directed toward the most rapid drop in pressure.

When we consider these large scale patterns along with the large scale topographical features in the Cook Inlet - Railbelt area we can understand a great deal about the more localized wind systems. For example, Dale (1956) described the local winds known as the Matanuska winds and the Knik winds in his paper on the climate of the Matanuska Valley. The Matanuska winds are cold, turbulent, and fairly high speed winds that blow down the Matanuska Valley causing wind damage and soil erosion near Palmer. The Knik wind, which is warmer, gentler, and more frequent than the Matanuska wind, blows down from the Knik Glacier. Dale examined the large scale 
weather patterns associated with each wind system and found preferred locations for low and high pressure centers associated with each wind system.

Dale found that the most frequently occurring Matanuska winds were associated with patterns describable by Type 1 or Type 6 patterns of Figure 3.9. The Matanuska wind is sometimes a narrow stream that only influences the northern part of the valley west of Palmer. This is associated with subtypes of Type 1 with the low center to either the west or east (low center for subtypes of Type 1 are marked with an $X$ in Figure 3.9). and with a large polar high influencing most of North Alaska. At other times the Matanuska wind influences the entire valley from the Little Susitna River to Eklutna. These cases are related to the subtype of Type 1 with low centers to the east and small high pressure centers scattered about in the northwest.

In all cases the Matanuska winds result from strong winds blowing up against the mountains separating the Copper River Valley from the Matanuska Valley. The winds are channelled by the upper Matanuska Valley as described in the above discussion of topographical indicators. The Matanuska winds are cold because the cold air collected in the Copper River Basin is the air that is moved through Tahneta Pass at the head of the Matanuska Valley. The cold, heavy air accelerates down the valley and results in turbulent winds at Palmer.

The Knik winds are related to Type 2 patterns or its subtype which has a high pressure ridge in the eastern Gulf of Alaska, or the western subtype of Type 1 storms, if the low pressure center is somewhat elongated in the north-south direction. The Knik winds are therefore also an example of strong winds being channelled by a valley. The knik winds are warm because the air moving through the pass above Knik Glacier is warmer maritime air. Since this air is warmer there is less acceleration down the valley due to gravity than in the case of Matanuska winds; for this reason the Knik winds are also less turbulent and generally of lower velocity. 
Knik winds occur about 50 days per year, throughout the year, whereas the Matanuska winds only occur about 30 days per year, principally in the winter (Dale, 1956). These frequencies are reflected in Table 3.2 by the prevalence of Type 2 patterns throughout the year and the lesser numbers of Types 1 and 6 which occur infrequently in the summer. The Knik and Matanuska winds do not occur frequently enough to make the Palmer area an usable: wind energy resource, as was discussed in Section 3.2 .

The patterns of Figure 3.9, the frequencies of Table 3.2, and the topographical indicators were applied to the rest of the study area to interpret the local wind climatology. In the region from Anchorage to the southern tip of the Kenai Peninsula the major topographical features of interest are the Kenai Mountains and the valley formed by the Cook Inlet estuary. During winter we would expect northerly (from the north) winds in Cook Inlet due to the Type 1 and Type 6 large scale circulations. However, Type 2 and Type 3, which represent flow perpendicular to the Kenai Mountains and across Cook Inlet, account for half of the wintertime patterns. Topographical indicators would imply high winds in the low spots of the Kenai Mountains, Kennedy entrance to Cook Inlet, and perhaps, analogous to the Knik winds, in Turnagain Arm. Because of these winds which blow perpendicular to Cook Inlet, the topographical indicators would not suggest strong winds in Cook Inlet under Type 2 or Type 3 flows. However, any air that comes into the Anchorage region, whether it comes from the Matanuska, Knik, Susitna River drainages or Turnagain Arm, will exit through Cook Inlet, the only significant exit available. The individual local winds draining into the Cook Inlet basin, such as the Knik or Matanuska winds, occur sequentially, rather than simultaneously. Therefore, there may be a fairly continuous stream of air available from several sources in sequence to supply drainage flow to lower cook Inlet.

In summer, Type 4, Type 5, and Type 2 (a subtype of Type 2 which is a low center over the Aleutians crowding into the high pressure ridge of Type 5) dominate the region. The local winds are therefore expected to be up Cook Inlet and up the major valleys draining into Cook Inlet. 
Wind direction frequency distributions and average wind speed versus direction are plotted in Figure 3.10. Although seasonal information is not presented in this plot we have examined the seasonal variations of these distributions. The peaks in the frequency distributions for northerly flow at Anchorage, Homer, Kenai, Skwentna, Summit and Talkeetna are primarily due to winter, spring and fall flows. Likewise, the lesser peaks in those distributions are southerly ${ }^{a}$ due to a summertime wind. We expect winds to be stronger in Cook Inlet in winter than summer, but the data at Anchorage International, Homer and Kenai show higher wind speeds associated with the more southerly summer winds. This behavior reflects the sheltering of these stations, which are located on south facing shores, from northerly winds.

The topographical indicators suggest that Turnagain Arm is a potential wind resource area. It is a narrow fjord that runs parallel to the large scale flows of Type 2 and Type 3. At the east end of the fjord there is a relatively low pass between the Kenai Mountains and the Chugach Mountains. Therefore, air from strong disturbances in the Gulf of Alaska will spill over the pass and into Turnagain Arm through the valleys of Portage Creek, Placer River, and possibly Twentymile River. The wind direction frequencies at Portage (not shown) on the west of this pass and North Dutch Island on the east confirm this flow pattern.

The flow in the vicinity of Summit is channelled by the valleys just as all of the other sites considered so far. However, the wind field near Summit is more complex and more difficult to interpret. Northeast of Summit there is a three way junction of valleys. Southwest of the junction is Summit and Broad Pass. The Nenana River, which has its headwaters on the south side of the crest of the Alaska Range comes into the junction from the east along the Denali Highway. At the junction, the Nenana River immediately turns to the north, punching through the low point of the Alaska Range near Windy and runs down toward Healy. It is necessary to

a At Homer the summertime winds are actually WSW which indicates some of the flow at Cook Inlet moves up Kachemak Bay. 


\section{DIRECTIONAL FREQUENCY AND AVERAGE SPEED PERCENT FREQUENCY LEFT ORDINATE - PERCENT ...... WIND SPEED ABSCISSA - WIND DIRECTION}
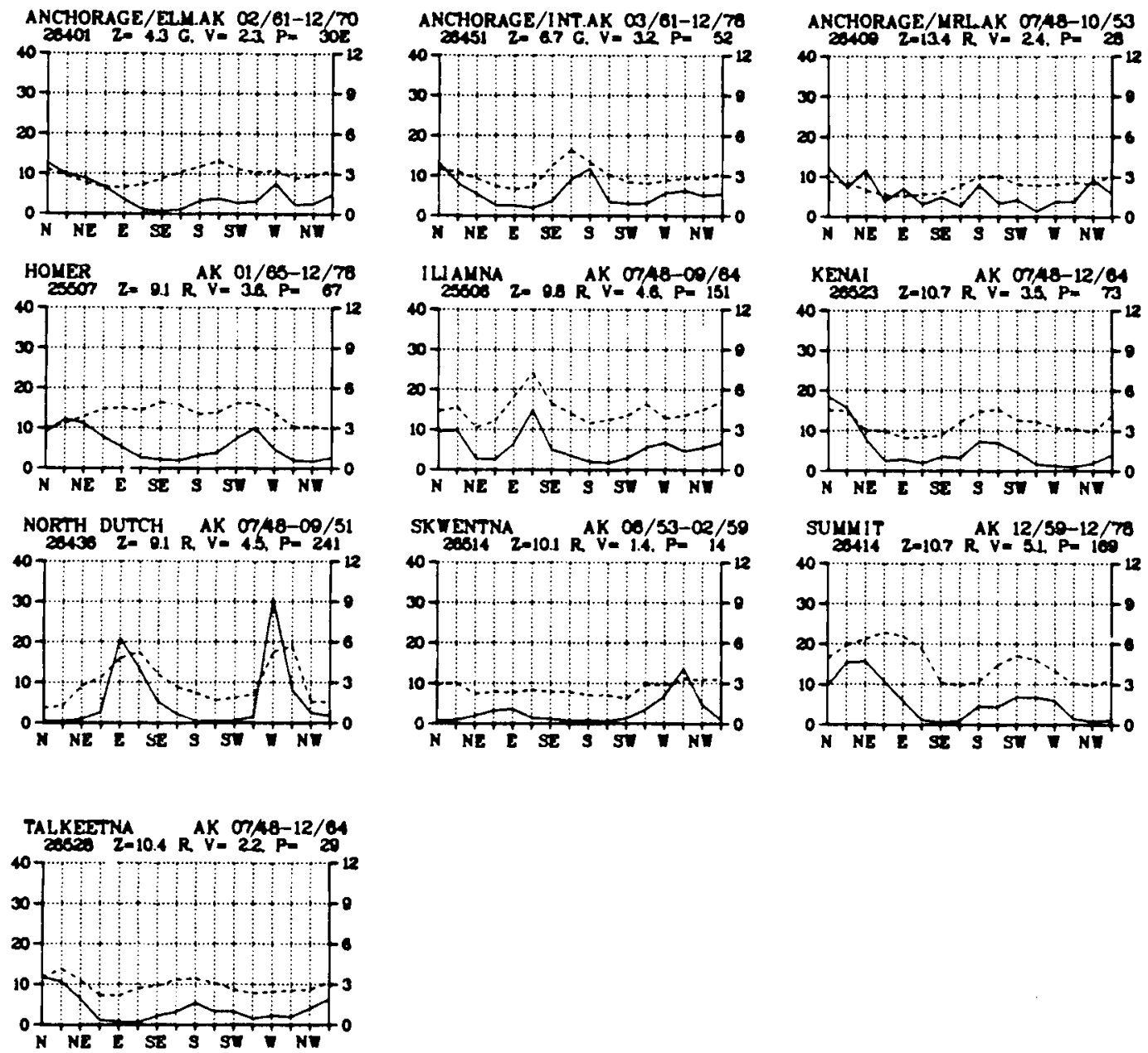

3.10 Directional Frequency and Average Speed Distributions 
understand how the mass flow is partitioned among these three valleys in order to locate preferred wind resource regions. In particular, three items require explanation:

- the prevailing wind direction at Summit is NNE

- the prevailing wind direction at Healy is SE

- the direction of maximum average wind speed at Summit is ENE

In wintertime, the Alaska Range is a barrier that separates a cold air mass to the north from a not-so-cold air mass to the south. The cold air is dense so the surface pressure on the north side is usually higher causing pressure gradients across the Alaska Range. This is reflected in the Type $1,2,3$, and 6 synoptic patterns that prevai1 in winter. It appears that, when strong easterly or southeasterly winds occur over the Copper River Basin, the flow is partially blocked by the Alaska Range so that strong winds blow along the Denali Highway near its junction with the Park Highway. When these winds are not so strong, flow moving along the Denali Highway may either turn south through Broad Pass as lines of constant pressure for Type 1 storms would incicate, turn north toward Healy (causing southerly winds near Windy) as winds of Type 3 press up against the mountains, or perhaps there is actually some splitting of the flow near the valley junction. Northerly winds would blow through the canyon at Windy as air accelerates in the direction of dropping pressure caused by storms of Type 1 or Type 2 that are either intensifying or moving into the cook Inlet area from the southwest. It is also possible that the primary source of Healy southeasterlies is wind moving down the Yanert Fork rather than the Nenana River. In this case the winds at Windy primarily result from accelerations caused by back and forth fluctuations of the pressure gradient across the Alaska Range. This is clearly speculative and further study is needed to adequately determine the winter wind characteristics near summit. 
In summer, the prevailing wind direction at Summit is southwest. This is consistent with the summer flow types 4 and 5 . The summer wind speeds are greatest for flow up the valley, and this is consistent with the topographical indicators for prevailing winds channelled up a gently sloping valley to a pass.

Conclusions

Local wind systems in the Cook Inlet area are dominated by blocking and channelling effects of the major mountains and valley systems. Whenever large scale wind systems become aligned with major valleys, strong winds in the valley result. With the possible exception of Turnagain Arm, no single valley is aligned with the large scale winds enough of the time to be considered a productive wind resource. However, most mass entering the Cook Inlet area from all valleys must exit through lower cook Inlet. Therefore, exposed locations in Cook Inlet may provide a viable and steady wind resource. The existing data stations in Cook Inlet are sheltered from northerly winter winds. The wind field near Summit is complex but enhanced resource areas may exist nearby.

\subsection{Selection of Candidate Sites}

The preceeding section determined that the wind climatology for the accessible areas within the study region consists of winds blowing up or down each valley. Major elevated features, such as the Kenai Mountains, or Portage Pass, are inaccessible; the only possible exceptions are near the southern tip of the Kenai Peninsula where winds may cross the lower mountains or at least pass around the end of the peninsula through Kennedy Entrance. Therefore, specific candidate sites were selected on the basis of topography which could enhance winds moving through the valley.

Topographic maps (1:250,000 scale, see Appendix A) were scanned for sites with one or more of the following five specific characteristics:

- narrow constrictions in the valley

- elevated hills or ridges in the valley 
- obstacle free exposure to prevailing winds

- outside corner of a turn in the valley

- steeper slopes for acceleration of descending cold air.

Twenty-one sites were selected for closer examination during the site inspection phase. These regions are described below, following a name for each site and a Figure number for the reference to the maps found in Appendix A.

1. Swan Lake, A.2. Exposed to the open flats of the Knik River just before it spreads out into the Matanuska Valley

2. Palmer - Wasilla, A.2. This region is exposed to both Matanuska and Knik winds.

3. Fishhook Junction, A.2. Fishhook Junction sits on top of large bluffs that face up the Matanuska River. These bluffs might enhance ordinary weak down valley winds.

4. Sutton, A.2. The region around Sutton is the last constriction of the Matanuska Valley. Because the Matanuska Valley is curving gently toward the south, the core of the Matanuska wind may hug the north side of the valley where there are large hills and bluffs.

5. Fish Lake, A.3. The hill just southeast of the lake appears to be moderately exposed up the valley.

6. Long Lake, A.3. There are well exposed and barren bluffs above Long Lake.

7. Snout of Matanuska Glacier, A.4. The Matanuska Glacier is a large source of cold air to be driven down the slope by gravity.

8. Tahneta Pass, A.4. From the Eureka Roadhouse west to Sheep Mountain Inn the Tahneta Pass narrows. This may amplify the easterlies that blow across the Copper River Basin. Just south of the pass proper is a large open area.

9. Chulitna Pass, A.5. If there is large scale flow moving along the Susitna River between the Alaska Range and the Talkeetna Mountains there may be some enhancement of winds through this narrow pass. This may be in Denali state Park.

10. Base of Ruth Glacier, A.6. The Ruth Glacier and Ruth Amphitheater are sources of cold air drainage flows. This may be in Denali State Park.

11. Honolulu, A.7. Across the valley and northwest of Honolulu is a large elevated bench. This bench has good exposure up the valley and there could be some flow enhancement as air flows onto the bench. Flow might be slightly stronger on that side of the valley due to the inertia 
(centrifugal force) as the flow negotiates the southward turn between Colorado and Honolulu.

12. Cantwe11, A.8. Northeast of Cantwell is a hill exposed to flow coming through Windy. East of this hill is a gap formed by the hill and the Reindeer Hills. The channelling by this gap could enhance the wind resource.

13. Windy, A.8. This is a narrow point in the Nenana River where it cuts through a low point in the Alaska Range. Its name is also suggestive, however the narrowness of this gap indicates that the winds there may be very gusty and turbulent.

14. Denali - Reindeer, A.8. Any flow streaming along the Denali Highway and turning southwest toward Summit will spread and weaken after the narrows just south of Reindeer Hills are passed.

15. Denali - Pyramid, A.8. Pyramid Peak and an unnamed ridge to the south form a very narrow constriction just west of the broad Monahan Flat. In the middle of this constriction is a well exposed elevated region.

16. Anchor Point, A.9. Anchor Point is well exposed to summertime southerly winds and the less frequent but strong southwesterly winds off of lower Cook Inlet. Although its exposure to northeasterlies blowing down Cook Inlet is not very good, it is better exposed than the towns of Homer or Kenai and should therefore register a better wind resource.

17. Diamond Ridge, A.9. Diamond Ridge is the most convenient and accessible of several similar hills and ridges north of Homer. These hills are tall enough and isolated enought to be well exposed to drainage flows down Cook Inlet. The hills are well shaped for enhancing winds without causing low level turbulence problems. If the wind resource exists these hills can support large clusters of WECS.

18. Chugach - Seldovia, A.10. The southern tip of the Kenai Peninsula is undoubtedly a good wind resource but it is not very accessible. Since some of Homer's strong southeasterly winds are probably due to winds from the Gulf of Alaska pushing over the low mountains south of Seldovia, there may be a good wind resource accessible from Seldovia (e.g., near the Kenai Chrome Mine).

19. Bird Point - Sniper's Point, A.11. These are two protrusions extending into Turnagain Arm from the opposite shores. Bird Point is in Chugach State Park.

20. Portage, A.11. Portage Creek, Placer River, or Twentymile River are the sources of Gulf of Alaska air entering Turnagain Arm due to strong easterly winds in Prince William Sound.

21. Windy Point, (not shown). This is a smali protrusion west of Sniper's Point that extends into Turnagain Arm from the south. 


\subsection{SITE INSPECTIONS}

During the site inspection phase each site and the intervening territory was visited. The purpose was to seek new information that was not available during the preliminary analysis phase. Primarily, we looked for reasons to disqualify a site from further consideration due to local terrain conditions, hazards, and accessibility. However, most of the sites listed in Section 3.4 were expected to be unacceptable simply because they are not windy enough. For example, even though there may be regions of terrain enhancement of wind in the Matanuska Valley, the infrequent occurrence of Matanuska winds at Palmer implies strong winds will probably also be infrequent higher in the valley. Therefore in this wind prospecting effort, we looked for reasons to continue considering a site. There is one wind prospecting tool well suited for this job.

The shapes of certain species of trees are good indicators of high winds. Trees are particularly useful in regions where large, local variations in wind speed are expected (as in regions of topographical enhancement) or in regions where wind data are sparse. Quantitative relationships between several different indices of permanent tree deformation (or flagging), and annual mean wind speed at 10m were established by Hewson, et.al., (1979). One such index, the Griggs-Putnam Index, is illustrated in Figure 4.1. The relationship between this index and mean wind speed for Douglas Fir and Ponderosa Pine was determined to be

$$
\bar{V}=0.96 G+2.6
$$

where $G$ is the Griggs-Putnam Index. This predicts annual average wind speed to within $\pm 20 \%$. Other species of trees are currentiy being calibrated. Absence of flagged trees is not necessarily an indication of absence of strong winds since strong winds could come from a number of wind directions. However, where winds are constrained to flow in valleys, as is the case in the cook Inlet area, trees are likely to be flagged where there is a good resource.

Wind erosion or deposition of soil or snow also provides clues to wind history. These eolian processes were also considered during the site 


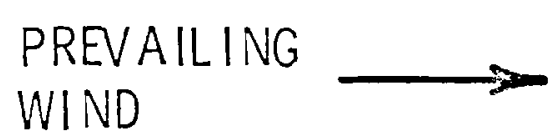

谍尘

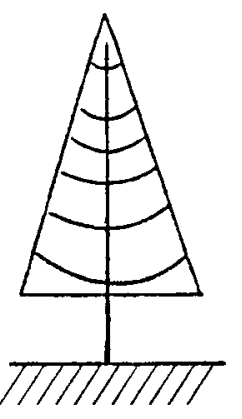

0

NO

DEFORMITY

II

SLIGHT

FLAGGING
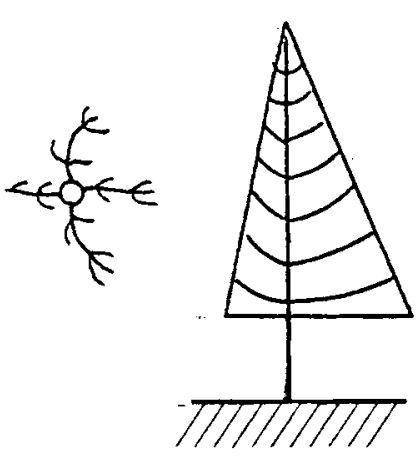

占
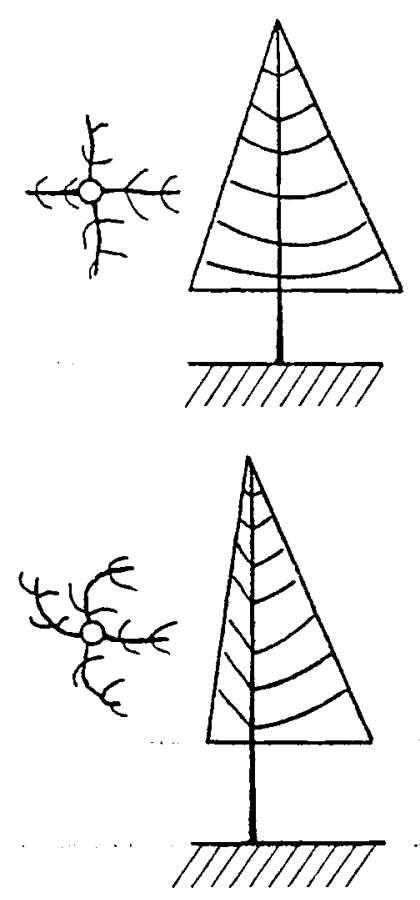

BRUSHING AND SLIGHT FLAGGING
III

MODERATE

FLAGGING

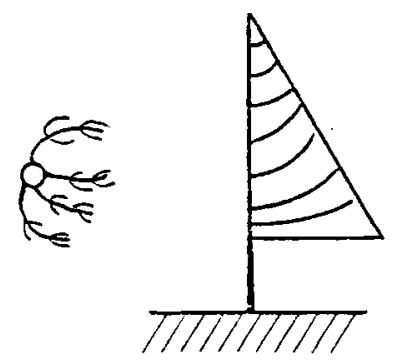

IV COMPLETE FLAGGING

VI

COMPLETE

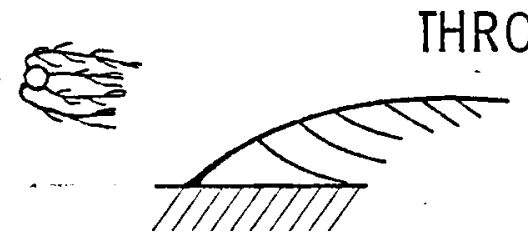

V

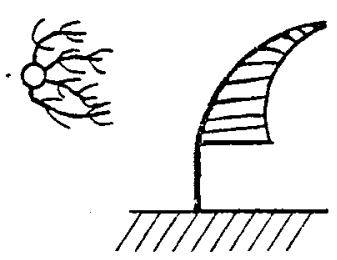

PARTIÁL

THROWING
VII

CARPETING

4.1 Griggs Putnam Index for Conifers 
inspection phase. One must use these techniques cautiously, however, because a very few high wind events can be responsible for most of the wind transport of material (Hiester and Penne11, 1980).

Finally, a great deal of useful information can be obtained from the people living in the study area. Although the information is qualitative, some people may be able to state with considerable confidence that it is more windy here than there or that when winds here behave this way the winds there behave another way. When such comments are interpreted by a meteorologist, significant understanding of the flow in data sparse areas results.

The site inspection visits were made between April 9, 1980 and April 12, 1980. On the morning of April 9, we visited the AEIDC to discuss the preliminary analys is phase and determine if other useful data existed. Two pieces of information were obtained, one regarding winds near Homer and the second regarding potential hazards along the Knik River.

First, we examined some wind data collected on the Diamond M. Dragon, a drilling rig located $12 \mathrm{~km}$ southwest of Anchor Point. The anemometer height is approximately $60 \mathrm{~m}$. Diamond $M$. Dragon data is not being summarized for inclusion into the DOE Alaskan Wind Resource Assessment but we felt that a look at those data would shed light on the wind resource near Homer, which is sheltered from winter northerlies, and on the winds at Anchor Point. The winds at Diamond M. Dragon in January of 1979 are predominantly down Cook Inlet and reasonably strong. The wind speed frequency distribution is shown in Table 4.1. The summertime winds at Diamond M. Dragon are much lighter and more consistent with the winds measured at Homer since Homer's summer winds approach from over the water to the south.

There is clearly a significant wintertime wind resource over the open water in Cook Inlet. We can make rough estimates for the magnitude of the wind resource near Homer (at $10 \mathrm{~m}$ since this is the reference height used throughout this paper) if we only consider the extra drag on the winds due to the forest 1 and. This is done by assuming that the winds at about $2 \mathrm{~km}$ above Cook Inlet are the same speed over land and water, using bulk drag 
TABLE 4.1

WIND SPEED FREQUENCY DISTRIBUTION FOR DIAMOND M. DRAGON DRILLING PLATFORM LOCATED $12 \mathrm{~km}$ SOUTHWEST OF ANCHOR POINT

January 1979

Anemometer Height: $60 \mathrm{~m}$ (estimated)

8 observations per day

Estimated mean wind speed $12.9 \mathrm{~m} / \mathrm{sec}$ o $60 \mathrm{~m}, 10 \mathrm{~m} / \mathrm{sec}$ a $10 \mathrm{~m}$

Speed (knots)

Precent
CALM

$4-6$

1

4

$7-10$

9

17-16

17-27

15

28

28-40

35
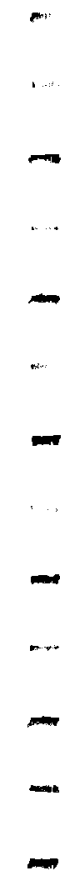

$-$

-

...
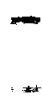

$-$

$-$ 
laws that relate the winds at that level to the winds near the surface and the roughness characteristics of the surface (Wegley, et al., 1980). We then estimate $10 \mathrm{~m}$ winter winds near Homer (not sheltered by topography) are about $7 \mathrm{~m} / \mathrm{sec}$. When combined with the more representative summertime estimate at Homer of $3.6 \mathrm{~m} / \mathrm{sec}$, we obtain an estimate for the annual average of somewhat more than $5 \mathrm{~m} / \mathrm{sec}$, or a resource to consider by our criterion of Section 3.1 . Some of the hills near Homer exceed $300 \mathrm{~m}$ elevation and therefore intercept the winds at a higher level where wind speeds are stronger. This indicates that there may indeed be a good wind resource near Homer.

The second piece of information obtained at the AEIDC pertains to potential hazards along the Knik River. We were told that the Knik Glacier sporadically advances in a way that a lake is dammed up behind a wall of ice. When the wall of ice breaks down during recession of the glacier, sudden and severe flooding results. We were also told that Knik Glacier is currently advancing. If this is true it is sufficient reason to disqualify the first site listed in Section 3.4 .

Following the brief stop at the AEIDC, each candidate site was visited or inspected from a distance except site 9 (Chulitna Pass) and site 18 (Chugach - Seldovia). Comments pertaining to each site are 1 isted below.

1. Swan Lake. There is no evidence of significant tree flagging, supporting the evidence presented in Section 3.3 that knik winds are too infrequent to be usable. The most windy places are likely to be those where the river bar is upwind; this constitutes a flood plain hazard.

2. Palmer - Wasilla. There is no evidence of a consistently usable wind resource. Local people claim this is a windy area but the bas is of these claims tends to be episodes or wind events. Eolian deposits of sand and soil in the valley are deeper and more extensive near the stream of the Matanuska wind. However, eolian deposits are affected most by a very few wind events. Also, eolian deposits indicate regions where the wind speed is dropping below the necessary threshold to maintain transport of soil.

3. Fishhook Junction. The vegetation on the bluffs that face up the Matanuska River show some flagging. This flagging is due to the enhancement of winds flowing up the steep bluffs. Within $100 \mathrm{~m}$ of the bluff edges there is no evidence of strong persistent winds. The bluff edges must be disregarded as potential wind turbine sites due to probable local turbulence caused by the bluffs and due to soil conditions; the bluffs are eroding westward into the highway. 
4. Sutton. The town of Sutton is sheltered. Local people spoke of strong winds near a microwave relay* on bluffs west of Eska. Those bluffs are well exposed to winds moving down the Matanuska River Valley and are situated on the outside corner of a slight turn in the valley. The area was not accessible at the time of the visit but may be reached with four wheel drive later in the year. It is probable that Eska also suffers from the infrequency of the Matanuska winds, although measurements may disprove this. The poor accessibility is the most serious problem.

5. Fish Lake. From the highway, slight but insufficient flagging of trees was observed on the hills northwest and northeast of Castle. One local individual claims that winds are stronger near the northern wall of the valley due west of Chickaloon. This is consistent with the topographical indicator that the core of the wind stream follows the outside corner at a turn in the valley.

6. Long Lake. The hills above Long Lake are well exposed and barren. However, they are too rugged. This could cause both access and possibly turbulence problems.

7. Snout of Matanuska Glacier. The wind resource could not be adequately judged. There may be good and continuous drainage winds blowing down the glacier. However, the site is inaccessible.

8. Tahneta Pass. There was no evidence of tree flagging. There was some sign of drifting and sculptured snow. Based on the topography, the most attractive area is near the Sheep Mountain Inn. The pass is wide open to the Copper River Basin and would be a good location for an instrument to measure mass flow into the Matanuska valley. A road cuts across the pass region to a microwave relay located above Knob Lake.

9. Chulitna Pass. This site was not visited, seen, or inquired about. There is a cabin on Byers Lake with an anemometer at $10 \mathrm{~m}$ (surrounded by 7-8 $\mathrm{m}$ trees). The owner of this cabin has a contract with the FAA to make hourly weather reports between 0600 and 1800. The owner claims the average wind speed is about 10 knots and intends to erect a small wind turbine.

10. Base of Ruth Glacier. This has the same problems as the Matanuska Glacier (site 7 ).

11. Honolulu. The bench across the valley from Honolulu could accomodate a large group of wind turbines. We could not interpret from the topography whether there would be any significant enhancement of the winds on that bench. There is an anemometer at the railroad station at Hurricane. The cabin owner was not at home so it was not determined if records are being made, or for whom. The principal problem is access.

*It is an unfortunate irony that most locations that are slightly elevated and have good exposure up and down the valleys are occupied by microwave relay links. 
12-15. Cantwel1, Windy, Denali Highway. This area was generally free of trees and the trees that were there are not significantly flagged. However, if strong winds do come from more than one direction, the lack of flagging is not a conclusive indicator that the area is not a good wind resource region. With no assistance from the vegetation, very little could be resolved regarding the complexities of this area that were discussed in Section 3.3. Three local Cantwell residents, including one pilot who also operated two $250 \mathrm{kw}$ diesel generators for the town, offered their understanding of the wind field. In general, their comments support the hypotheses suggested in Section 3.3. In addition, they indicated that the winds tended to be stronger at Healy than at Summit. Frequently the winds at Healy and Summit are from opposite directions, but when this occurs the winds usually are not strong at both places simultaneously. The pilot also suggested that winds coming down the Yanert Fork are a significant source of winds affecting Healy. There is interest in wind power in the Cantwell area; several residents along the Denali Highway were reported to have small wind turbines installed.

16. Anchor Point. The point is located within a state park. Vegetation just above the beach is well flagged from the west, indicating strong northerly winter winds, good southerly summer winds, and occasional westerlies that blow across lower cook Inlet. Flagging that close to costal waters can be enhanced by salt spray so the uncertainty in interpreting the wind speeds at Anchor Point is large. There is an anemometer located right on Anchor Point that was placed there by the Pacific Marine Environmental Laboratory/National Oceanic and Atmospheric Administration (NOAA) in March 1980. No reduced data is yet available from this anemometer but it should be obtainable in the near future. North of Anchor Point are bluffs which overlook cook Inlet. Trees along the bluff edge are moderately to completely flagged and some trees several hundred meters inland show slight to moderate flagging. However, the inland trees are not really isolated enough to serve as good samples. We conclude that because of the good access to this region, there may be sufficient resource along the bluffs north of Anchor point to justify making simple measurements. This will be discussed further is Section 5 .

17. Diamond Ridge. There was no significant flagging of trees on Diamond Ridge but this could be due to the exposure of the ridge to winter northerlies, summer southerlies, strong southeasterlies that cross the low mountains southeast of Homer, or the westerlies moving across lower cook Inlet. There are a number of positive attributes for this site. The ridge is well exposed and largely free of trees. There is good road access to the ridge. A transmission line runs the length of the ridge and connects to a substation on the east end. There are, however, negative attributes to the site. There are single family residences located up on what is certainly the finest view property near Homer. There is an FM radio transmitter (KGTL) and several microwave relays 
(including U.S. Air Force) atop Diamond Ridge. ${ }^{\text {a }}$ Although we do not endorse assigning significance to sinort term measurements, we could not help being impressed by the strong, yet non-turbulent character of the northerly winds blowing across Diamond Ridge during a mid-morning and mid-afternoon visit on April 11. A fisherman, who lives atop the ridge, owns an anemometer (not yet recording), and is reasonably well acquainted with the publications of the Federal Wind Eneray Program, claimed the day was fairly typical. The resource in the Diamond Ridge area is worth evaluating. However, the negative attributes of that site may prevent the siting of large WECS there. If so, there are other hills that may serve as well. From the air above Homer a transmission line was observed running to the south of (we believe) Lookout Mountain and Bald Mountain. Further to the north are the Caribou Hills, south of Tustamena Lake. The Caribou Hills are the tallest on the Kenai Forelands. They also are without trees and cover enough area to support a large array of wind turbines, if the resource is validated. Though they currently appear to have no access, the eastward development from Highway 1 may eventually lead to further consideration of the Caribou Hills area.

18. Cugach - Seldovia. This site was not visited, but only viewed from Homer. It appears that there may be usable terrain that could capitalize on the winter winds blowing down Cook Inlet or on the winds coming over the low mountains at the end of the Kenai Peninsula. There is currently no access to this high ground above Seldovia.

19. Bird Point - Sniper's Point. Virtually every place from Rainbow to Bird Point on the north side of Turnagain Arm showed flagged trees, both coniferous and deciduous. Figure 4.2 shows a completely flagged tree near Indian Creek. At McHugh Creek the Alaskan Highway Department has a shed on the shore of Turnagain Arm with an anemometer and a small wind turbine. We did not attempt to recover any data from this station. At Bird Point there is complete flagging of some trees and partial throwing (see Figure 4.1 and Figure 4.3). This indicates that the annual mean wind speed may exceed $6 \mathrm{~m} / \mathrm{sec}$. The principal problem with sites in Turnagain Arm are limitations on the available land (assuming that land within the state parks could be used for wind turbines). Even though Bird Point could possibly accomodate one or two megawatt scale wind turbines, it may make more sense to consider medium scale (10C-600 kw) wind turbines, such as either the horizontal axis or vertical axis versions of the MOD- 6 yet to be developed in the DOE Wind Energy Program. Railroad right-of-way clearance may also be a problem. The limited space available for siting wind turbines also suggests that turbulence generated by the interactions of the wind with the canyon walls could be a hazard. Bird Point juts out into the fjord far enough that turbulence may not be a problem there. Ultimately the turbulence characteristics at a potential wind turbine site

a Large wind turbines interfere with electromagnetic radiation in certain configurations of transmitter-turbine-receiver. 


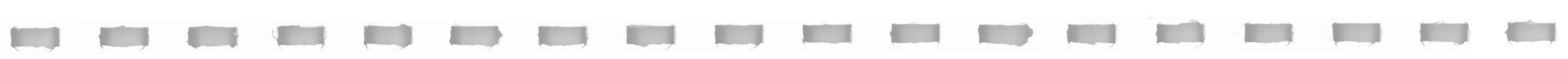

G

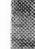

(1)

.

$3+\frac{2}{2}$

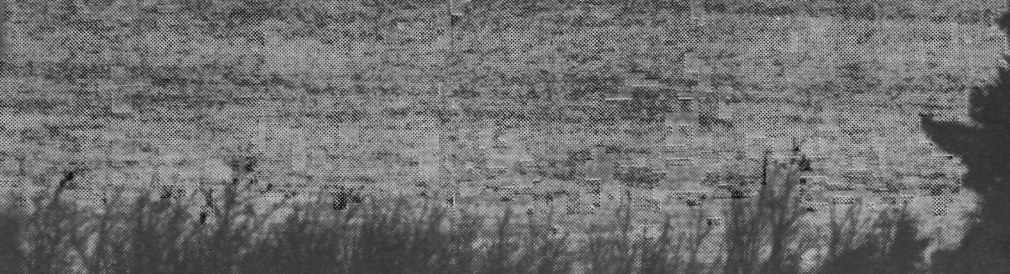

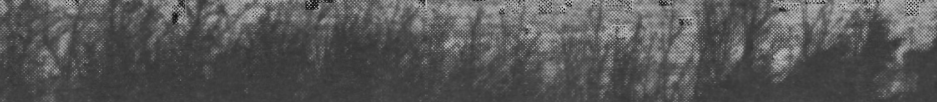

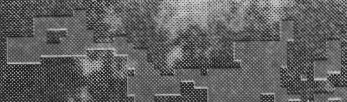

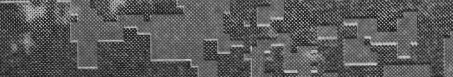

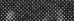

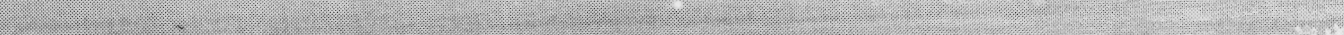

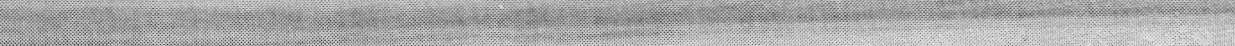
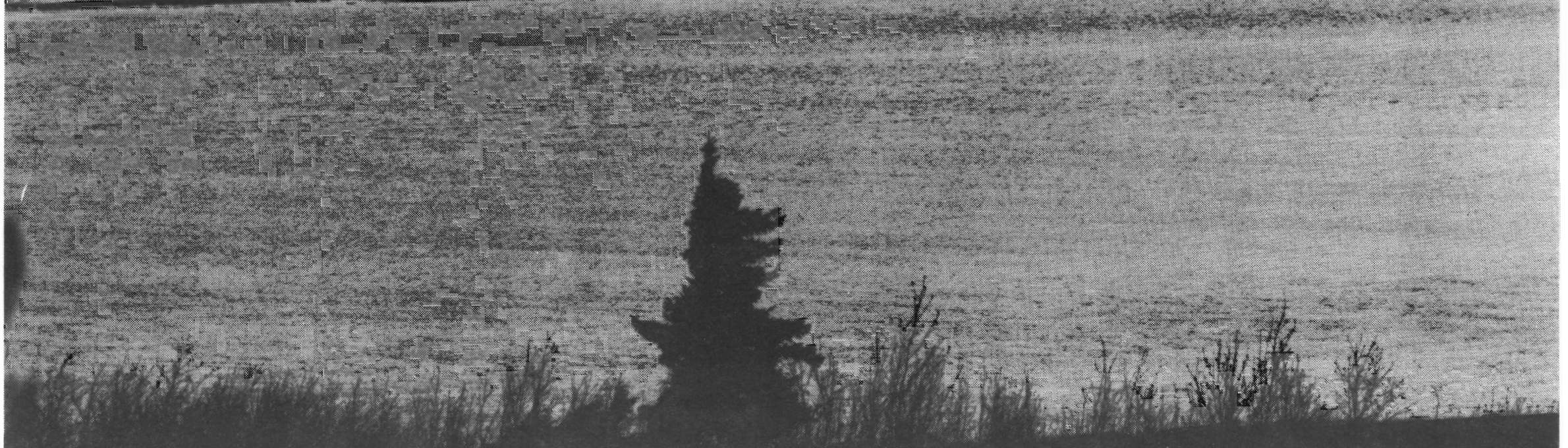

4.2 Flagged Tree near Indian Creek, Turnagain Arm 
must be assessed. Sniper's Point was not visited but, as viewed from Bird Point, it appears more sheltered from strong winds blowing down Turnagain Arm. The potential earthquake hazard in Turnagain Arm is proven.

20. Portage. From the highway there is no biological or geological evidence of persistent strong winds in either Twentymile River Valley or Placer River Valley. The same is true at the mouth of Portage Creek except for a highway sign that had recently blown over. Within $6 \mathrm{~km}$ of Portage Lake were signs of strong and violent winds. A temporary road sign "Extreme Wind Ahead" appeared just downstream of a region of wind-broken trees (10cated between the two westernmost campgrounds shown in Figure A.11). About 15 to 20 broken trees were observed from the road. This was determined to be wind damage rather than avalanche damage because the broken trees were scattered among standing trees, whereas an avalanche would cause more thorough damage. Judging from the condition of the trunks and stumps the damage was recent, probably in the spring of 1980 . Had there been an avalanche so recently, the remnant snow accumulation in the avalanche outrun would have been noticeable. This wind damage was probably a fairly rare event since there was no observable similar damage attributable to previous years' storms. It also is not attributable to the $50 \mathrm{~m} / \mathrm{sec}$ wind storm that damaged Anchorage in the first week of April, since those winds came from the southwest, whereas the wind damage near Portage reflects southeasterly winds. Further consultation should be sought to determine the wind speeds necessary to cause this wind damage, and compared to the 60 to $70 \mathrm{~m} / \mathrm{sec}$ wind speeds that large wind turbines are designed to withstand. The more significant hazard to large wind turbines sited near Portage Lake is icing. Some trees just down from the lake have no bark (and no branches) on the upwind sides of the trunks and stems indicating wind driven ice particle damage. Furthermore, the steel flagpole at the Portage Glacier visitor center was bent in the middle 30 degrees from vertical. This probably occurred when ice built up on the pole causing increased drag and wind loading. The flagging of the trees showed partial throwing (see Figure 4.1) near Portage Lake, decreasing to moderate or slight flagging at the boundary of the Chugach State Park Recreation Area. This decrease in apparent wind resource is more rapid than might be expected since the Portage Creek Valley remains fairly narrow throughout. This decrease may just indicate the downstream increase in forest cover (which itself indicates decreasing wind resource) that causes more drag near the surface. If this is true there may still be a usable wind resource in the downstream end of the valley at the higher levels seen by large wind turbines. Another mechanism is possible however. When shallow high speed flows descend a steep slope, then reach a level surface, kinetic energy of the shallow flow can be converted to potential energy of a lower speed, deeper layer. This is the atmospheric analog to the hydraulic jump of fluid mechanics. If hydraulic jumps occur just downstream of Portage Lake, then the wind resource farther downstream is likely to be weaker throughout a layer seen by larger WECS and is also likely to be subject to rapid changes in wind speed and turbulence intensity as the transition from shooting to tranquil flow moves up or downstream. 


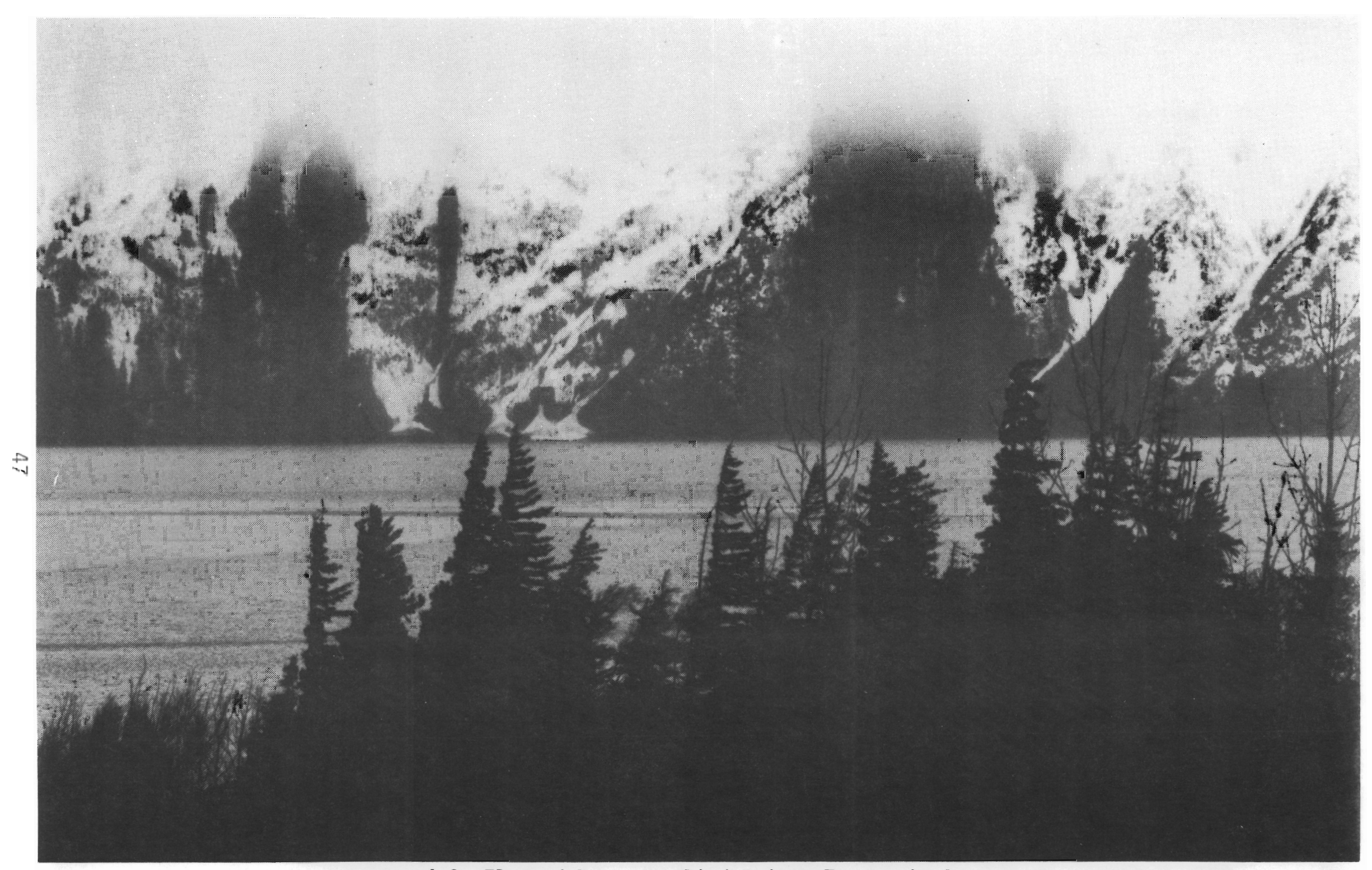

4.3 Flagged Trees on Bird Point, Turnagain Arm 
Similar wind characteristics may be found at the bases of Spencer Glacier or Skookum Glacier, although these areas were not visited.

21. Windy Point. This site was not inspected, but judging from the evidence seen in the rest of Turnagain Arm, a usable resource probably exists if there is sufficient land available and if site turbulence is not too high. 


\subsection{RECOMMENDATIONS FOR MEASUREMENT PROGRAMS}

\subsection{Instrumentation}

Wind data can serve several functions. Some of these functions are:

- to estimate the gross magnitude of the resource at a site

- to evaluate the quality of the resource at a site

- to quantify the economic value of the resource at a site

- to interpolate wind characteristics between sites

The measurements and instrumentation required to gather data for these functions are discussed elsewhere (Hiester and Pennel1, 1980), but we shall mention them briefly here.

The gross magnitude of the wind resource is obtained from the average wind speed. This is measured most simply and inexpensively with wind-run anemometers. A wind-run anemometer is an odometer that measures the distance of wind that has passed through an anemometer. This distance is divided by the time between readings (e.g., one month) to yield an average wind speed over that interva1. Wind-run anemometers cost about $\$ 50$ to $\$ 250$.

Quality of the resource refers to the turbulence and change in wind speed with height (wind shear) characteristics. Measuring wind shear requires two sensors. An estimate of turbulence intensity can be obtained with one sensor if time series are collected at an appropriate sampling rate.

The data requirements for economic assessment of wind energy are still somewhat uncertain. This is because it is not known absolutely what data (number of levels, sampling rate) are required to predict wind turbine output with a specified confidence. The rate at which wind turbine cluster power output fluctuations must be known for reliability calculations is also somewhat uncertain at the present time. Future operational experience will answer these questions. Until this experience is at hand, hourly average wind speeds near hub height are assumed to be adequate for the early stages of site evaluation. A measurement program should retain the flexibility for increasing the sampling rate and possibly the number of sensors per tower 
in later stages of site evaluation at sites were WECS are likely to be installed.

To interpolate wind characteristics between sites, numerical models are used. The modes require input that is representative of air motions on time scales shorter than the changing weather conditions but longer than the turbulence fluctuations. Therefore, synchronous hourly averaged data from several locations are appropriate.

There are several means of recording time series data. These include strip chart recorders, magnetic tape cassettes, solid state memory, and telemetry through a storage buffer and ultimately into a user's computer. Raw data may be recorded directly or it may be preprocessed (e.g., hourly averages and variances computed) by a microprocessor before storage. There is, as yet, no universal agreement on which systems are most reliable or cost effective in harsh environments.

Strip chart recording systems cost between $\$ 300$ and $\$ 1500$ per unit. However, to transfer data from strip charts to a computer tape file can be tedious and time consuming. Assume a technician with a charge rate of $\$ 16 /$ hour ( $\$ 8$ wage plus $\$ 8$ overhead) reduces data by reading four samples per hour of chart record every 20 seconds and enters these data through a key board into a computer terminal with an off-line cassette tape storage buffer. This data transcription would require about two weeks and $\$ 2,000$ to reduce a year of wind speed and wind direction data. Strip chart system failures commonty include paper jams, time base errors, or zero-offset (bias) errors.

Magnetic tape systems cost from $\$ 500$ through $\$ 6,000$ per unit, al though some units can record several levels of anemometry on one tape. Converting cassette data tapes to computer tapes is less labor intensive than processing strip charts, though probably no less expensive. Assuming the sponsor chooses to subcontract out the data collection and translation to a subcontractor, the fee could be about $\$ 4,000$ per site (wind speed and direction measurement at two leve1s) per year. Magnetic tape systems may fail in cold weather if the data logger is not in a heated enclosure. Occassionally tapes can be very difficult to read if the recorder has been jarred or damaged. 
Solid state memory devices are convenient because they are less prone to failure in cold temperature since they have no moving parts. However, unlike strip chart or cassette systems, if a solid state data logger does fail it may lose all of the data in storage not just the data after the time of failure. Solid state systems costs are comparable to cassette tape systems. Just as cassette systems need a tape reader/translater, solid state systems require a "milker" to retrieve the data from memory, temporarily store it on a cassette, then transfer data from the cassette to a computer tape.

Telemetered systems that transmit via satellites are very new. Cost estimates will change as the technology becomes more widespread. Cost estimates of $\$ 6,000$ to $\$ 12,000$ per site are reasonable. The great advantage of these systems for remote applications is that site visits may be made more infrequently. This is because system failures would be detected almost immediately so there is less risk or a costly data loss through infrequent visits.

Towers for mounting instruments vary widely also. Simple $10 \mathrm{~m}$ tubular aluminum or steel poles with guy wires and stones piled around the base are the least expensive option. They can be bought and erected for $\$ 200$ to $\$ 500$ depending on the site. Triangular truss towers, $10 \mathrm{~m}$ high, are more durable, where conditions of heavy icing or livestock/wildlife abuse are expected. These towers can be erected for about $\$ 3,000$ each. Telephone poles are less expensive and shed ice well if an auger truck can reach the site. Taller triangular truss towers wi11 cost between $\$ 3,000$ and $\$ 15,000$ to purchase and insta 11 .

\subsection{Options}

In this section we present three optional first year measurement programs that could be followed, in whole or in part, by the APA or the utilites of the Cook Inlet area. These options illustrate a spectrum of approaches from conservative to aggressive. We wish to emphasize, however, that our preliminary study does not suggest that the wind resource in the cook Inlet area is likely to be of outstanding potential. The more conservative approaches, which will provide quantitative estimates of the magnitudes of the wind 
resource, are therefore the most logical. The aggressive options provide a view of the more advanced stages of the wind prospecting strategies which are outlined in Appendix $B$. The suggested options are:

- Demonstration Program (DP)

- Rapid Investigation of Significant Large Wind Turbine Penetration (LWTP)

- Gross Resource Assessment (GRA)

The sites considered for instrumentation are those which show the most promise for wind energy development or because data from the sites would be useful as spot or check measurements. The sites to be discussed are:

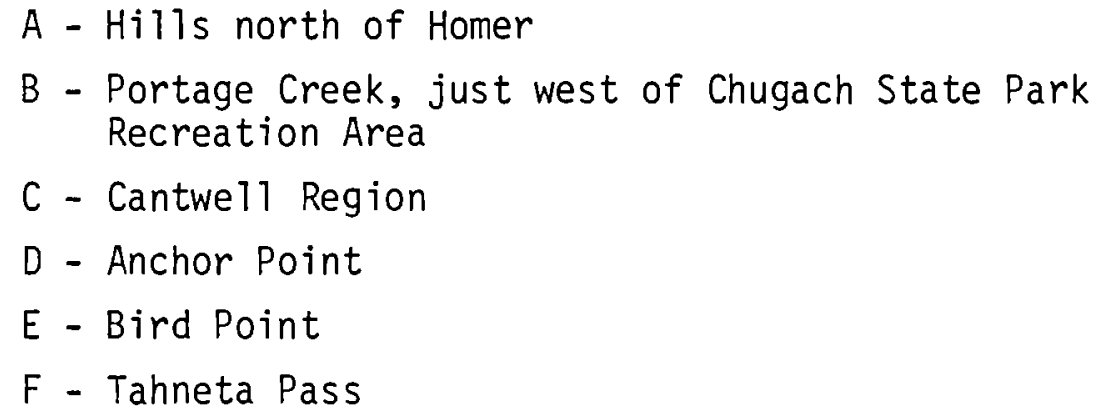

We present some rough estimates for costs of the optional programs. These estimates are only guidelines and they may vary substantially depending on what assumptions are made. We assume that the responsibility for data collection, reduction, analysis and reporting would belong with subcontractors though not necessarily the same subcontractors for each task. For example, local residents could be contracted to visit sites, change data tapes, and report malfunctions that they could not handle. An Anchorage based organization is assumed responsible for managing and executing the data collection and quality assurance programs and for transferring the data to computer tapes. Using these data, simple resource assessment computations may be performed by anyone who is well acquainted with the wind energy literature. As more detailed questions on the economic value of the resource come to the forefront, consultants experienced in the evaluation of wind, or other stochastic resources, should be retained.

Some of the cost estimates presented vary from site to site. For example, site visits to change tapes or strip charts are expected to cost more if 
remote sites must be reached than if sites are easily accessible from all weather roads. Similarly, management costs are highest for the most complex programs.

DP - The demonstration program option presumes that it is desirable to obtain actual operating experience with a large wind turbine. The actual value or cost of the wind energy produced is of secondary importance. The crucial factor is that there be sufficient wind to operate the machine enough to gain experience and that risks to the machine be minimized. It is also important to collect sufficient data for evaluation of the wind turbine performance and interaction with the network. Public visibility may or may not be an issue. Rapid progress is important.

Two sites could be used for the DP; the hills north of Homer (Site A), and Bird Point (Site E). Site A could be used for megawatt scale wind turbines, whereas Site $E$ could be used for mid-sized (perhaps vertical axis) wind turbines. Onsite data collection should consist of one year of wind speed and direction time series data sampled at least as fast as once every two minutes. The data should be collected at least at two levels, near hub height and at $10 \mathrm{~m}$. With these data an energy production estimate could be made and wind shear can be evaluated.

A tower would be erected at Bird Point. If insurmountable problems bar development on Diamond Ridge above Homer, a tower would have to be erected on some other less accessible site. However, a conservative option exists. The KGTL radio tower could be instrumented for a year and the data evaluated before a decision is made to install a tower at some other location. This would, of course, have to be negotiated with KGTL. When adequately shielded, the sensors should operate properly on that tower and the data logger could be stored inside the residence beside the tower. Magnetic cassette data loggers are preferred for this option. The costs of the DP option are shown in Table 5.1.

RLWP - The assumption of this option is that a serious effort is to be made to determine what large scale wind energy production might be feasible in the very near future. The RLWP program could look at four sites; these sites are $A, B, C$, and $E$. 
TABLE 5.1. Rough Cost Estimates for Demonstration Program (DP) Option

\begin{tabular}{|c|c|}
\hline ITEM & $\begin{array}{c}\text { Cost } \\
(\$ 1000)\end{array}$ \\
\hline \multicolumn{2}{|l|}{ Homer (Diamond Ridge) } \\
\hline Installation of Equipment on KGTL Tower & 3.0 \\
\hline Sensors and Cassette Tape Data Logger & 6.0 \\
\hline Tape Changing Visits $(30 / y r \times \$ 15)$ & 0.5 \\
\hline Site Visits and Sensor Calibration (4/yr $\times \$ 250)$ & 1.0 \\
\hline Data Translation & 4.0 \\
\hline Data Analysis & 10.0 \\
\hline Reporting & 3.0 \\
\hline Management $(\$ 500 / \mathrm{mo} \times 12 \mathrm{mo})$ & 6.0 \\
\hline SUB-TOTAL & 33.50 \\
\hline \multicolumn{2}{|l|}{ Bird Point } \\
\hline Purchase and Installation of $45 \mathrm{~m}$ Tower & 10.0 \\
\hline Sensors and Cassette Tape Data Logger & 6.0 \\
\hline Tape Changing Visits $(30 / y r \times \$ 60)$ & 1.8 \\
\hline Site Visits and Sensor Calibration (4/yr $\times \$ 250)$ & 1.0 \\
\hline Data Translation & 4.0 \\
\hline Data Analysis & 10.0 \\
\hline Reporting & 3.0 \\
\hline Management (Insignificant Addition to Above) & 0.0 \\
\hline SUBTOTAL & 35.80 \\
\hline Summary Report and Recommendations & 4.0 \\
\hline GRAND TOTAL & 73.3 \\
\hline
\end{tabular}


The strategy at Site $A$ near Homer could be the same as in the DP. A less expensive option for Bird Point (Site $E$ ) would be to neglect time series and wind direction, and simply use a wind-run anemometer at 10 to $20 \mathrm{~m}$. The choice to initially go with less sophisticated instrumentation at Bird Point is justified by the limited space available there for installing wind turbines.

The Portage Creek site (Site B) may have severe and gusty winds. Therefore two minute sample interval time series data are required, or perhaps hourly averaged data with sub-hourly variances computed and stored each hour. The least expensive option for Portage is to use strip chart recorders which can yield crude gust information by visual inspection of the trace. It is desirable to install at least a 20 to $30 \mathrm{~m}$ mast at Portage.

There is sufficient land area near Cantwell and Summit to support large clusters of wind turbines if enhanced resource areas can be located. We suggest that the best way to determine if such areas exist is to employ numerical models developed for the Federal Wind Energy Program. Sufficient data to drive the simplest of these models could be obtained from a year (or at least a winter) of synchronous hourly averaged wind data collected at 10 to $20 \mathrm{~m}$ from five locations. The five locations should include:

- along Denali Pass Highway

- near Summit

- in the gap near Windy

- in the Yanert Fork of the Nenana River

- in the Nenana River Valley south of Healy but below the Yanert Fork.

The latter two stations could be dropped in a pinch, but this is not desirable. Winter temperatures must be considered in this region, especially. Cassette data loggers may not function well so strip chart recorders (using pressure sensitive paper, not ink) or solid state memory loggers are better options.

The costs of both of these options are estimated in Table 5.2. Two options for Cantwell are included. The first was $10 \mathrm{~m}$ towers and solid state data loggers; the second assumes $10 \mathrm{~m}$ poles and strip charts are used. 
TABLE 5.2. Rough Cost Estimates for Rapid Investigation of Large Wind Turbine Penetration (RLINP) Option

Homer (Diamond Ridge)

Installation of Equipment on KGTL Tower

Sensors and Cassette Tape Data Logger

Tape Changing Visits (30/yr $\times \$ 15)$

Site Visits and Sensor Calibration (4/yr $\times \$ 250)$

Data Translation

Data Analysis

Reporting

Management $(\$ 500 / \mathrm{mo} \times 12 \mathrm{mo})$

3.0

6.0

0.5

1.0

4.0

10.0

3.0

6.0

$$
\text { SUB-TOTAL }
$$

$\overline{33.50}$

Bird Point

Purchase and Installation of $20 \mathrm{~m}$ Tower

Wind-Run Anemometer (1 plus 1 spare)

4.0

Data Collection Site Visits $(12 \times \$ 60)$

Data Analysis

Reporting

Management

$$
\text { SUB-TOTAL }
$$

0.4

0.7

0.3

0.3

0.3

6.0

Portage Creek

Purchase and Instal1 $30 \mathrm{~m}$ Tower

Sensors and Strip Chart Data Logger

Site Visits $(12 \times \$ 60)$

Data Reduction to Computer Tape

Data Analys is

Reporting

Management

SUB-TOTAL

Cantwell (Using Solid State Data Loggers and Towers)

Purchase and Insta11 $510 \mathrm{~m}$ Towers $(5 \times \$ 3000) \quad 15.0$

Sensors and Solid State Data Logging System ( $5 \times \$ 2500) 12.5$

Data Logger Mi 7 ker $(1 \times \$ 2500)$

Site Visits $(12 \times \$ 250)$

Data Reduction and Analysis (No Computer Modeling) 15.0

Data Analysis 
TABLE 5.2. Rough Cost Estimates for Rapid Investigation of Large Wind Turbine Penetration (RLWP) Option

(continued)

ITEM

Cost

$(\$ 1000)$

Cantwe11 (continued)

Data Analysis for Computer Modeling

Reporting

Management

4.0

2.0

2.0

SUB-TOTAL

$\overline{56.0}$

Cantwel1 (Using Strip Charts and Masts)

Purchase and Insta11 $510 \mathrm{~m}$ Masts $(5 \times \$ 500)$

2.5

Sensors and Strip Chart Data Loggers (5)

7.5

Site Visits $(12 \times \$ 250)$

3.0

Data Reduction to Computer Tape

10.0

Data Analysis

10.0

Data Analysis for Computer Modeling

4.0

Reporting

2.0

Management

2.0

SUB-TOTAL

$\overline{41.0}$

Anchor Point

Purchase and Install $410 \mathrm{~m}$ Masts $(4 \times \$ 500)$

Wind-Run Anemometers ( 4 plus 2 spares $\times \$ 200$ )

Data Collection Sites Visits $(12 \times \$ 60)$

Data Analys is

Reporting

Management

SUB-TOTAL

2.0

1.2

0.7

1.2

0.3

0.5

$\overline{5.9}$

Summary Report and Recommendations

4.0

GRAND TOTAL (Cantwe11 High Option)

120.4

GRAND TOTAL (Cantwel1 Low Option)

105.4 
GRA - In the GRA program wind prospecting proceeds at a slower pace. Sites $A$ through $F$ would be considered. Anchor Point, which may have a good enough wind resource to be considered in the RLWP program, is placed here because prospecting spot measurements along the coast are probably the most effective way of pinning down the enhanced resource areas. Tahneta Pass is included to insure that the pass and the Matanuska Valley do not fall through the cracks if the conclusions stated previously in this report regarding those areas are wrong. Only three sites are considered near Cantwe11; Cantwe11, Windy, and Denali Pyramid. The Nenana River and Yanert Fork sites used in the RLWP option are not needed since numerical models are not used in the GRA. Exploration of the hills north of Homer could extend to all of the major hills up to the Caribou Hills. Exploration near Portage could extend up to the Placer River, Skookum Creek, and Twentymile River Valley. For these measurements, wind-run anemometers on $10 \mathrm{~m}$ masts would be adequate. The estimated costs of the GRA option are listed in Table 5.3.

After a year of data collection the high average wind resource areas would be identified. More sophisticated measruement programs leading to wind turbine cluster development could begin in the second year, as needed. 
TABLE 5.3. Rough Cost Estimates for Gross Resource Assessment (GRA) Option

\begin{tabular}{|c|c|}
\hline I tem & $\begin{array}{c}\text { Cost } \\
(\$ 1000)\end{array}$ \\
\hline \multicolumn{2}{|l|}{ Anchor Point } \\
\hline $\begin{array}{l}\text { Purchase and Install } 410 \text { m Masts }(4 \times \$ 500) \\
\text { Wind-Run Anemometers }(4 \text { plus } 2 \text { spares } \times \$ 200) \\
\text { Data Collection Site Visits }(12 \times \$ 60) \\
\text { Data Analysis } \\
\text { Reporting } \\
\text { Management }\end{array}$ & $\begin{array}{l}2.0 \\
1.2 \\
0.7 \\
1.2 \\
0.3 \\
0.5\end{array}$ \\
\hline SUB-TOTAL & 5.9 \\
\hline \multicolumn{2}{|l|}{ Tahneta Pass } \\
\hline \multirow[t]{2}{*}{$\begin{array}{l}\text { Purchase and Install } 10 \mathrm{~m} \text { Mast } \\
\text { Wind-Run Anemometers }(1 \mathrm{plus} \text { spare } \times \$ 200) \\
\text { Data Collection Site Visits }(12 \times \$ 60) \\
\text { Data Analysis } \\
\text { Reporting } \\
\text { Management }\end{array}$} & $\begin{array}{l}0.4 \\
0.4 \\
0.7 \\
0.3 \\
0.3 \\
0.3\end{array}$ \\
\hline & 2.4 \\
\hline
\end{tabular}

Hills North of Homer

Purchase and Install 610 masts $(6 \times \$ 1000)$

Wind-Run Anemometers ( 6 plus 3 spares $x \$ 200$ ) 1.8

Data Collection Site Visits $(12 \times \$ 250)$

Data Analysis $\quad 1.8$

Reporting $\quad 0.5$

Management $\quad 1.0$

SUB-TOTAL $\overline{14.1}$

Cantwel1 (Windy, Cantwe 11 , Denali Pyramid Sites)

Purchase and Install $310 \mathrm{~m}$ Masts $(3 \times \$ 500)$

Wind-Run Anemometers ( 3 plus 2 spares $x \$ 200$ ) 1.0

Data Collection Site Visits $(12 \times \$ 60) \quad 0.7$

Data Analysis 0.9

$\begin{array}{ll}\text { Reporting } & 0.5\end{array}$

$\begin{array}{ll}\text { Management } & 0.5\end{array}$

SUB-TOTAL 
TABLE 5.3. Rough Cost Estimates for Gross Resource

Assessment (GRA) Option

(continued)

\begin{tabular}{cc}
\hline Item & Cost \\
$(\$ 1000)$ \\
\hline
\end{tabular}

Portage Area

Purchase and Instal1 $610 \mathrm{~m}$ Masts $(6 \times \$ 1000)$

6.0

Wind-Run Anemometers ( 6 plus 3 spares $x$ \$200)

1.8

Data Collection Site Visits $(12 \times \$ 250)$

Data Analysis

Reporting

3.0

1.8

Management

$$
\text { SUB-TOTAL }
$$

0.5

1.0

$\overline{14.7}$

Summary Report and Recommendations

2.0

GRAND TOTAL

43.6 


\section{REFERENCES}

Alaska Power Administration. 1979. Upper Susitna River Project Power Market Analysis. APA, U.S. Department of Energy, Juneau, AK.

Barry, R.G. and A.H. Perry. 1973. Synoptic Climatology: Methods and and Application. Methuen and Co., $553 \mathrm{pp}$.

Cliff, W.C. 1977. The Effect of Generalized Wind Characteristics on Annual Power Estimated from Wind Turbine Generators. PNL-2436, PNL-2436, Pacific Northwest Laboratory, Richland, WA, 99352.

Dale, R.F. 1956. The Climate of the Matanuska Valley. Technical Paper \#27, U.S. Department of Commerce, Weather Bureau.

DOE Workshop. 1979. Large Wind Turbine Design Characteristics and R\&D Requirements. Doe Publication CONF-7904117. NTIS, Springfield, VA.

Hewson, W.E., J.E. Wade, and R.W. Baker. 1979. Vegetation as an Indicator of High Wind Velocity. RLO/227-T-24-79-1. NTIS, Springfield, VA.

Hiester, T.R., and W.T. Pennel1. 1980. The Meteorological Aspects of Siting Large Wind Turbines. PNL-2522, Pacific Northwest Laboratory, Richland, WA 99352.

JBF Scientific. 1979. Wind Energy Systems Application to Regional Utilities Vol. 1, JBF Scientific, Wilmington, MA 01857

Marsh, W.D. 1979. Requirements Assessment of Wind Power Plants in Electric Utility Systems. EPRI ER-978-SY, General Electric Company, Schenectady, NY 12345 .

Overland, J.E. and T.R. Hiester. 1980. Development of a Synoptic Climatology for the Northeast Gulf of Alaska. Journal of Applied Meteorology, 19; 1-14.

Putnins, P. 1966. The Sequence of Basic Pressure Patterns over Alaska. Studies on the Meteorology of Alaska. First Interior Report, Environmental Data Service, ESSA, Washington, DC, $57 \mathrm{pp}$.

Sorkina, A.I. 1963. Atmospheric Circulation and the Related Wind Fields over the North Pacific. Israel Program for Scientific Translations, Jerusalem, $247 \mathrm{pp}$.

Thomas, R.L., and W.H. Robbins. 1979. "Large Wind Turbine Projects," Proceedings of the Fourth Biennial Conference and Workshop on Wind Energy Conversion Systems. CONF 791097, NTIS, Springfield, VA. 
U.S. DOE Solar Working Group. 1978. Solar Energy Research and Development: Program Balance. HCP/M2693-02, U.S. Department of Energy.

Wegley, H.L., J.V. Ramsde11, M.M. Orgi11, R.L. Drake, 1980. A Siting Handbook for Smal1 Wind Energy Conversion Systems. PNL-2521, Rev. 1. Pacific Northwest Laboratory, Richland, WA 99352.

Wende11, L.L. 1979. "Overview of the Wind Characteristics Program." Proceedings of the Fourth Biennial Conference and Workshop on Wind Energy Conversion Sys tems. CONF 791097, NTIS, Springfield, VA. 


\section{APPENDIX A}

TOPOGRAPHIC MAPS OF THE COOK INLET AREA 

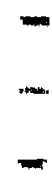

.
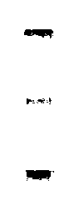

$-$ 


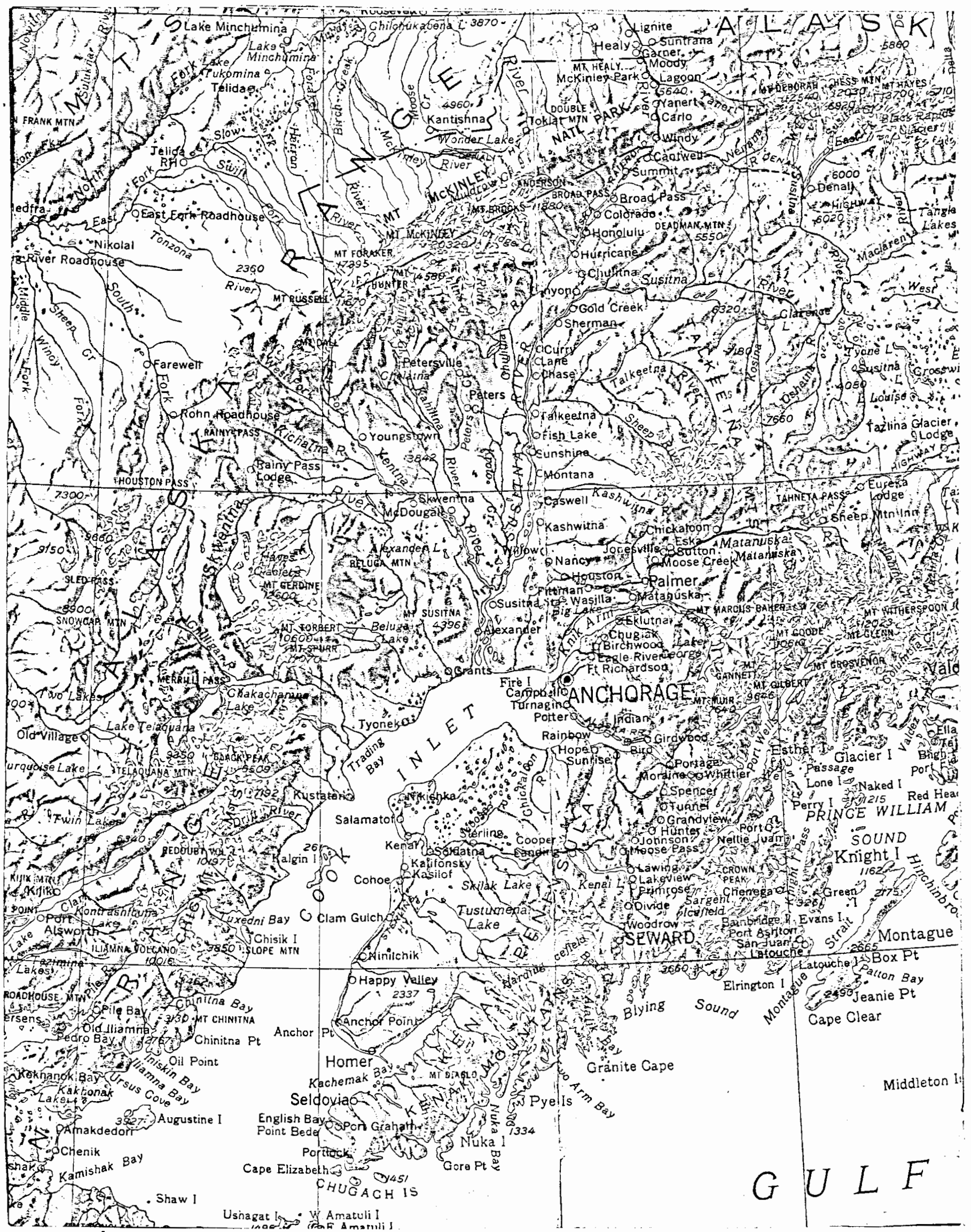

Figure A.1. Cook Inlet-Railbelt Area 


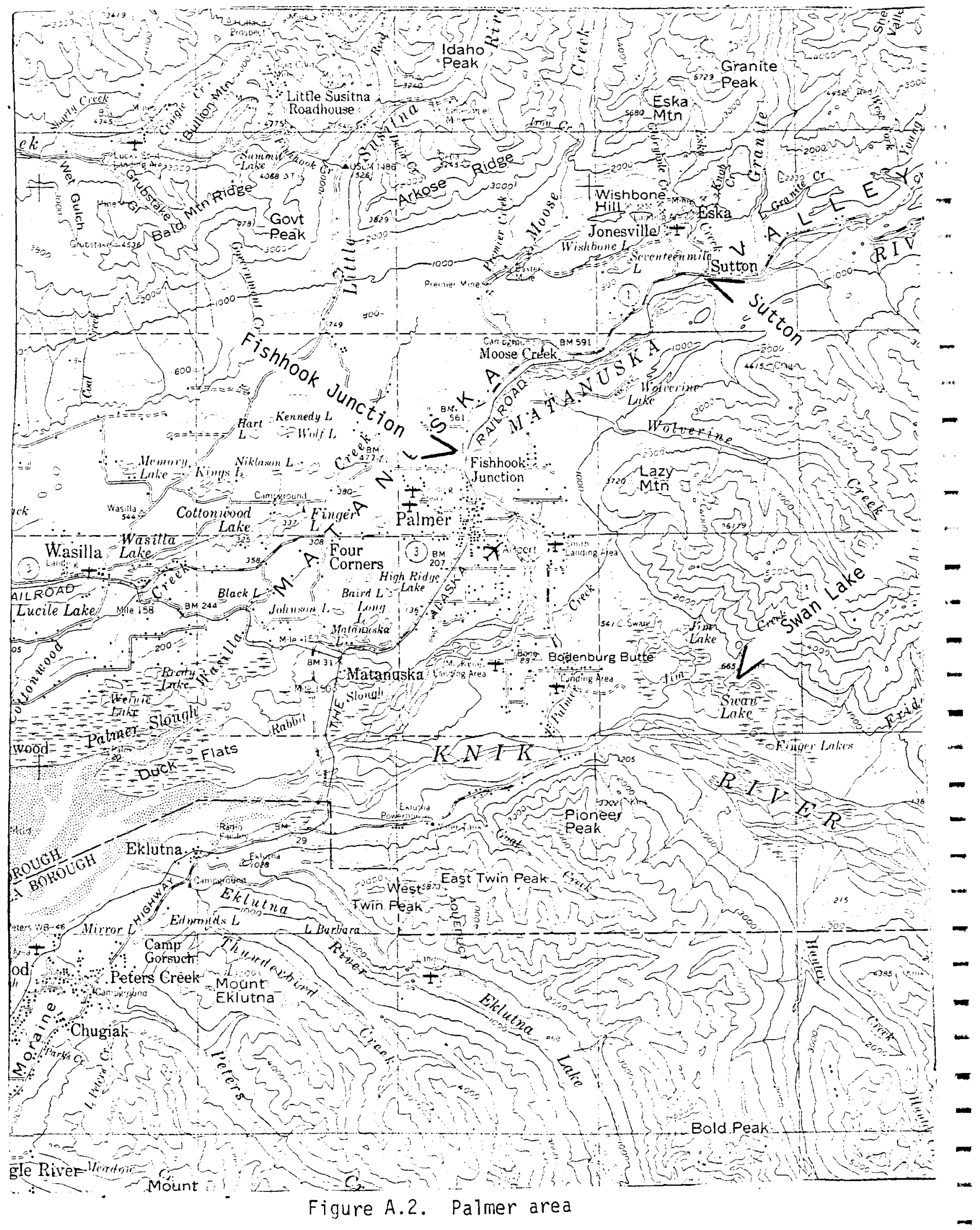




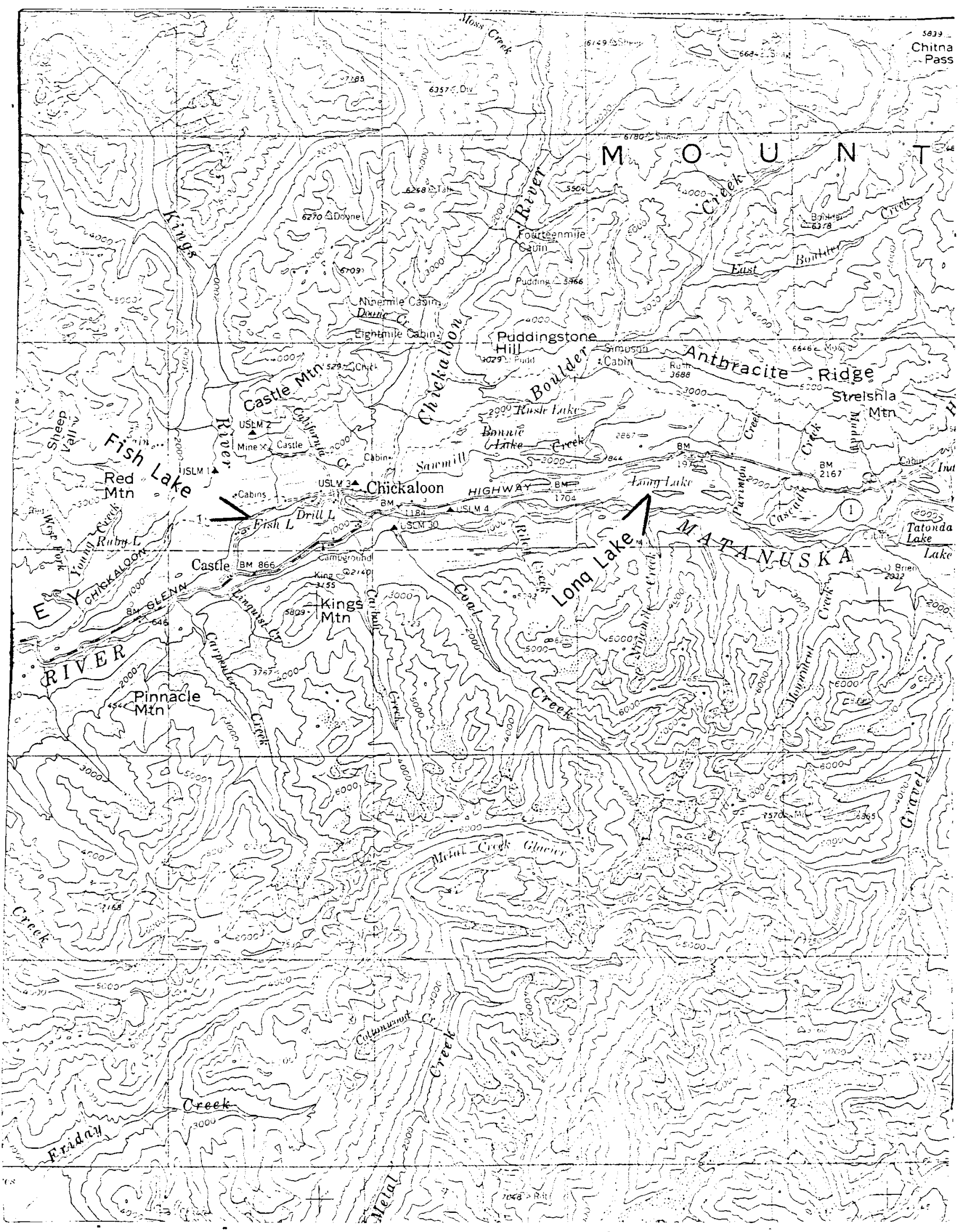

Fiqure A.3. Matanuska River Valley 


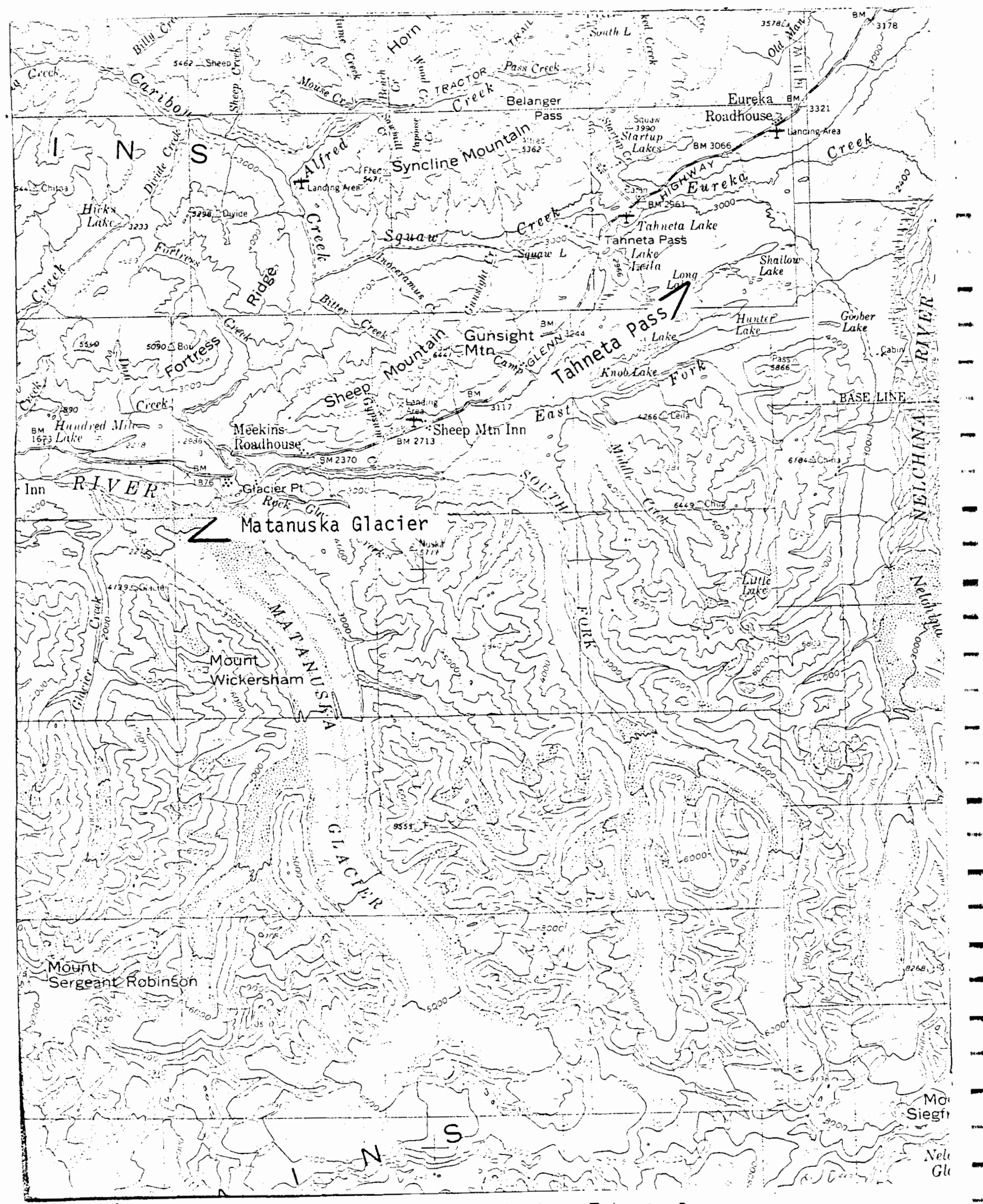

Figure A.4. Matanuska Glacier, Tahneta Pass 
a do

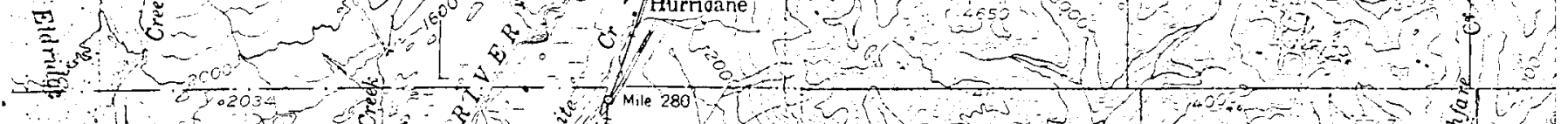
(1)

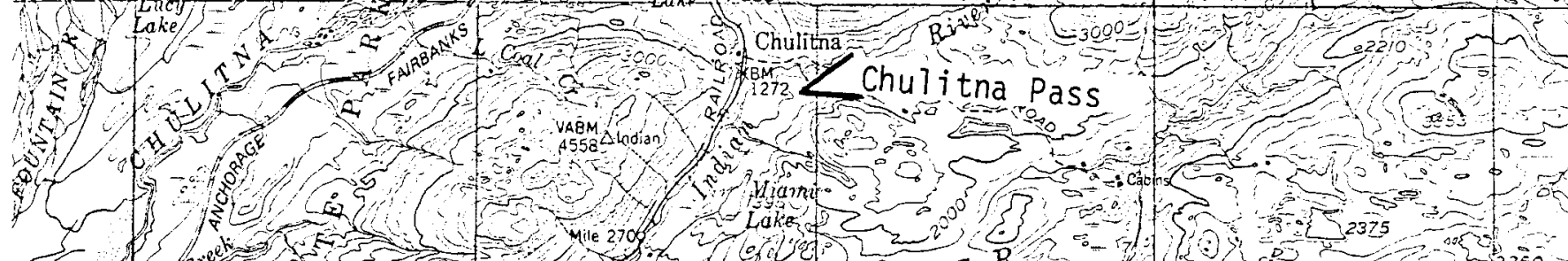

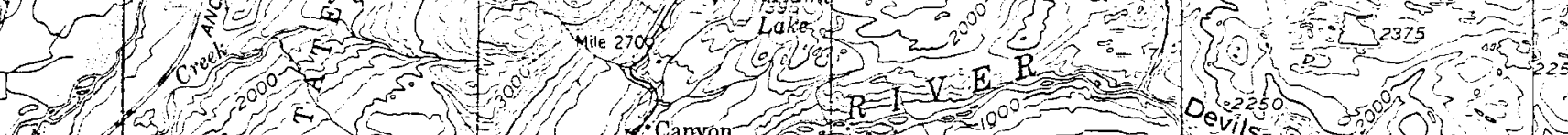
(1)

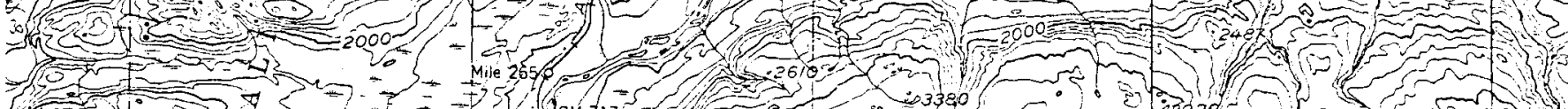

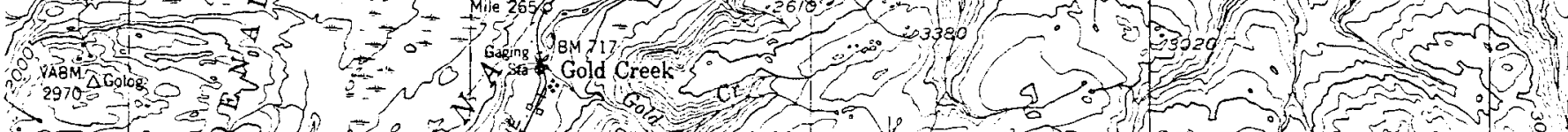

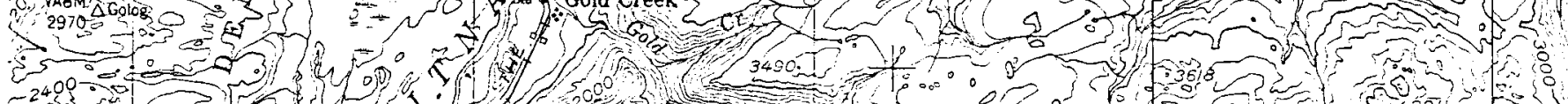

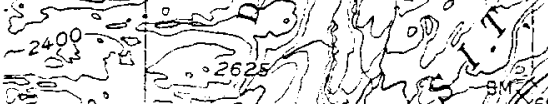
D.

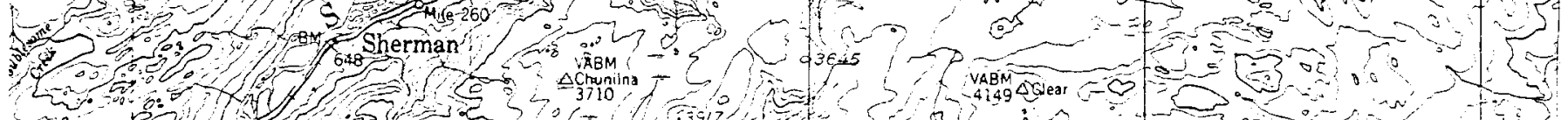
(n)

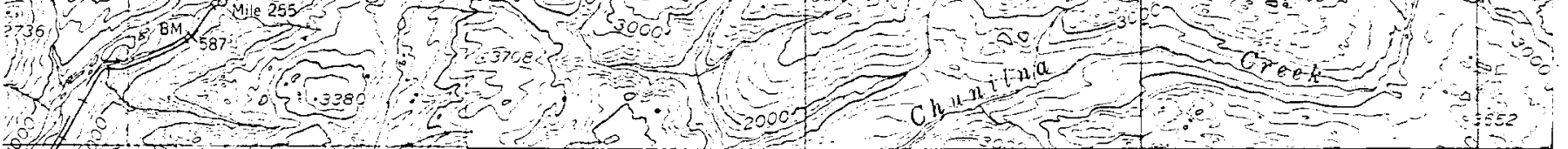

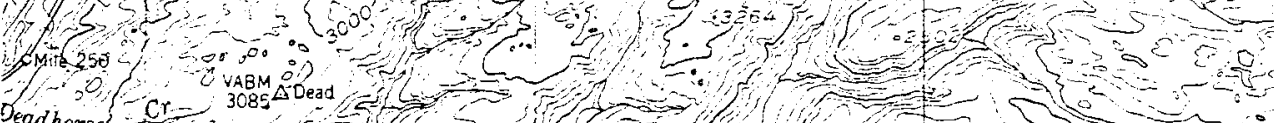

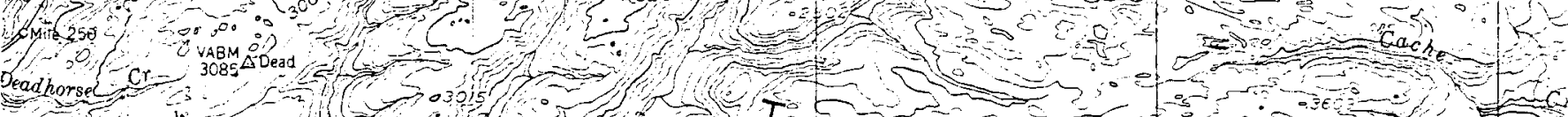

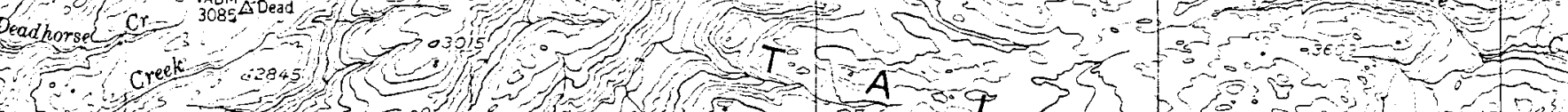

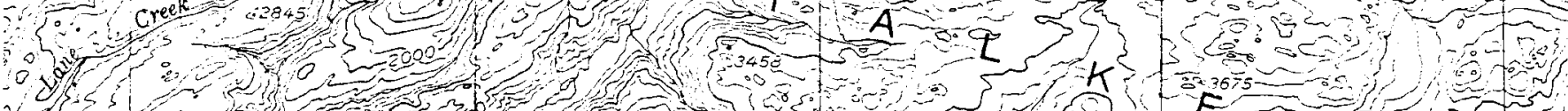

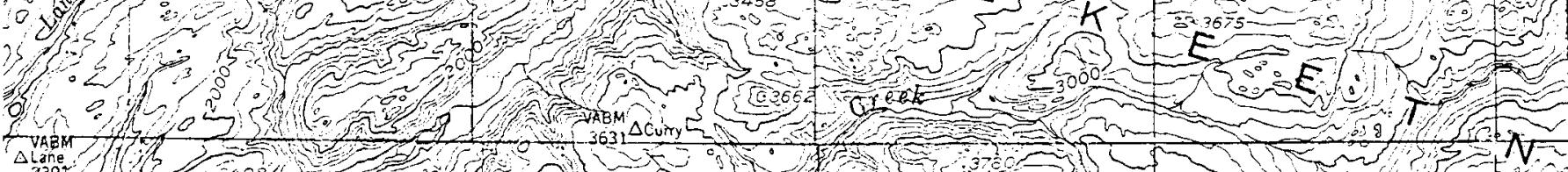

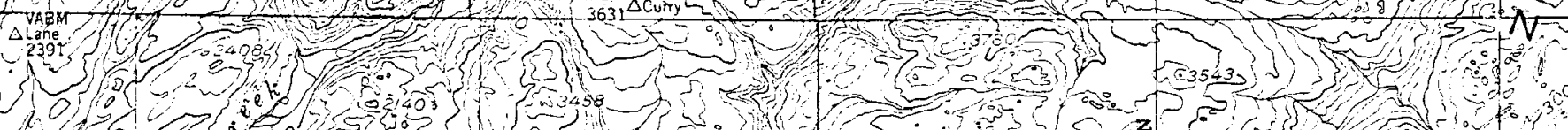

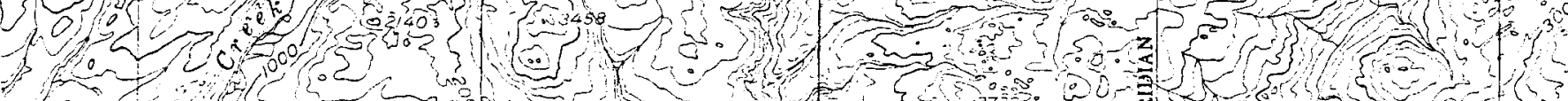
for 7. 


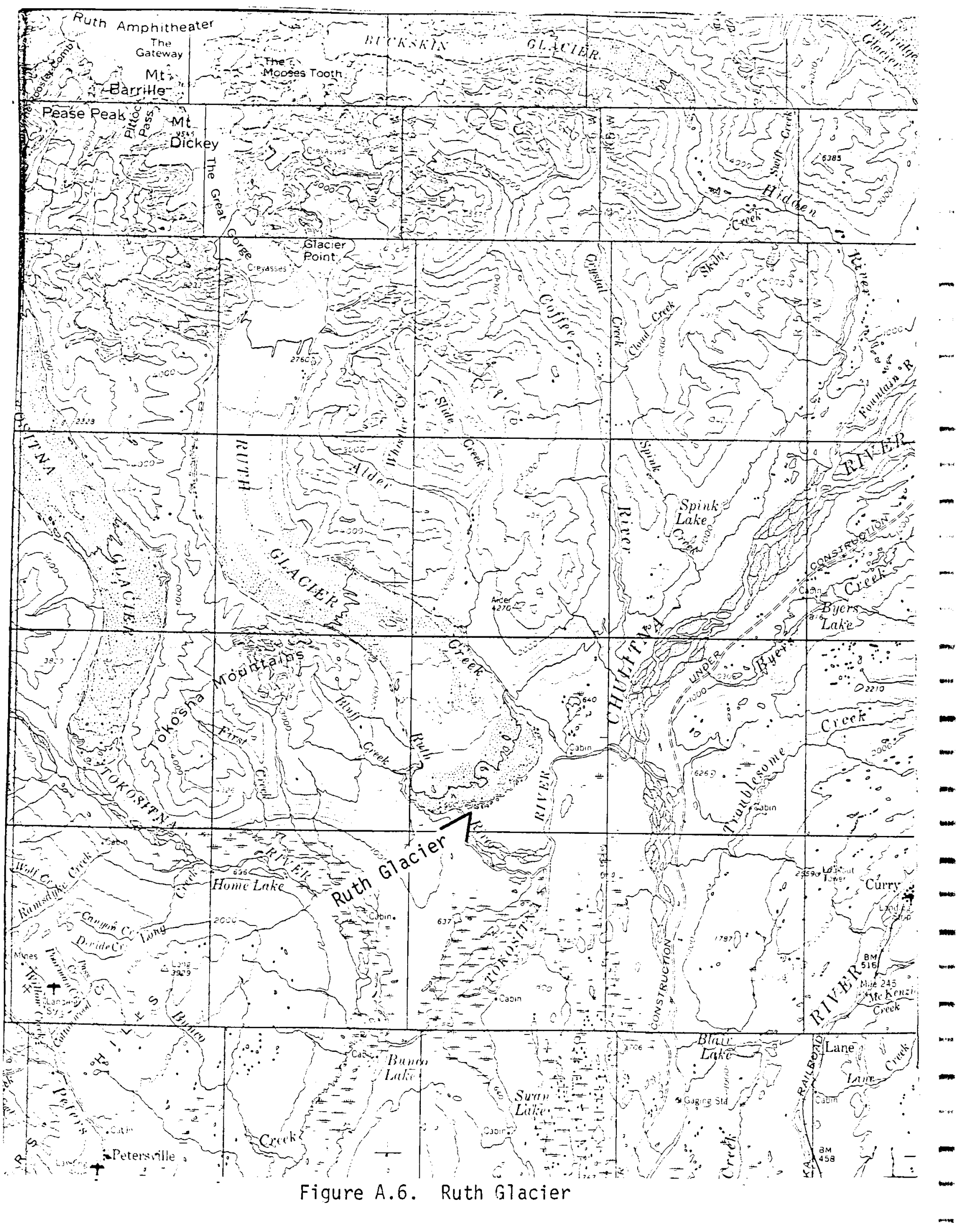



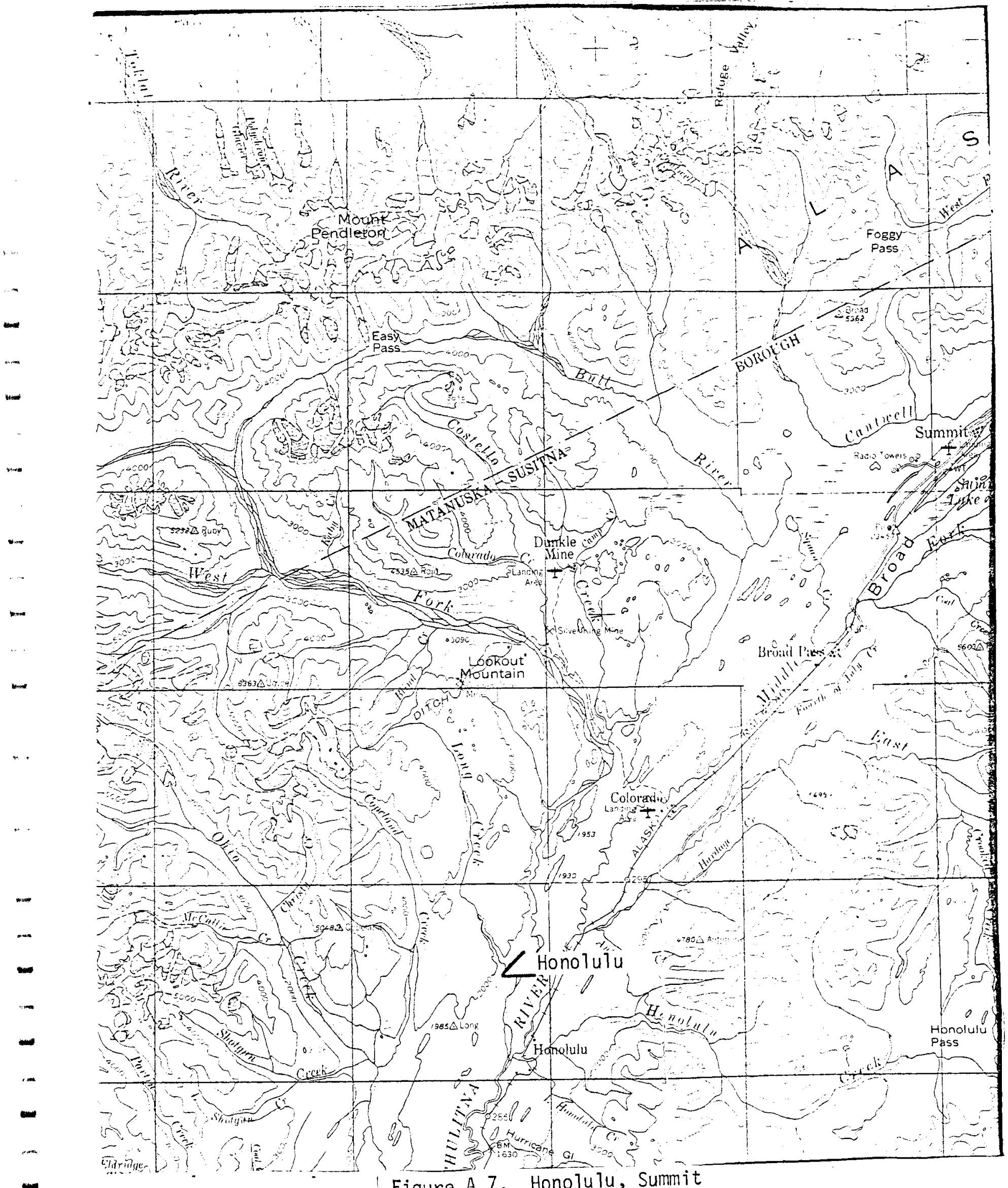


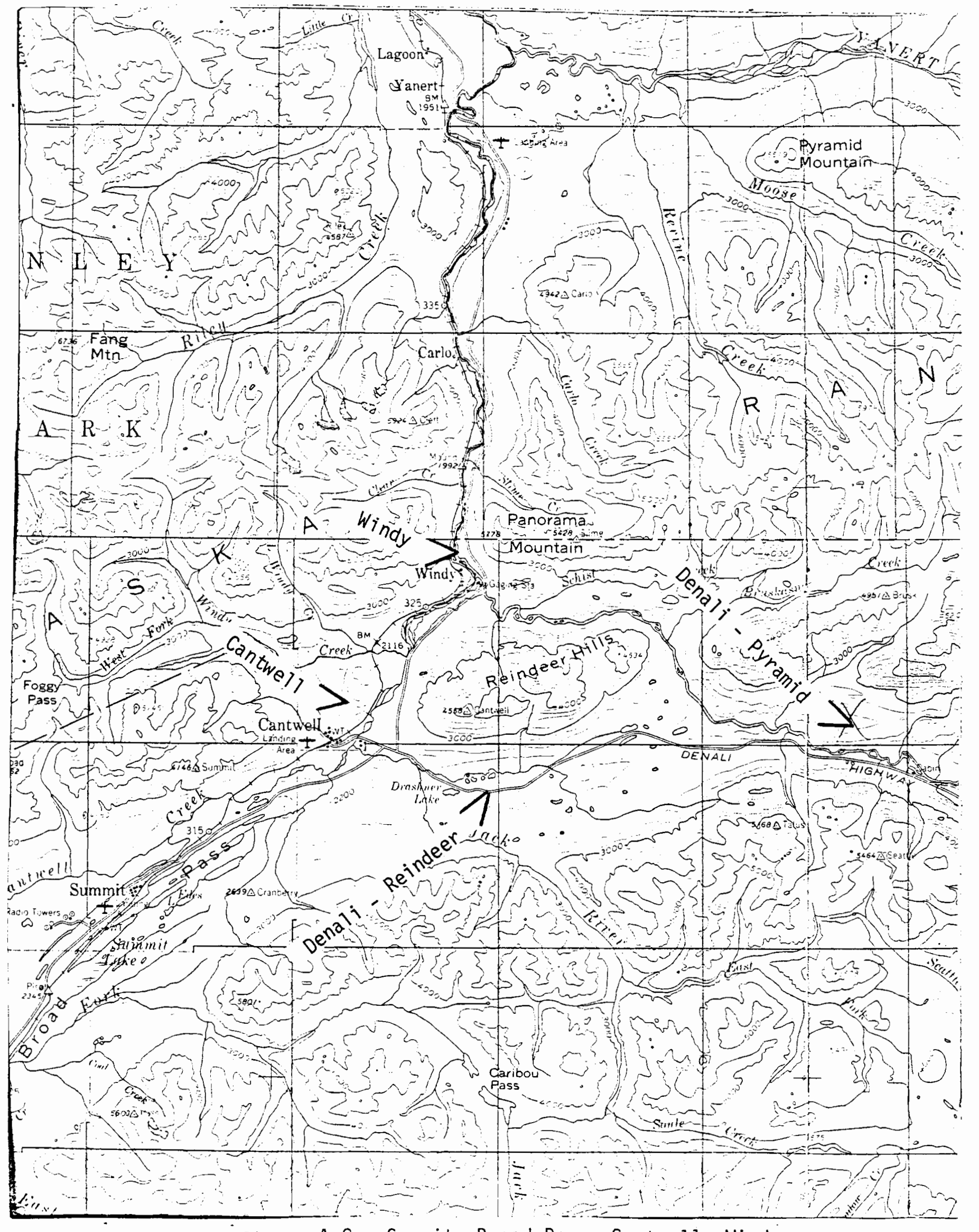

Figure A.8. Sumit, Broad Pass, Cantwe11, Windy 


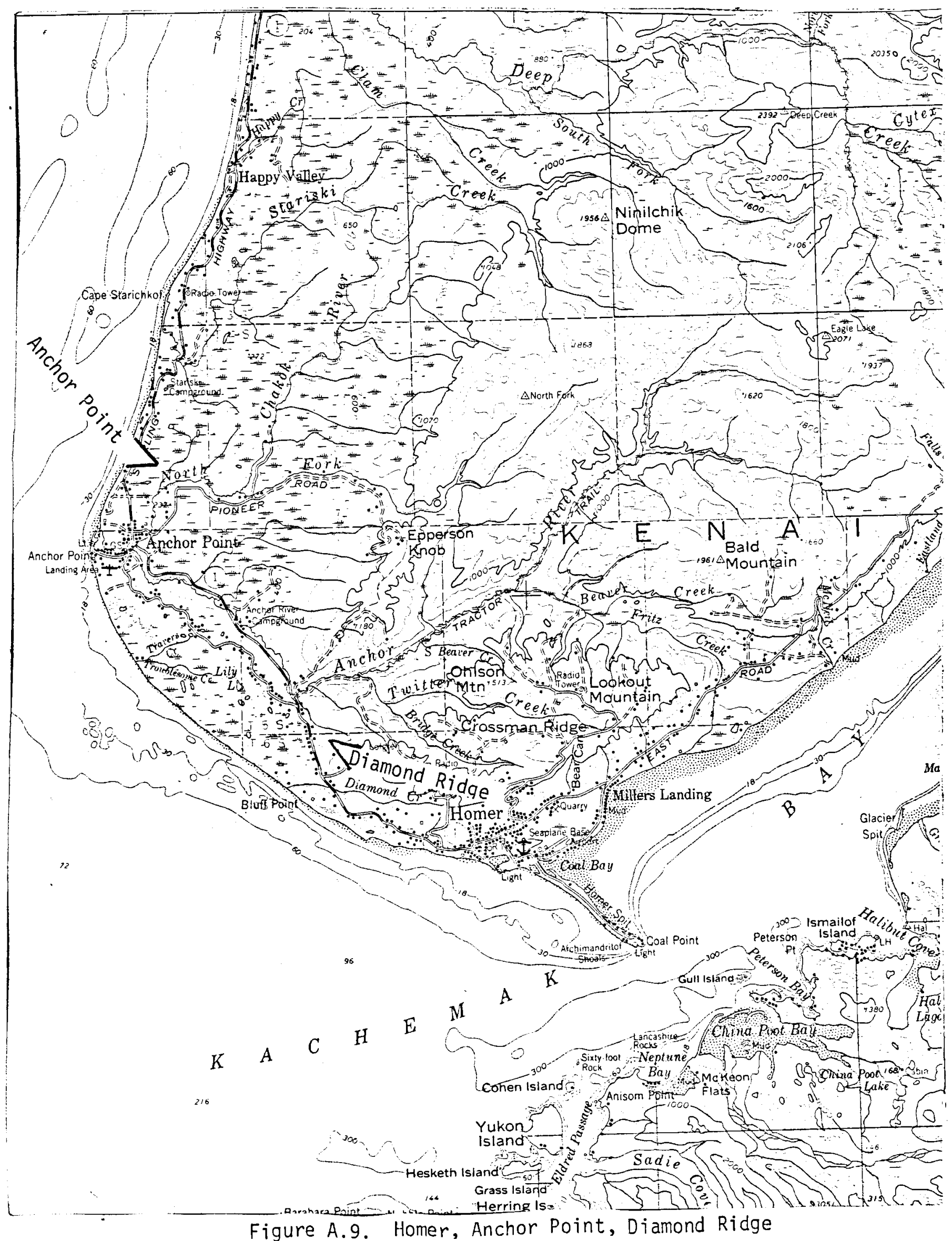




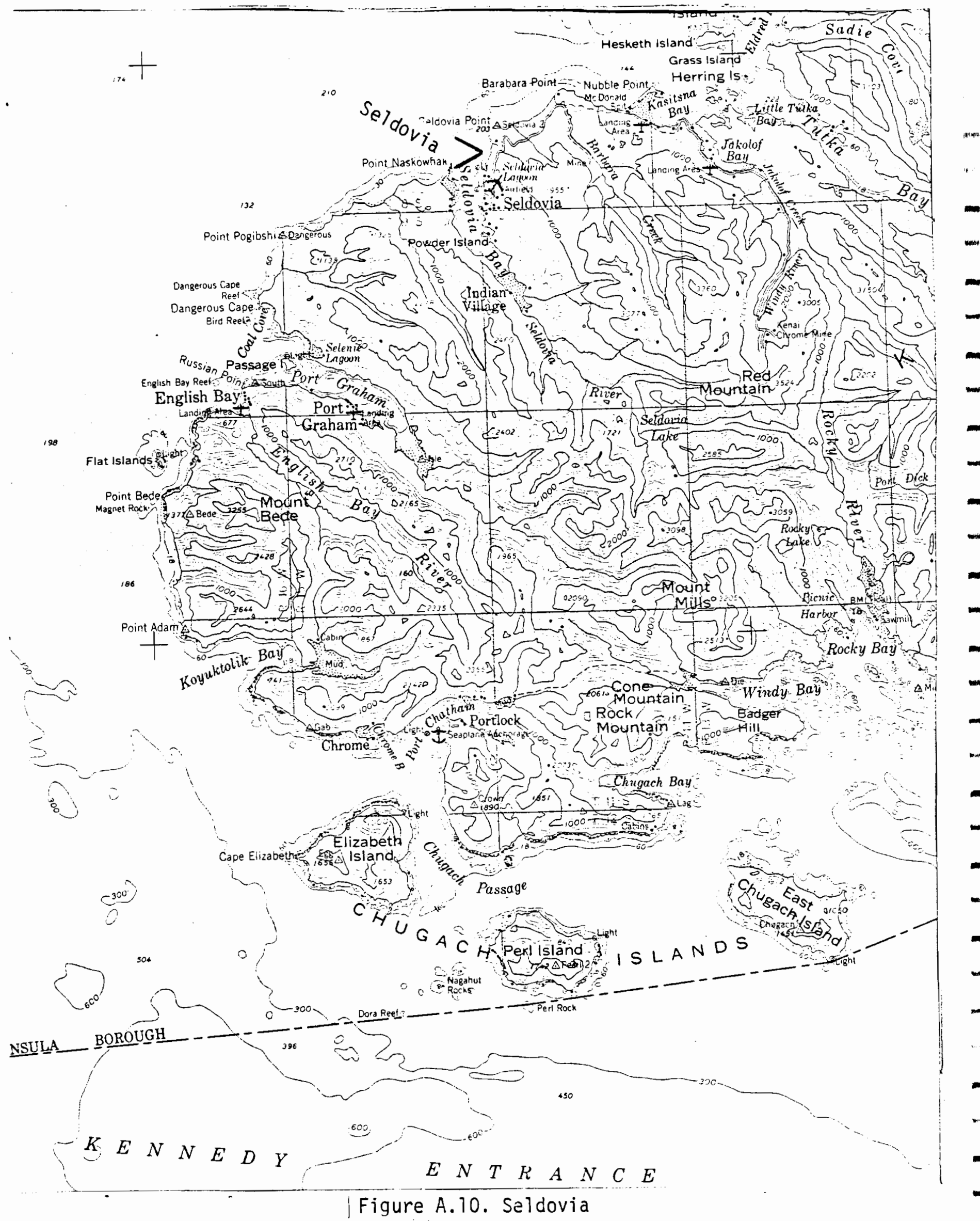




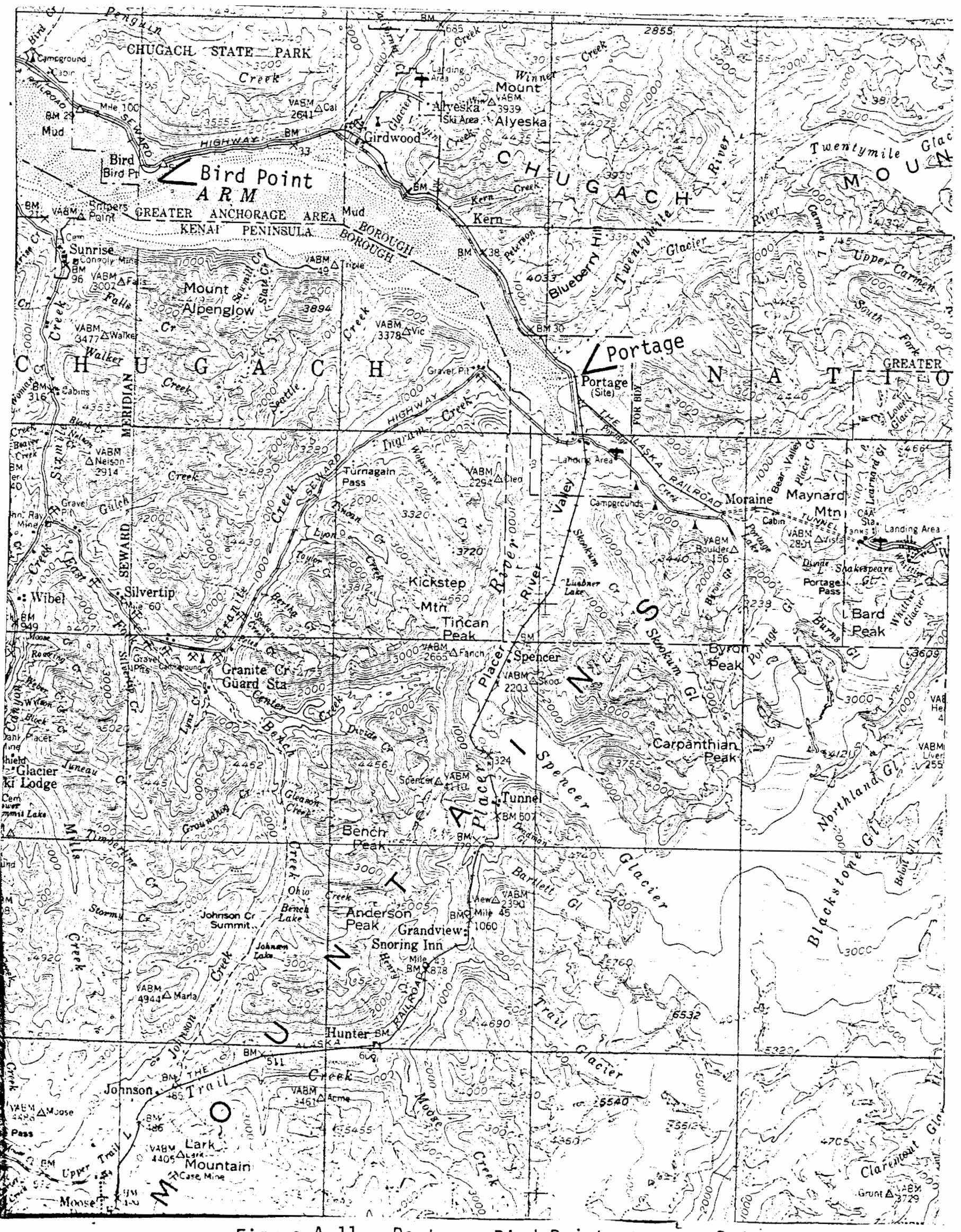

Figure A.11. Portage, Bird Point, Snipers Point 


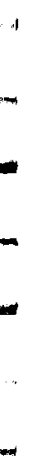

APPENDIX B

SITING TECHNOLOGIES FOR LARGE WIND TURBINE CLUSTERS 

SITING TECHNOLOGIES FOR

LARGE WIND TURBINE CLUSTERS

T. R. Hiester

W. T. Pennell

November 1979

To be published in the

Proceedings of the

International Energy Expert Meeting in

Boone, iNorth Carolina

September 26-27, 1979

Work Supported by the U.S. Department of Energy under Contract EY-76-C-06-1830

Pacific Northwest Laboratory

Richland, Washington 99352 


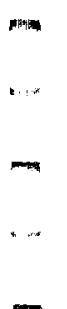

$m$<smiles>C1CCCCC1</smiles>

$-$ 


\section{SITING TECHNOLOGIES FOR \\ LARGE WIND TURBINE CLUSTERS (a) \\ T. R. Hiester and W. T. Pennell \\ Pacific Northwest Laboratory}

\section{INTRODUCTION}

The objective of the U.S. Federal Wind Energy Program is ". . .to accelerate the development, commercialization and utilization of reliable and economically viable wind energy systems" (ERDA 1977). To achieve this objective, the program is organized into several elements. The Wind Characteristics Program Element (WCPE), one of these elements, is managed for the U.S. Department of Energy (DOE) by Pacific Northwest Laboratory (PNL). PNL has the specific responsibility for providing the appropriate information on wind characteristics to those involved in:

- energy program planning and energy resource analysis

- selection of sites for wind energy conversion systems (WECS)

- design and performance evaluation of WECS

- day-to-day operations of WECS (Wendell et al. 1978).

Applied research and development within the WCPE currently focus on:

- developing effective siting technologies

- defining the wind energy resource

- providing information on wind structure and turbulence to designers

- investigating wind-forecasting techniques that would improve the integration of wind turbines with existing electrical networks.

This paper discusses the first of these activities as applied to large wind turbine clusters and describes a possible site-selection strategy for a large public utility that is considering the inclusion of WECS into its mix of generating equipment. The utility is assumed to be looking for areas where a

(a) This paper was based on work performed under U.S. Department of Energy Contract No. EY-76-C-06-1830. 
large number of megawatt-scale machines (say, 10 to 50 machines) can be placed in reasonable proximity. In this context, the term site refers to the location of a WECS cluster.

The site-selection strategy is conservative, partly because the largescale generation of electricity by wind turbine generators is still a developing technology. Wind characteristics at a site will have to be thoroughly documented, because the nature of the wind at the site not only governs the energy output of the cluster, it also affects the service life of the wind equipment and both scheduled and unscheduled maintenance costs. Perhaps with experience, the site-selection process can be simplified. Certain steps may be found unnecessary, or requirements on the quantity and quality of wind data collected at each step may decrease. However, at this stage of wind energy development, a conservative approach seems prudent, even though such an approach is not cheap. Extensive measurements cost a great deal to make and to interpret, but a simple analysis shows that reasonable meteorological siting costs should be paid back very quickly through improved machine performance.

There are basically two ways to approach WECS siting: by "wind prospecting" and by wind-potential evaluation at a predetermined site. In wind prospecting, an area must be screened for high-wind potential before we can proceed with the siting steps that the two ways share: evaluating the site and developing the site. In the second way, a site has already been determined to be a high-wind area, and wind-related information has been gathered on the site, so the second way is simply an abridgement of the first. In this paper, we describe wind prospecting and discuss site-selection techniques and how they apply to the steps in wind prospecting.

\section{SITE-SELECTION TECHNIQUES}

Numerous techniques can be used to identify WECS sites. The following techniques have been examined in the Federal Wind Energy Program. Their applicability to the siting steps of wind prospecting is shown in Figure 1 . 


\begin{tabular}{|c|c|c|c|c|c|}
\cline { 2 - 6 } \multicolumn{1}{c|}{} & $\begin{array}{c}\text { LARGE- } \\
\text { AREA } \\
\text { ANALYSIS }\end{array}$ & $\begin{array}{c}\text { MESOSCALE } \\
\text { EVALUATION }\end{array}$ & $\begin{array}{c}\text { CANDIDATE } \\
\text { SITE } \\
\text { SCREENING }\end{array}$ & $\begin{array}{c}\text { CANOIDATE } \\
\text { SITE } \\
\text { EVALUATION }\end{array}$ & $\begin{array}{c}\text { SITE } \\
\text { DEVELOPMENT }\end{array}$ \\
\hline $\begin{array}{c}\text { NUMERICAL } \\
\text { MODELING }\end{array}$ & $\mathrm{x}$ & & & $\mathrm{x}$ \\
\hline $\begin{array}{c}\text { PHYSICAL } \\
\text { MODELING }\end{array}$ & $\mathrm{x}$ & $\mathrm{x}$ & $\mathrm{x}$ & $\mathrm{x}$ \\
\hline $\begin{array}{c}\text { BIOLOGICAL } \\
\text { INDICATORS }\end{array}$ & $\mathrm{x}$ & $\mathrm{x}$ & $\mathrm{x}$ & & $\mathrm{x}$ \\
\hline $\begin{array}{c}\text { GEOLOGICAL } \\
\text { INDICATORS }\end{array}$ & $\mathrm{x}$ & $\mathrm{x}$ & $\mathrm{x}$ & & \\
\hline $\begin{array}{c}\text { TOPOGRAPHICAL } \\
\text { INDICATORS }\end{array}$ & & & & \\
\hline $\begin{array}{c}\text { SOCIAL \& CULTURAL } \\
\text { INDICATORS }\end{array}$ & & & & & \\
\hline
\end{tabular}

\section{FIGURE 1. Applicability of Siting Techniques to} the Various Steps in Wind Prospecting

NUMERICAL MODELING

Numerical models provide an objective method for estimating the effects of terrain on airflow and for interpolating wind data from locations for which wind observations are available to locations for which none are available. The accuracy of these simulations depends on the accuracy and density of the input data and the amount of realism inherent in the mathematical relationships that make up the moder.

\section{PHYSICAL MODELING}

Flow over terrain may also be modeled by placing a scaled representation of the terrain in a suitably designed wind tunnel. This approach can yield useful information as long as the horizontal length scale of the modeled region measures no more than a few tens of kilometers and the portion of the atmosphere to be studied is the lowest few hundred meters. Wind tunnels are limited in their ability to simulate all aspects of flow over terrain; however, they simulate the effects of small-scale terrain features on nearly neutral flow better than currently available numerical models. 


\section{BIOLOGICAL INDICATORS}

The shapes of certain species of trees are good indicators of high winds. Trees are particularly useful in regions where large, local variations in wind speed can be expected or in regions where wind data are sparse (Hewson and Wade 1977; Putnam 1948).

\section{GEOLOGICAL INOICATORS}

The wind produces certain features of the land surface, such as sand dunes. These eolian features are easily detected from satellite or aircraft photographs. The existence of eolian features, however, is not a guarantee of persistently strong winds. Eolian landforms can be caused over a period of years by occasional strong winds (Marrs and Koprina 1978).

\section{TOPOGRAPHICAL INDICATORS}

Empirical guidelines describing the general effects of terrain or surface obstacles on the wind are invaluable in interpreting the results of numerical and physical modeling studies and measurements. Topographical guidelines are either based on a physical understanding of how such features affect flow or on experience gained through observation. Historically, these guidelines have been applied to the siting of wind machines without supporting measurements (Golding 1955; AWEA 1977).

\section{SOCIAL AND CULTURAL INOICATORS}

A valuable source of indirect wind information can be found by examining land-use patterns and by questioning people who live or work in areas that are expected to be windy. Population centers are good indicators of wind: We do not expect large population centers to be in areas with high wind-energy potential. Agricultural uses of the land are also indicators: windy areas are more likely to be used for grazing than for row crops. Other indicators could be the locations of snow fences along the highways or the locations of frequent wind damage to power 1 ines. 


\section{WIND-PROSPECTING STRATEGY}

The goal of the wind-prospecting strategy outlined here is to identify several WECS clusters that could be developed sequentially. In choosing these sites, the issues of land use, accessibility, public acceptance, and proximity to existing transmission lines must be considered in addition to wind power potential. A proper combination of sites would be one in which the net power output best matches the load and generating characteristics of the utility. The seasonal and diurnal characteristics of the wind are therefore important, since these characteristics determine the seasonal and diurnal characteristics of wind-generated power.

Terrain should be of particular concern in making siting decisions. Locating WECS clusters in flat areas could result in lower costs for siting evaluations and operation, since wind characteristics tend to be more benign over gentle terrain. On the other hand, the more rugged the terrain in and around the site, the greater the horizontal variability in the wind resource and the greater the likelihood of large wind shear and turbulence, which could result in higher costs for site evaluation and for machine operation.

Figure 2 is a flow chart outlining the wind-prospecting strategy that leads to the development or rejection of sites. The major steps in this strategy are best described by considering each one in sequence.

\section{LARGE-AREA ANALYSIS}

The first step in a large-area analysis is to examine pertinent wind resource assessments for the utility's service area and any additional windrelated information the utility might have. When land use, power transmission corridors and accessibility issues are considered along with the wind resource assessments, smaller areas are identified for more detailed study (see Figure 3 ).

Resource assessment, as addressed in the WCPE, refers to the large-scale analysis (i.e., the United States or a collection of several states) of the wind energy resource by estimating the wind power potential of a given area and the distribution of the wind energy within that area. If a regional assessment is available, the large-scale analysis takes ${ }^{\circ}$ ittle time (more 


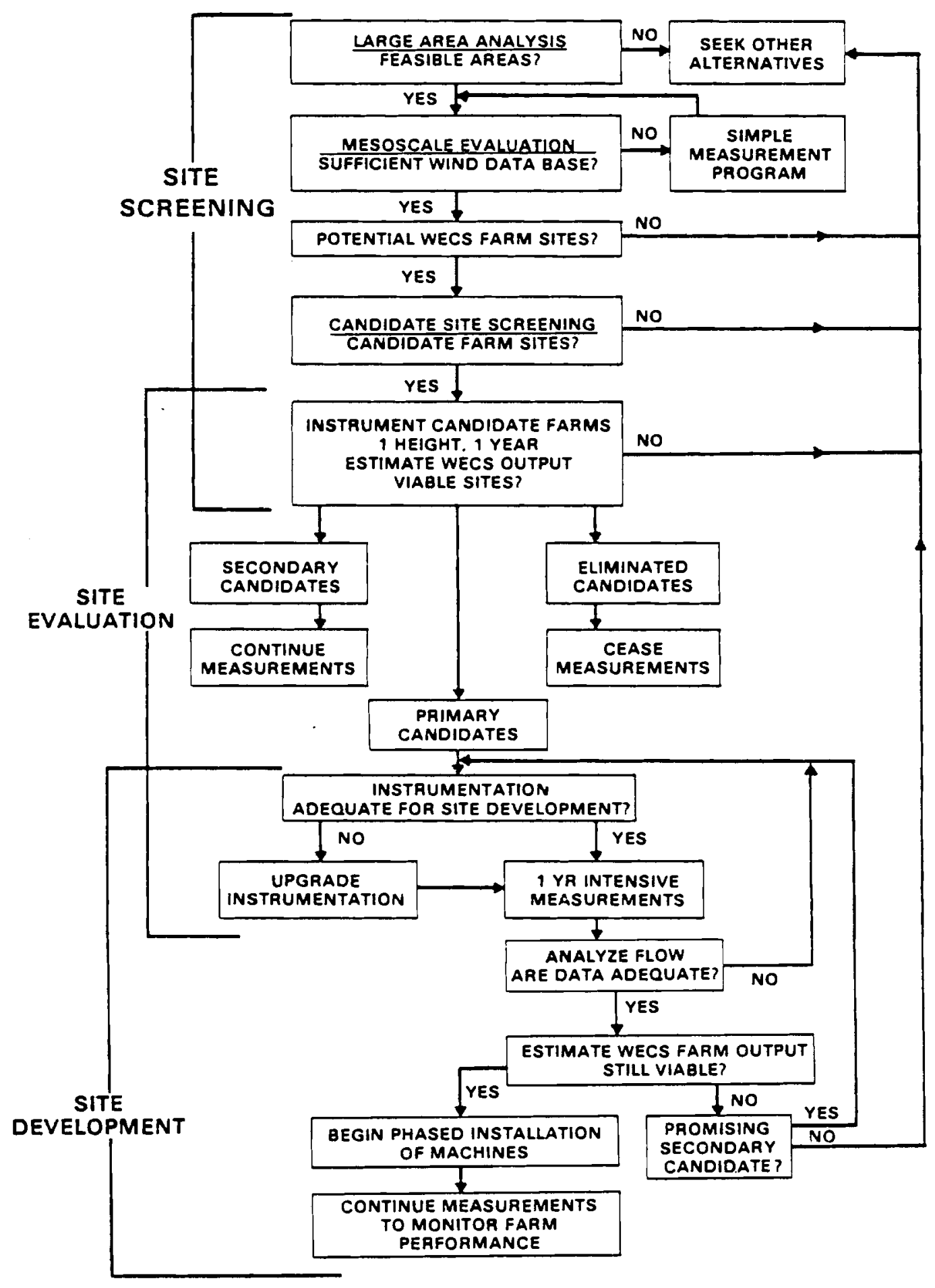

FIGURE 2. A Strategy for Wind Prospecting 


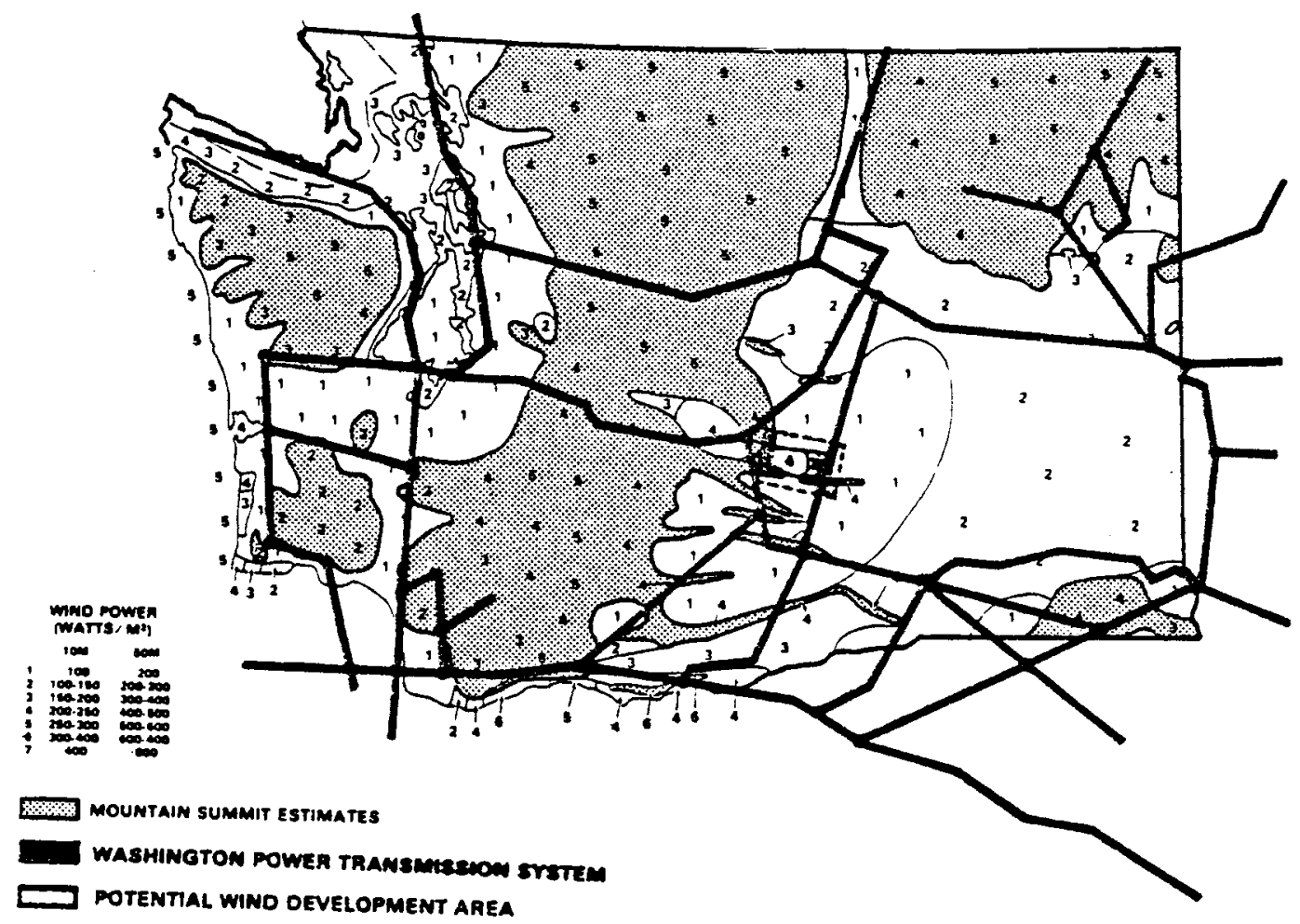

FIGURE 3. Large-Area Analys is Showing Major Power Transmission Lines Overlaid on the Annual-Average Wind Power Map.

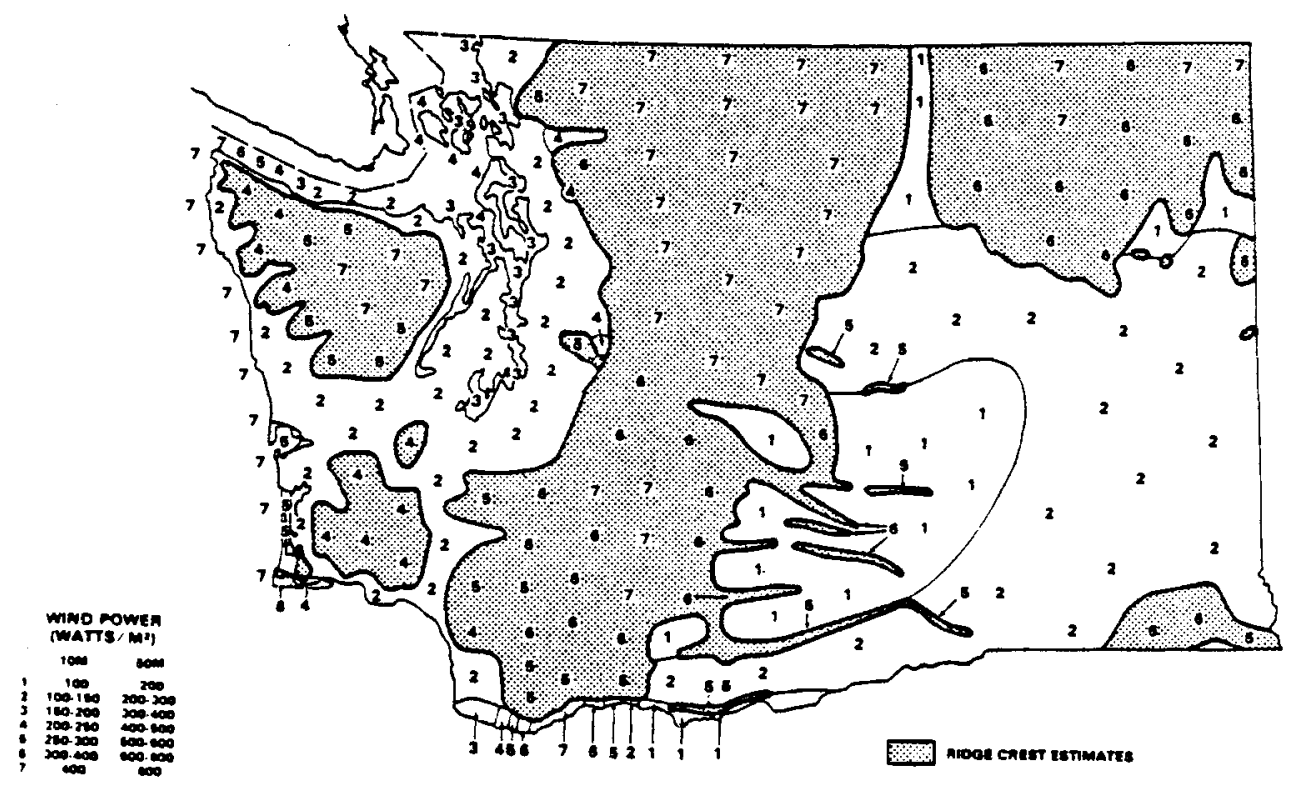

FIGURE 4. An Example from the Northwest Regional Assessment Showing the Average Winter Wind Power Flux $\left(\mathrm{w} / \mathrm{m}^{2}\right)$ for the State of Washington. Shaded areas indicate mountainous terrain. 
time is spent finding high-wind areas that satisfy the nonmeteorological site criteria).

A regional wind-power resource assessment for the Northwest (Renne and Elliott 1978) has shown that significantly higher resolution can be obtained from existing meteorological data that were not used in earlier assessments and from responsible use of extrapolation techniques that can be used to make estimates of the resource in areas where data have not been collected. Figure 4 is an example from the Northwest Regional Wind Energy Atlas that shows an estimate of wind power density over the state of Washington in winter. The wind resource in eleven other regions spanning the United States will be analyzed according to the Northwest assessment prototype.

\section{MESOSCALE EVALUATION}

If wind power is feasible, the large-area analysis will have identified several attractive areas with dimensions on the order of $100 \mathrm{~km}$ by $100 \mathrm{~km}$. The wind energy potential within one of these areas varies considerably, and a single area could contain several potential wind clusters. The next step is screening these areas to identify potential wind clusters (see Figure 5). (Figure 1 shows the techniques that could be used.) For areas without data, a supplemental wind measurement program may be required.

The amount of wind data required depends upon the terrain and meteorological complexity of the area. If the topographical forcing of the flow is strong and the seasonal and diurnal variations in forcing are large, data spanning at least one year are required for an analysis of the flow characteristics of the region. (a) The surface data should come from those key locations that provide the most information on the mass flow through the area: major valleys parallel to prevailing flow, major passes, and major ridges perpendicular to the prevailing flow. Numerical models may be used to assist in this analysis. Models require input data that are representative of a time that is short compared to the time scale of the changing forces, yet long compared to the turbulent motions that are insignificant to the total mass flow. Typical

(a) Here an analysis is an estimate of the flow at all points in a given region subject to the constraints of the physical laws governing the atmosphere. 


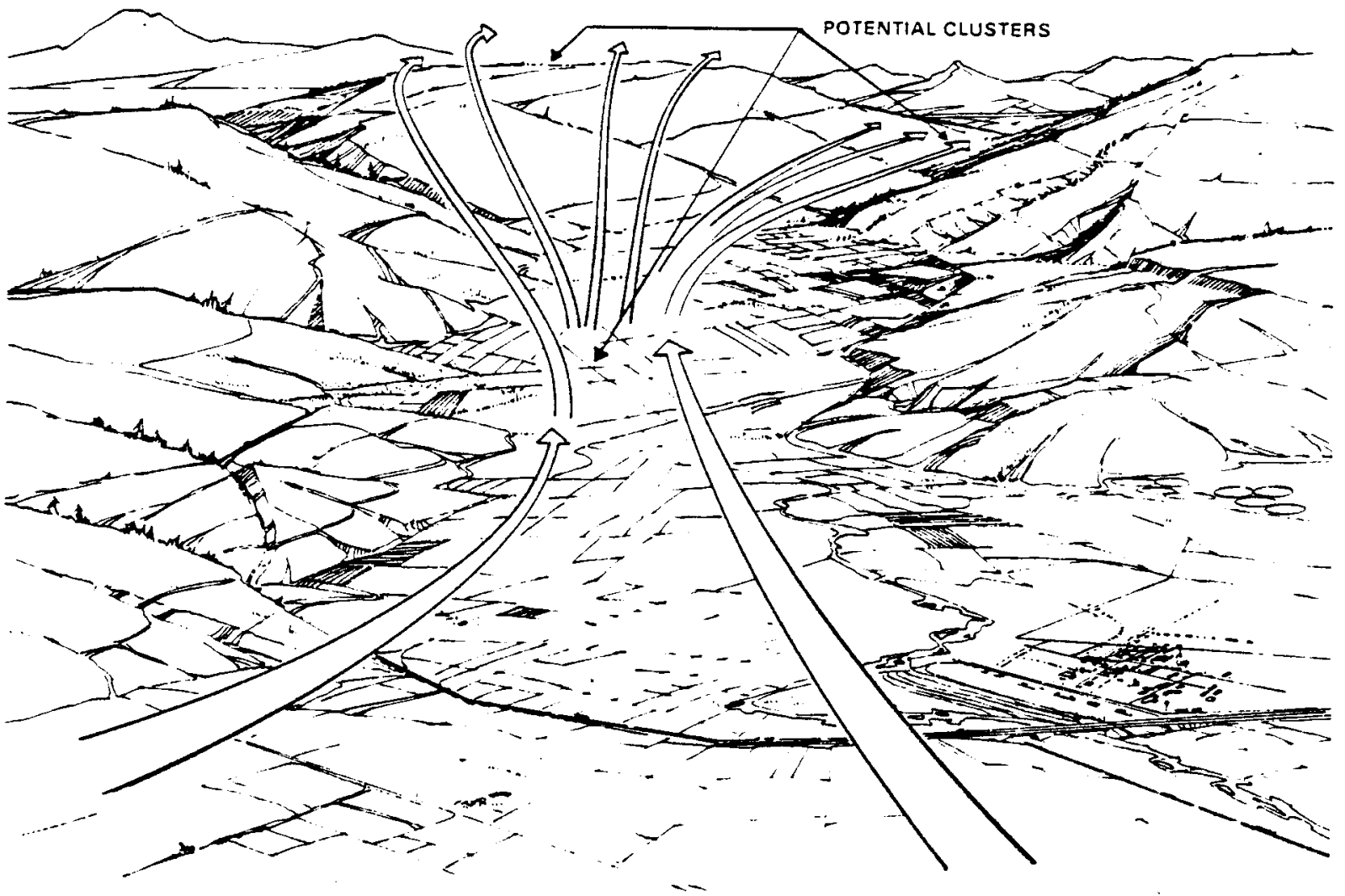

FIGURE 5. Mesoscale Evaluation

data requirements of a fairly simple numerical model simulation would, therefore, be:

- synchronous measurements of one-hour averages of surface wind speed and direction at key locations

- vertical profiles of wind speed and direction.

Numerical models assist in mesoscale wind energy analysis by simulating a representative cross section of the climatology. We cannot, of course, know a priomi that a given day is representative; therefore, selection of the cases for simulation can only be done once the season or year of data has been collected and analyzed.

A rigorous mesoscale analysis that uses the supplemental wind data described above can provide a great deal of information about the entire 
regional flow, whether or not anemometers were located in what the analysis showed to be high-wind areas. A less rigorous more risky approach may be taken, described more appropriately as mesoscale wind documentation rather than mesoscale wind analysis. Here, supplemental data are collected at what are presumed to be the windiest locations. The techniques listed in Figure 1 are used to estimate these locations. Numerical models may be used as a guideline here, too, but one must assume the input climatology. If the model's indications of high wind areas are very sensitive to the input, an analysis probably needs to be performed.

Mesoscale wind documentation can be obtained with equipment as crude as wind-run anemometers. However, information on hourly wind speed and direction as a function of time-of-day is better, because the information can be used to compute WECS power output more accurately. This type of data can be obtained from simple systems such as mechanical weather stations or from "smart" data loggers employing microprocessors to sample and bin the data.

\section{CANDIDATE SITE SCREENING}

After a number of potential sites for multiple WECS installations have been identified through large-area analysis and mesoscale evaluation, the sites need to be further screened. This screening is accomplished by site visits (see Figure 6). During these visits, the surrounding terrain is examined, and any small-scale terrain features or obstacles that could affect wind characteristics at the site are noted. Soil conditions are also examined. Site screening is not a time-consuming process and, depending on the number of sites, can be completed in a few weeks to months.

Valuable information on wind characteristics at the site can be obtained by measuring the wind profile, using wind-sensing kites or instrumented tethered balloons, and by examining the vegetation. Profile measurements made during site visits would primarily be used to identify obvious potential hazards, such as flow separation zones and the turbulence and high wind shear that accompany them. The measurements cannot provide a meaningful profile climatology because they are such a small set of observations. 


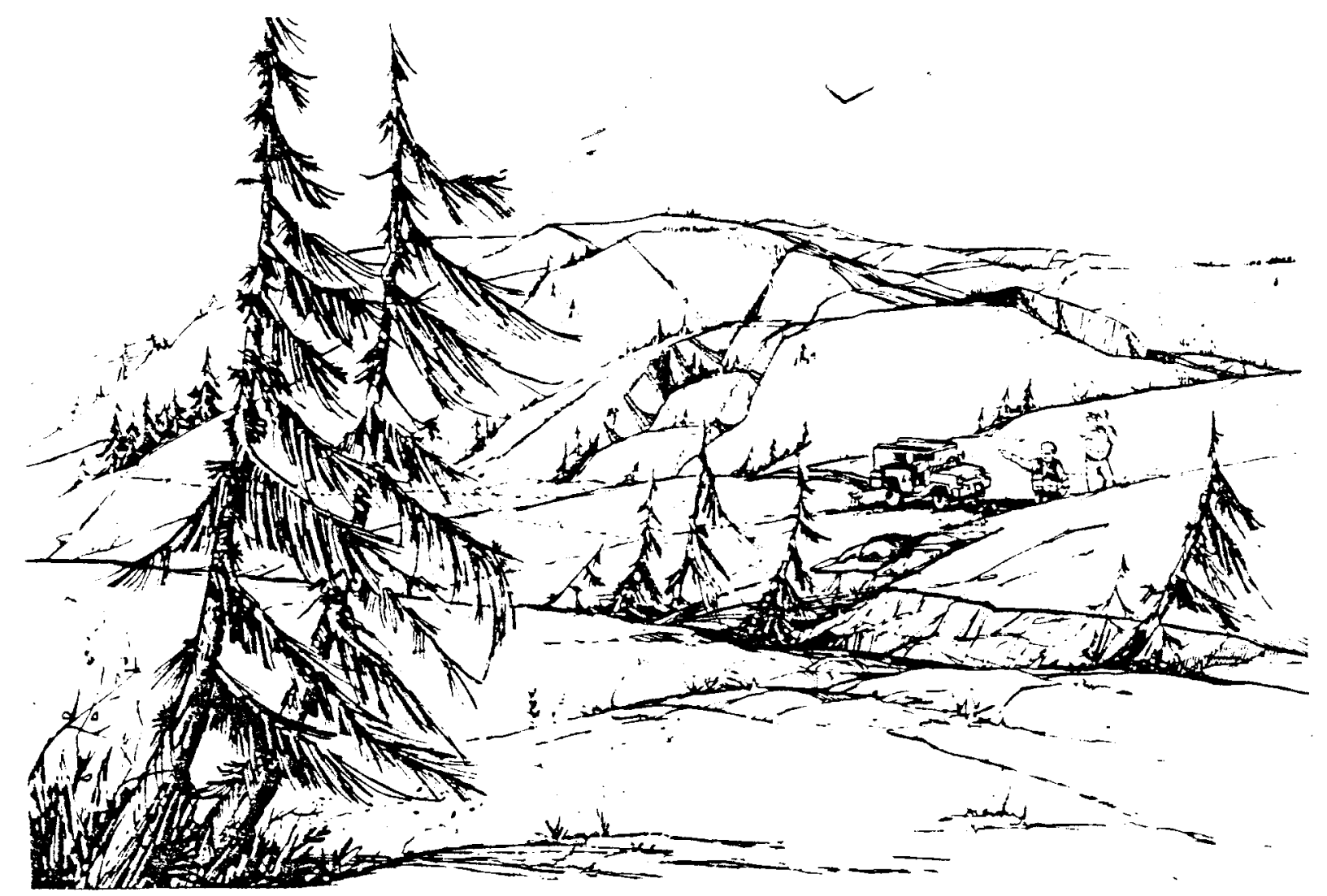

FIGURE 6. Candidate Site Screening

CANDIDATE SITE EVALUATION

Candidate site evaluations determine more accurately how wind machines would perform at each of the sites and ascertain the combination of sites that would result in power output characteristics best matching the needs of the utility (see Figure 7).

At this stage of the site-selection process, wind data are needed at only one level -- as near hub height as possible. In flat terrain, a single measurement location will be sufficient; in more complex terrain, measurements at several places may be required.

Although the length of time data must be collected is uncertain at present, at minimum two years of data are needed to establish the optimum mix of WECS clusters from a set of candidate sites. However, one year of data should be enough for identifying the leading sites in terms of total annual 


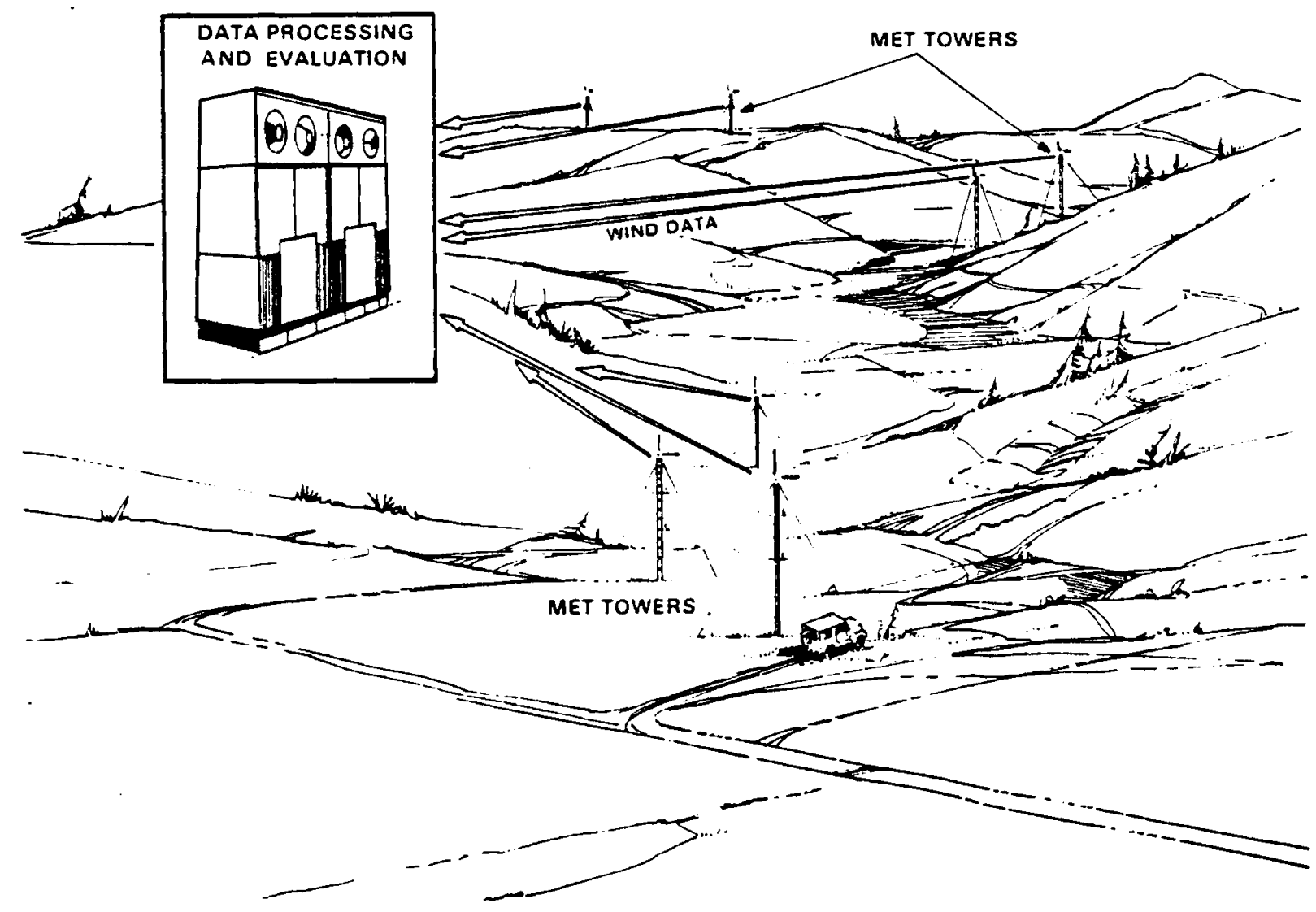

FIGURE 7. Candidate Site Evaluation

energy production, unless the year was climatologically abnormal. Experience with the 17 candidate sites in DOE'S MOD-OA demonstration program showed no significant changes in site ranking by annual energy production when a two-year record was used instead of a one-year record.

The data required during site evaluations are wind speed and direction. Hourly averaged wind speeds have been assumed to be adequate to estimate the power output of WECS, since a utility's estimates of hourly loads may not be particularly accurate. (a) Wind direction measurements are needed to determine the principal wind power directions and to gauge wind direction variability. The variability in wind direction could be an important factor affecting WECS

(a) More analys is of machine performance of large turbines is required before we can say how accurately machine performance may be modeled by hourly data. 
operations, since most machines are designed to track changes in wind direction to minimize the degree of off-axis operation. Utility-scale machines require large motor-driven yawing mechanisms; therefore, a site where the wind is fairly steady is clearly preferable to one with large, capricious changes in direction.

One way of logging wind information is to record time series of hourly averaged wind speed and direction. Standard deviations of wind speed and direction defined with respect to the hourly averages should be recorded to provide information on turbulence levels and wind direction variability. Data could either be recorded at the location of each instrument or transmitted to a central recording station. Recording the data at a central location provides obvious advantages in managing the data and in maintaining system reliability; however, it requires large initial expenses. Recording data in a time-series format provides the greatest flexibility for future use of the information. The data can be used either to produce statistical summaries of wind characteristics, such as wind speed probability functions, or to model the dynamic characteristics of a network of wind generators. The disadvantages of a timeseries format lie in the volume of data produced.

Information on wind characteristics at candidate sites can also be logged by a smart data logger. Such a device accumulates hourly averages of wind speed and direction in bins corresponding to the time of day and intervals of speed and direction. Data are recorded in a solid state memory; thus, data can be retrieved more reliably than when it is recorded on mechanically driven tape or strip chart recorders. The smart data logger can produce histograms of speed, direction and their variances as a function of time of day. The principal advantage of the smart data logger is that it reduces the amount of subsequent data processing, although flexibility is decreased (e.g., the ability to model dynamic characteristics of a WECS network is lost).

The smart data logger also shares several disadvantages with other on-site data-logging options. An on-site logger must be serviced on a rigid schedule to prevent loss of data either through saturation of memory or by running out of tape. Large blocks of data can also be lost if the instrument malfunctions. The only checks on system operation are during the scheduled maintenance visits. 


\section{SITE DEVELOPMENT}

After data are collected at the candidate sites for one year, the basic characteristics of the wind resource at each site will have been establisined. An evaluation of the resource magnitude and its seasonal or diurnal behavior at each site may lead to the selection of a given site as the primary candidate that best matches the needs of the utility. A few sites may be eliminated and some sites may become secondary candidates where candidate site evaluation should continue (see figure 2).

At the primary candidate site, the WECS cluster development stage begins (see Figure 8 ). The three main objectives are:

1. to determine the location for each machine to be placed in the cluster,

2. to estimate the power output characteristics of the cluster,

3. to document those wind characteristics that affect WECS operation and service life.

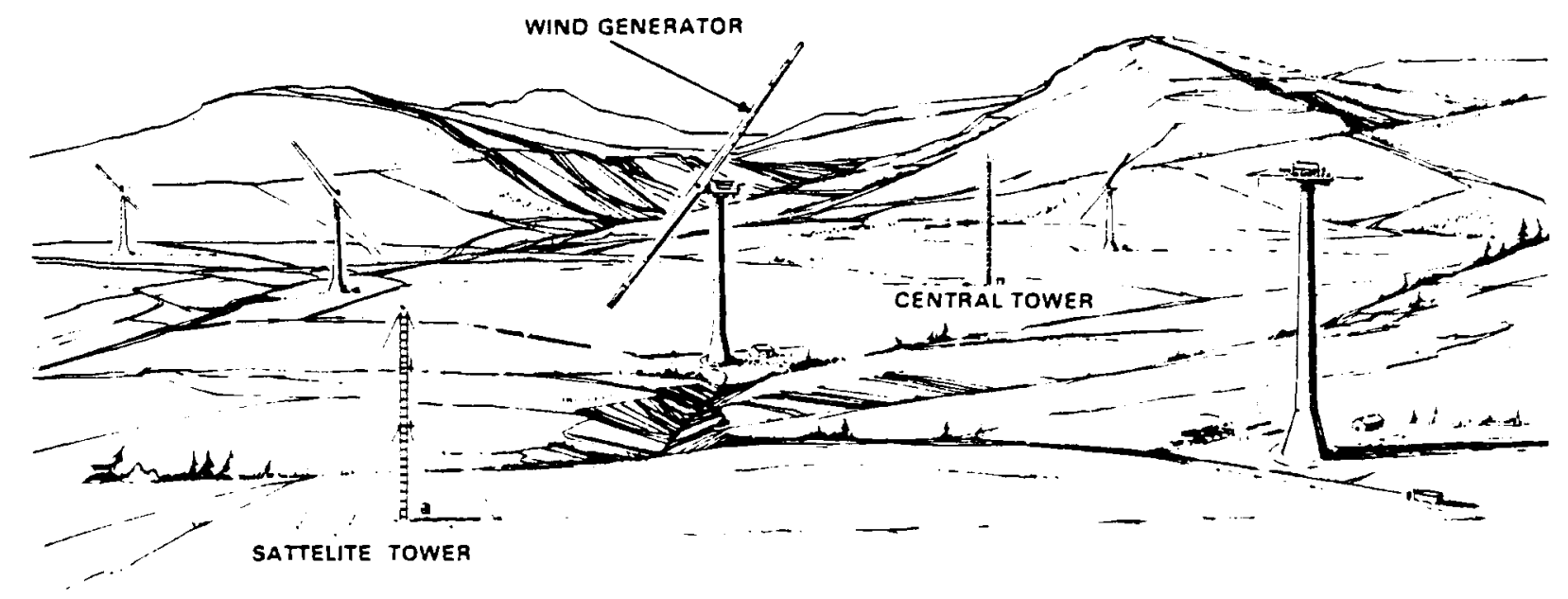

FIGURE 8. Cluster Development 
Determination of machine locations requires detailed measurements, followed by an analysis of the flow through a section of the atmosphere 100-m deep and spanning the horizontal extent of the proposed WECS cluster. The analysis techniques would include subjective analysis, and numerical and physical modeling. It is possible, though not probable, that the analysis may indicate the need for a longer period of data collection, an even more extensive data collection network, or both. If so, the site development cycle would be repeated (see Figure 2).

The second major objective of the WECS site development stage is to estimate the power output characteristics of the proposed WECS cluster. Currently, insufficient experience with utility-scale wind machines exists for a definitive statement to be made on what data are needed to make this estimate. This is particularly true for very large systems in the megawatt range with rotor diameters up to $100 \mathrm{~m}$. However, in a conservative approach, wind data collected should be sufficient:

- to model time variations in power output, both for individual machines and for the entire cluster;

- to tune control systems governing machine start-up and shutdown, since behavior in the neighborhood of these wind speeds affects both net power output and service life;

- to evaluate the effects of wind direction changes on the operation of yawing mechanisms.

In addition, frequency of icing conditions information is desirable since even under light icing conditions, the personnel hazard (due to ice throwing by the rotor) may require periods of shutdown.

The third major objective of this stage is to document those wind characteristics that affect WECS operations and service life, i.e., extreme wind events and turbulence. Techniques that predict the frequency of occurrence of extreme wind events with high precision and confidence have not been developed. It is expected that if and when they are developed, the input data reeded by these techniques will not require any measurements beyond those made to satisfy the other two objectives discussed above. Documenting the turbulence characteristics, however, requires a more specialized measurement system. 
Measurement Systems - Flat Terrain

The layout of a wind measuring network for site development will depend on whether the goal is merely to map the mean flow field and locate individual machines at the locations with highest mean wind speed or whether the goal is to model and to evaluate the performance of each machine in an array. For clusters of large machines, we assume that the latter goal would be the case.

The layout of a wind measurement network also depends on terrain complexity. Flat terrain is obviously the simplest. Choosing the sites for individual machines in an array will depend very little on the terrain, since the most significant differences in average wind characteristics will be due to surface roughness changes or to the wake effects of the machines themselves.

Installation of a central tall tower at the site, as shown in Figure 8 , is strongly recommended. Significant low-level wind shears, for instance, can be experienced, even over flat terrain. It is important to document whether these shears exceed the design limits of the machines under consideration. Considering the capital investment a WECS cluster represents, knowledge of wind characteristics across the rotor disk would seem essential.

The tall tower should be located at the center of the planned WECS array. This will enable an assessment to be made of the effects upstream machines may have on site wind characteristics as installation of the array proceeds.

Even over flat terrain, satellite towers would be required to supplement the data from the tall towers. Satellite towers would serve:

- to monitor the flow approaching the WECS array,

- to fine-tune the array layout,

- to model the short time-scale performance characteristics of machines within the array.

The satellite towers would have to be instrumented at only one level - as close to hub height as possible.

The number and the placement of satellite towers for monitoring approach flow conditions is very straightforward. They are set by the prevailing wind directions and the placement of the array. 
Unless machines are spaced more than ten rotor diameters apart, wind characteristics within an array will be dominated by wake effects from upstream units. Eventually, the arrangement of machines within arrays on flat land will be set by empirical guidelines. Experience should also indicate how machines within the array will perform. Until such experience makes it unnecessary, a satellite system within the array is recommended. The satellite system will document the horizontal variability of wind characteristics within the array more thoroughly than a single tower. Information from the satellite towers would be used to document how the installation of machines in the array is affecting wind characteristics. These data could be used to model how new machines would behave and would be used to fine-tune the array design.

The arrangement of towers within the array would be set by the array design. Over flat land, WECS arrays will be in some sort of geometrical pattern, probably a diamond lattice as viewed from the prevailing wind direction. One or two satellite towers are recommended per row of machines, where a row is defined perpendicular to the prevailing wind direction. Staggering the towers will result in the best coverage.

Measurement Systems - Hilly Terrain

For hilly areas (i.e., local relief is greater than 50 to $100 \mathrm{~m}$ ), the placement of machines within a WECS array will be dominated by the morphology of the terrain and the orientation of the principal terrain features to the prevailing wind directions. Again, information will be needed on the vertical structure and horizontal variability of the wind over the site. In contrast to siting in flat terrain, wind measurements will play a more important role in documenting the characteristics of the flow over the site and in locating individual machines in the WECS array.

Physical modeling can play a very important role in planning the layout of a WECS array in hilly terrain. Placing a detailed scale model in a suitably designed wind tunnel and examining the flow over the model for the predominant wind directions provides guidance on the locations for individual WECS in an array and on the locations for the wind measuring systems needed to document the flow. 
As in the flat terrain case, a centrally located tall tower will be the heart of the measurement system. Satellite systems consisting of wind speed and direction sensors at a single height would be placed according to the guidance of physical modeling and experience. The satellite systems would probably be more numerous than for a flat site.

If the terrain within the site is particularly complex, a single tall tower may not be adequate for accurately characterizing the vertical structure of the wind for the entire array. Again, physical modeling would be helpful in determining if this were the case. However, it is doubtful that large machines would be placed in a site so complex that significant differences in the vertical structure of the wind would be experienced over a distance equal to the size of a WECS array.

As data are collected from the site measurement system, they should be analyzed. Simple numerical models can be used to create an objectively analyzed field from a set of distributed point measurements. Analyzed wind fields corresponding to the important wind directions would be compared to the results of physical modeling. These comparisons would determine whether flow over the site was behaving as expected and whether the existing measurement system was adequate.

\section{Data Reguirements}

At the tall towers, wind speed and direction measurements would be required at a minimum of three levels: hub height, near the bottom, and the top of the rotor disk. Data sampling rate for the tall tower systems would be four times the angular speed of the rotor of the machines under consideration. This rate will be adequate to resolve vertical wind gradients and to evaluate their effects.

Sampling rates for the satellite towers should be compatible with the response characteristics of the machines. The principal purposes for modeling the behavior of the individual units are to simulate machine start-up and shut-down operations and to model short-term fluctuations in power output from the array. In order to do the latter, only wind gust scales greater than the distance between machines in the cluster would need to be resolved. Power fluctations, due to smaller gusts, should show little coherence between 
machines and would have no effect on array output. Given a minimum spacing of five rotor diameters, a sampling rate of five per minute would be adequate for modeling power output (Pennell et al. 1980). This sampling rate would also be compatible with the rate required to simulate machine start-up and shut-down procedures.

The measurement system described above would produce a large amount of information, particularly if the data were continuously sampled at the maximum rates for both the tall and satellite towers. Data could be recorded on two time scales: the basic data set would be time series of hourly averages of wind speed, direction, and associated variances at each tower; the second would be recorded on a separate system at high sampling rates.

The basic data set would satisfy most of a utility's needs (assuming machine performance can be adequately predicted with hourly data), since this is the finest time scale in current utility planning models (Marsh 1979).

The second data set would not be needed all the time, since analysis of a small number of significant or representative events should provide the information needed. The recording of high sample-rate data could be keyed to wind speed ranges or wind directions of interest, or the data could be recorded on a continuous loop that would retain two or three days of information. Retention of the data for this period would allow sufficient time to retrieve information on significant events. These systems that sample or retain only a fraction of the data may prove to be unnecessarily complex, since the costs of archiving and processing all of the high sample-rate data are not large when compared with the costs of the data measurement system. Retaining all data reduces the possibility that crucial information could be lost.

After sufficient data have been collected and analyzed, individual machines can be located and the output of the entire cluster estimated. If the cluster meets the utility's needs, installation could begin, assuming a phased program. In a phased program, on-site experience could be obtained before a complete commitment is made to install all the machines, and modifications could be made to another cluster layout as additional data are gathered on machine operations and the wind resource. 
A commitment to install machines at a site could be made after two years of collecting on-site data (one year in the site evaluation stage and one year in site development). However, a reasonable estimate of the interannual variability in power output could not be made with so little information. Some utilities may want to base a decision on a worst-wind-year-basis. Statistics representing a poor year might be determined by examining data from nearby locations with long-term wind records. However, such an analysis should be interpreted with caution. Little evidence exists that indicates that wind data can be reliably extrapolated from one location to another, especially in regions of complex terrain and with complicated meteorology. Moreover, very few locations have anemometers that have been fixed in position and altitude for long periods. Changes in wind characteristics, due to changes in anemometer location, are frequently greater than the interannual variability.

\section{CONCLUSION}

Site selection for large wind turbine clusters requires thorough documentation of the wind characteristics at the site, because of the influence these characteristics will have on the economics, operations, and service life of the wind turbines.

The wind prospecting strategy can be used by a utility to determine specific locations for each wind turbine in a cluster of 10 to 50 or more machines. This strategy consists of five main steps:

1. large-area analysis. The utility service area is screened for potential high-wind-power area with available land in reasonable proximity to transmission corridors.

2. mesoscale evaluation. Potential high-wind areas, identified by the large-area analysis, are screened and a number of potential candidate sites are identified.

3. candidate site screening. Visits are made to each potential candidate site. Some sites are eliminated during this step because of inaccessibility, soil or terrain conditions, or if site examination and measurements indicate excessive and frequent turbulence or wind shear. 
4. candidate site evaluation. The candidate site screening steps are instrumented and sufficient measurements are made to make an economic assessment of the wind resource. If the site appears economically viable, the fifth step begins.

5. site development. Specific locations for each machine are determined, estimates of the cluster output characteristics are made, and installation of machines begins.

The key to site selection is knowing what and where to measure. Siting techniques to be used at the various stages of the wind-prospecting strategy were discussed. These techniques help determine where to measure. What to measure at a site is still a moot question. We have made suggestions on what data are needed at what sampling rates. These are based on the assumption that until further experience in siting large clusters of wind turbines is in hand, thorough documentation of wind characteristics affecting machine and cluster output characteristics, operation strategies, and service life are necessary.

Many of the recommendations presented here are based on theory, since no one has sufficient experience to speak with authority on this subject. Still, large utility-scale machines are being produced and will have to be sited. Experience with these initial installations will be critical in evaluating current siting approaches and in defining the crucial characteristics of a good wind turbine site. 


\section{REFERENCES}

American Wind Energy Association. 1977. Survey of Historical and Current Site Selection Techniques for the Placement of Small Wind Energy Conversion Systems. PNL-2220 Wind-9, report to Pacific Northwest Laboratory, Richland, WA (available from NTIS).

Energy Research and Development Administration. 1977. Summary Report, Federa 1 Wind Energy Program, ERDA-77-32, Division of Solar Energy, Wind Systems Branch, Washington, $D C$.

Golding, E. W. 1955. The Generation of Electricity by Wind Power. John Wiley and Sons, New York.

Hewson, E. W. and J. Wade. 1977. Vegetation as an Indicator of High Wind Velocity. RLO/2227-T24-77/2, available from National Technical Information Service, Springfield, $V A$.

Marrs, R. W. and S. Koprina. 1978. Regions of the Continental United States Susceptible to Eolian Action. RLO/2343-78/2, available from National Technical Information Service, Springfield, VA.

Marsh, W. D. 1979. Requirement Assessments of Wind Power Plants in Electric Utility Systems, EPRI ER-978-SY (three volumes). Available from EPRI Research Center (RRC), Palo Al to, CA 99303.

Pennell, W. T., W. R. Barchet, D. L. Elliott, L. L. Wendell and T. R. Heister. 1980. "Meteorological Aspects of Wind Energy: Assessing the Resource and Selecting the Sites." PNL-SA-7895. Journal of Industrial Aerodynamics.

Puinam, P. C. 1948. Power from the Wind, Van Nostrand, New York.

Renne, D. S. and D. L. Elliott. 1978. "Overview of Techniques for Analyzing the Wind Energy Potential Over Large Areas." DOE/IR/0114-1. In Proceedings of Solar 78 Northwest Conference, July 14-16, 1978, Portland, OR. Available through Pacific Northwest Energy Association, Seattle, WA 99112.

Wende11, L. L., J. R. Conne11, W. T. Penne11, D. S. Renne and H. L. Wegley. 1978. Annual Report of the Wind Characteristics Program Element for the Period July 1977 through July 1978. PNL-2545, Pacific Northwest Laboratory, Richland, WA 99352. 


\section{DISTRIBUTION}

NO. OF

COPIES

Offsite
A.A. Churm
DOE Patent Division
$9800 \mathrm{~S}$. Cass Avenue
Argonne, IL 60439

10 Floyd R. Summers

U.S. Department of Energy

Alaska Power Administration

P. 0. Box 50

Juneau, AK 99802

27 DOE Technical Information Center

Onsite

DOE Richland Operations Office

H. E. Ransom

21 Pacific Northwest Laboratory

T. R. Hiester (10)

J. J. Jacobsen (3)

L. L. Wendel 1 (1)

Publishing Coordination (2)

Technical Information (5) 
